\title{
Predicting physicians' intention to measure body mass index and assessing their identification and evaluation practices in overweight children and adolescents
}

\author{
Rahul Khanna \\ West Virginia University
}

Follow this and additional works at: https://researchrepository.wvu.edu/etd

\section{Recommended Citation}

Khanna, Rahul, "Predicting physicians' intention to measure body mass index and assessing their identification and evaluation practices in overweight children and adolescents" (2007). Graduate Theses, Dissertations, and Problem Reports. 4311.

https://researchrepository.wvu.edu/etd/4311

This Thesis is protected by copyright and/or related rights. It has been brought to you by the The Research Repository @ WVU with permission from the rights-holder(s). You are free to use this Thesis in any way that is permitted by the copyright and related rights legislation that applies to your use. For other uses you must obtain permission from the rights-holder(s) directly, unless additional rights are indicated by a Creative Commons license in the record and/ or on the work itself. This Thesis has been accepted for inclusion in WVU Graduate Theses, Dissertations, and Problem Reports collection by an authorized administrator of The Research Repository @ WVU. For more information, please contact researchrepository@mail.wvu.edu. 
Predicting Physicians' Intention to Measure Body Mass Index and Assessing their Identification and Evaluation Practices in Overweight Children and Adolescents

\author{
Rahul Khanna
}

Thesis Submitted to the

School of Pharmacy

at West Virginia University

in partial fulfillment of the requirements

for the degree of

\title{
Master of Science
}

in

Pharmaceutical Systems and Policy

Virginia (Ginger) Scott, Ph.D., Chair

Jan Kavookjian, M.B.A., Ph.D., Co-Chair

Lesley-Ann Miller, Ph.D.

Khalid M. Kamal, Ph.D.

William A. Neal, M.D.

Department of Pharmaceutical Systems and Policy

\author{
Morgantown, West Virginia \\ 2007
}

Keywords: Obesity, Body Mass Index, Theory of Reasoned Action/Theory of Planned Behavior, Physician Practices 


\title{
ABSTRACT \\ Predicting Physicians' Intention to Measure Body Mass Index and Assessing their Identification and Evaluation Practices in Overweight Children and Adolescents
}

\author{
Rahul Khanna
}

One health challenge receiving a lot of attention today is childhood obesity. Numerous public and professional organizations recommend that physicians periodically measure BMI in children and adolescents. In addition, guidelines recommend medical evaluation of overweight children and adolescents. However, studies have shown an inconsistent use of body mass index (BMI). This study uses the Theory of Reasoned Action (TRA) and the Theory of Planned Behavior (TPB) to identify factors that explain physicians' intention to measure BMI in children and adolescents. Salient beliefs associated with intention were compared between intenders and nonintenders. The study also determines how physicians identify and evaluate overweight children and adolescents. A self-administered questionnaire was mailed to a random sample of 2,590 physicians (family physicians and pediatricians) practicing in four states. The theoretical variables assessed in the study were: intention to measure BMI, attitude, subjective norm, perceived behavioral control, attitudinal beliefs and evaluation, normative beliefs and motivation to comply, and control beliefs and evaluations. Physician practice-related and demographic information were also collected. The factors explaining intention were examined using correlation and multiple regression analysis. Salient beliefs between intenders and nonintenders were compared using ANOVA. Overall, 583 physicians returned the questionnaire (usable response rate of $22.8 \%$ ). Only $44 \%$ of surveyed physicians strongly intended to measure BMI in children and adolescents. The theoretical models explained up to $51.2 \%$ of variance in intentions to measure BMI. There were significant behavioral and normative belief differences between physicians who intended and those who did not intended to measure BMI. A majority of physicians frequently used clinical impression, weight-for-age percentile, and weight-for-height percentile to identify overweight children and adolescents, with less than 57\% actually using BMI percentiles. In terms of evaluating overweight children and adolescents, $15 \%$ followed all recommendations for family history assessment; however, $6 \%$ followed all recommendations for clinical evaluations and medical history and physical examination. Roughly one-third of physicians followed all recommendations for behavioral history assessment. The study also reflected variation in physicians practice across states. The TRA and the TPB provided a useful framework for studying physicians' intentions to measure BMI. Physicians' adherence to the recommended evaluation practices for overweight children and adolescents was low. 


\section{ACKNOWLEDGEMENT}

I would like to take this opportunity to thank those people without whom this study would not have been possible. I express sincere thanks to Dr. Ginger Scott for her support and continuous encouragement throughout the course of this study. I would also like to thank Dr. Jan Kavookjian for her guidance and assistance. Working with both of them has been a very fruitful learning experience.

A special thanks to Dr. Khalid Kamal for his useful recommendations and suggestions. Khalid, as I call him, has been of help to me throughout the course of my graduate studies. I express my gratitude to Dr. William A. Neal for his clinical input. I thank Dr. Lesley Ann Miller for her time and advice as my committee member. I also thank Dr. Suresh Madhavan for his suggestions and intuitive questions during my defense.

Big thanks to all the physicians who agreed to participate in my interview and survey. I am grateful to Dr. Mary T. Story and Dr. Lakshmi Kolagotla, respectively, for sharing their work and giving me the consent to use a part of their survey instrument. Next, I express thanks to the entire faculty and staff of the Department of Pharmaceutical Systems and Policy. Huge thanks to my friends, especially Anuja and Sanjoy, for their constant support and help.

Every achievement in my life is dedicated to my family. This study would not have been possible without their support and inspiration. 


\section{TABLE OF CONTENTS}

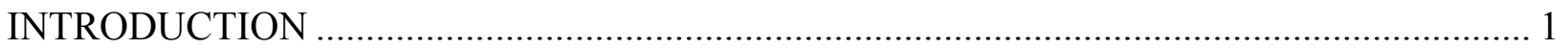

Obesity Prevalence and Cost Implications ............................................................................ 1

Identification and Classification of Obesity in Children and Adolescents ................................. 4

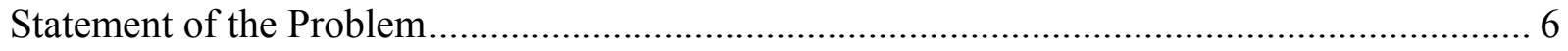

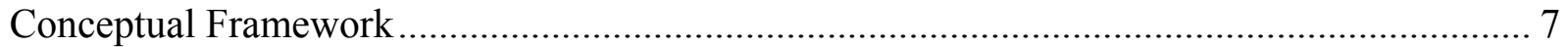

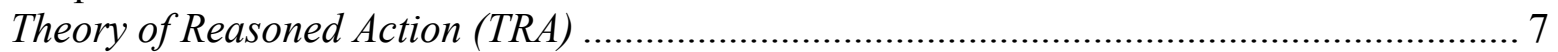

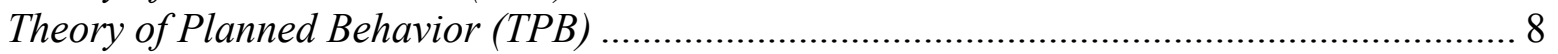

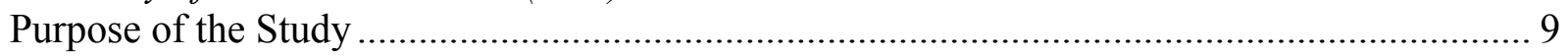

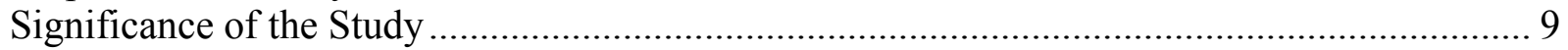

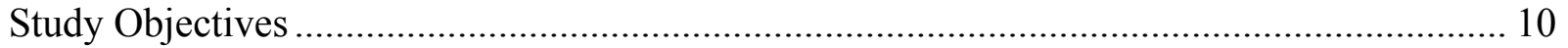

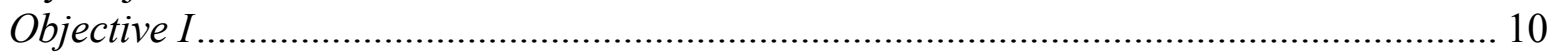

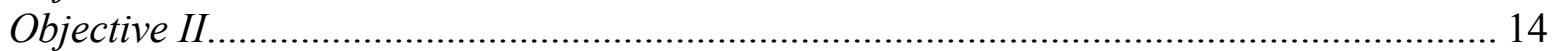

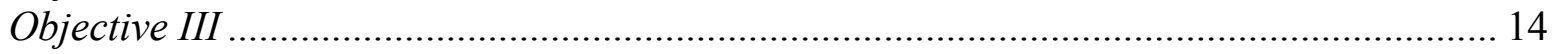

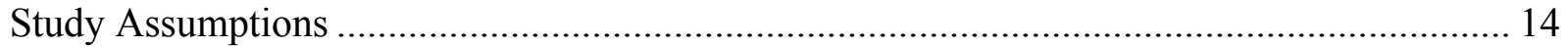

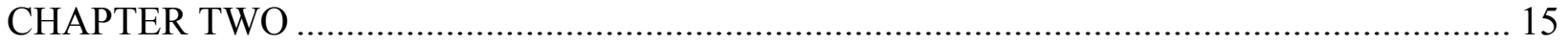

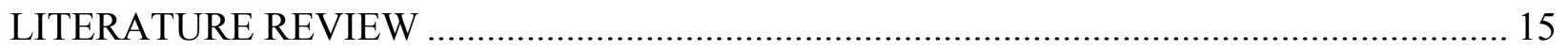

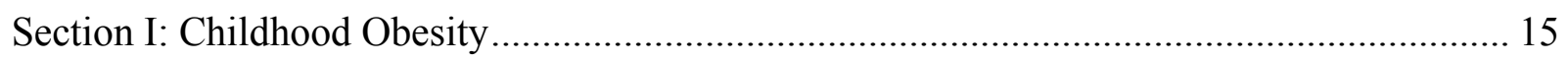

Causes of Obesity .......................................................................................................... 15

Health Implications of Childhood and Adolescent Obesity ................................................ 20

Childhood Obesity Identification Methods ......................................................................... 22

Role of Physicians in Assessment and Evaluation of Overweight Children and Adolescents

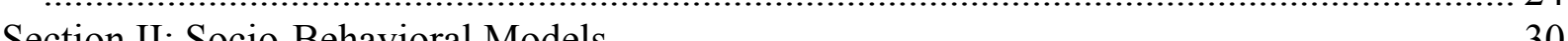

Theory of Reasoned Action (TRA) ............................................................................... 30

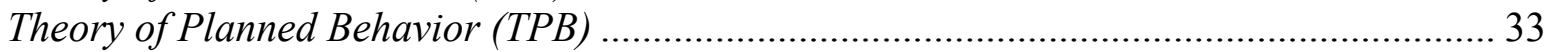

Applications of the Theory of Reasoned Action and the Theory of Planned Behavior......... 36

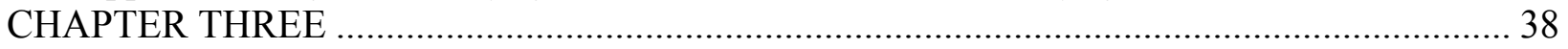

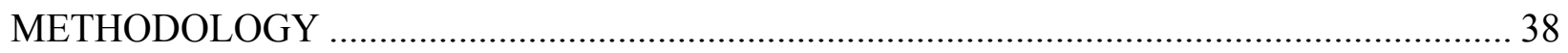

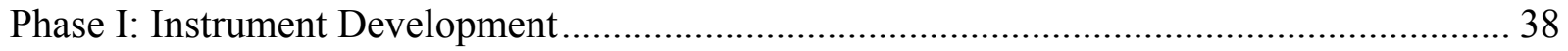

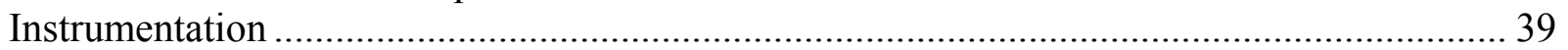

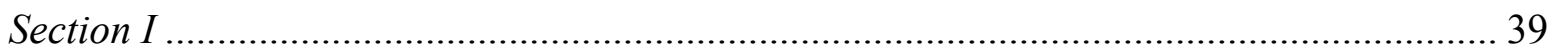

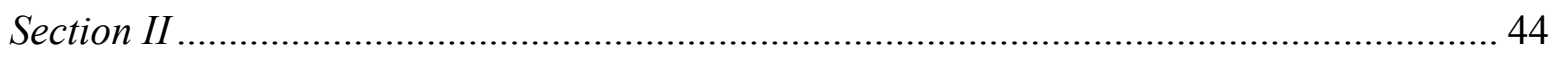

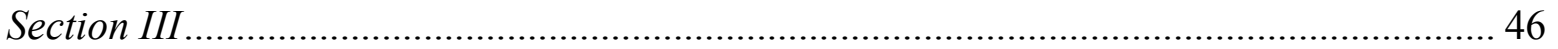

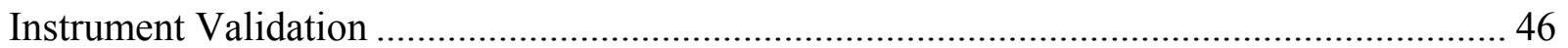

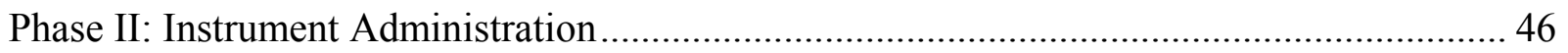

Study Sample and Sample Size Determination .................................................................. 46

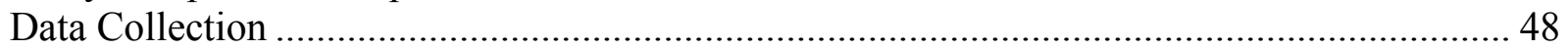

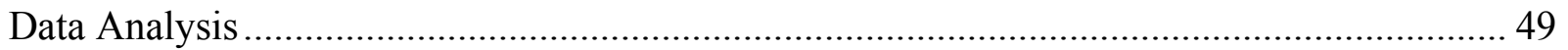

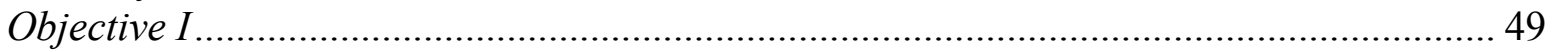

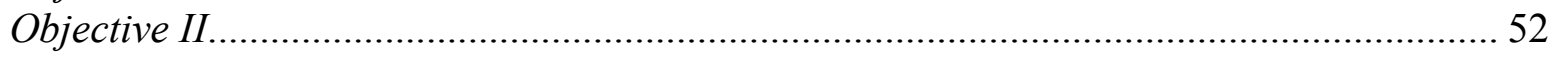

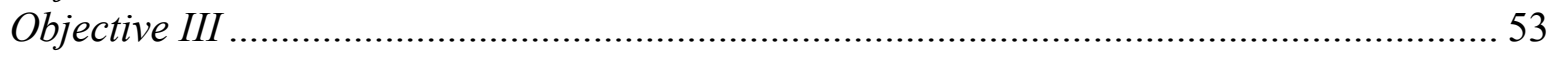

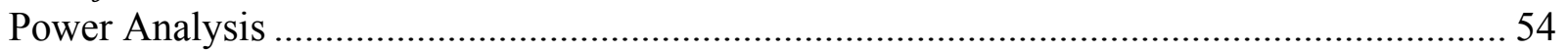

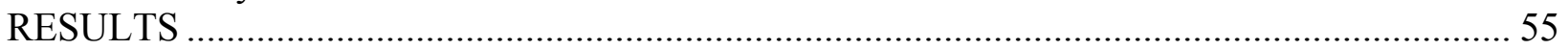

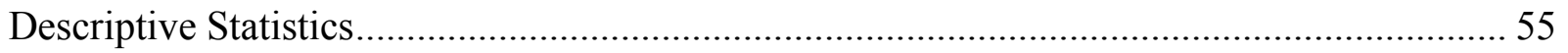




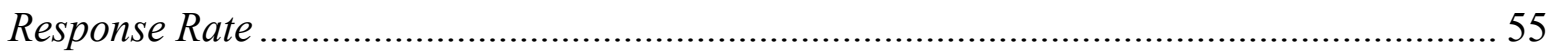

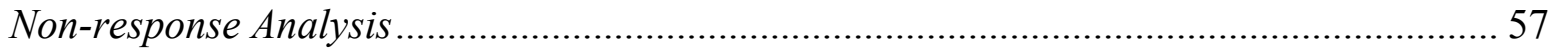

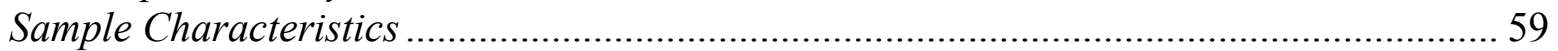

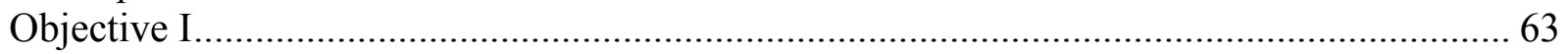

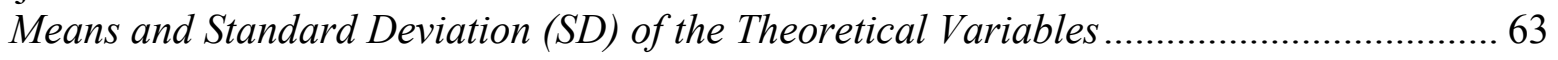

Psychometric Evaluation of Section I of the Instrument ................................................... 69

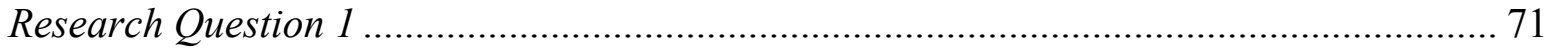

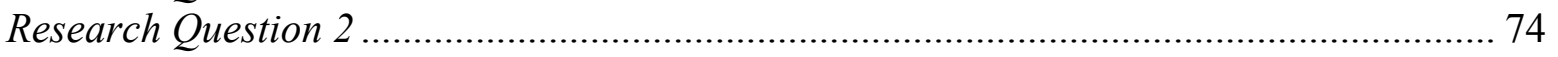

Research Question 3 ............................................................................................... 80

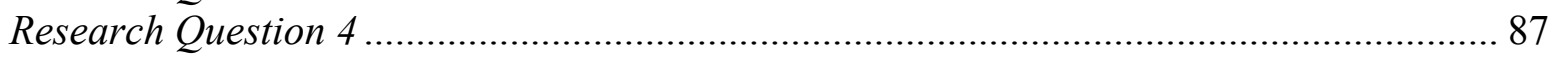

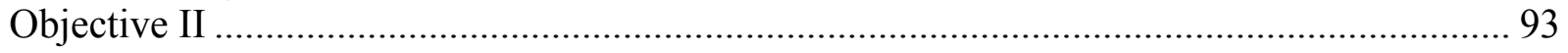

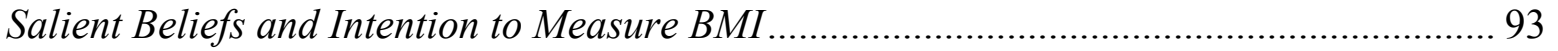

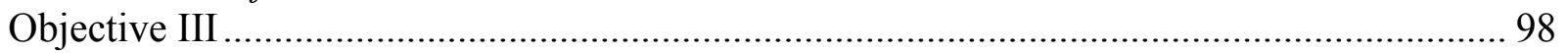

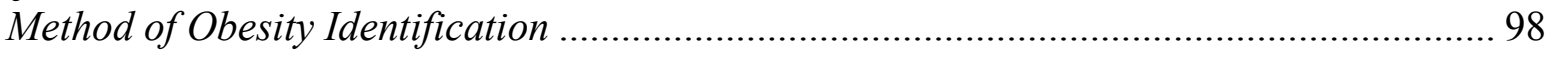

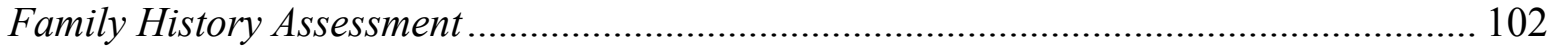

Clinical Evaluations.............................................................................................. 105

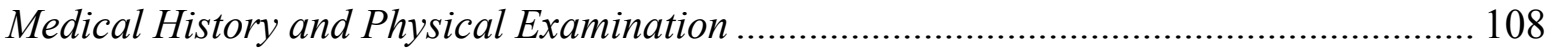

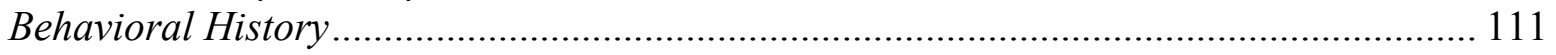

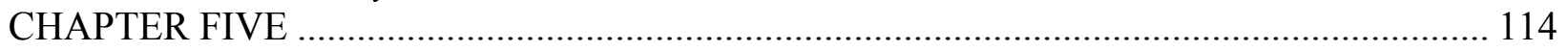

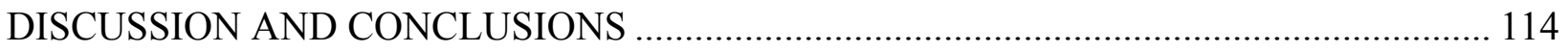

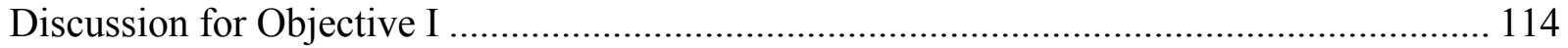

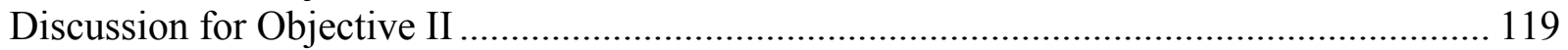

Discussion for Objective III............................................................................... 120

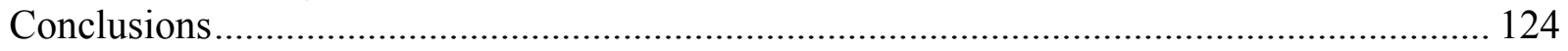

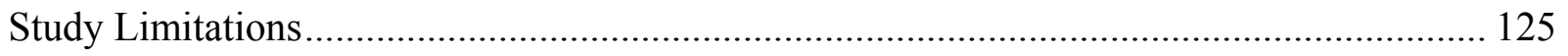

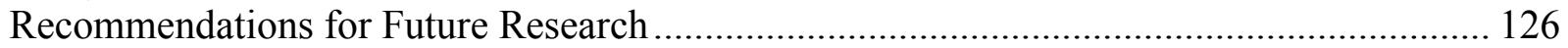

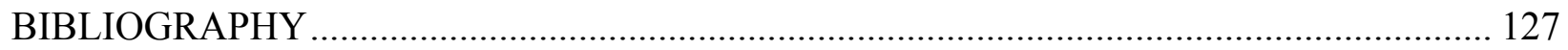

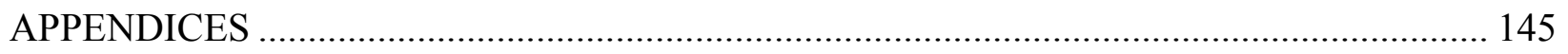

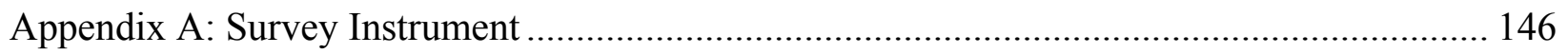

Appendix B: First Mailing Cover Letter....................................................................... 151

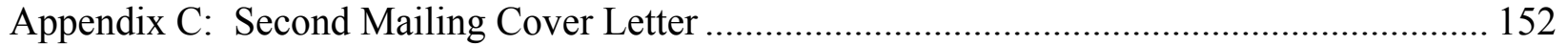

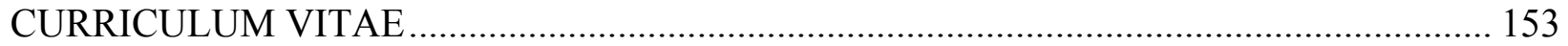




\section{LIST OF TABLES}

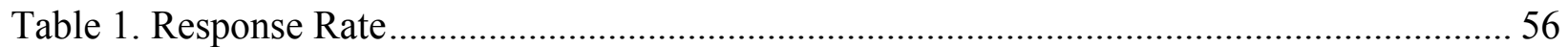

Table 2. Characteristics of Early and Late Responders .......................................................... 58

Table 3. Demographic and Practice Characteristics of the Sample ......................................... 59

Table 4. Demographic and Practice Characteristics of Physicians by State Obesity Prevalence

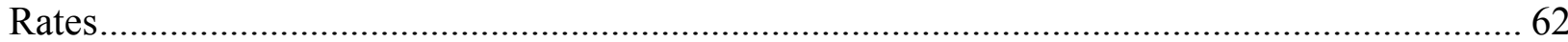

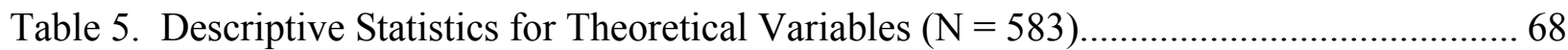

Table 6. Reliability Results for Theoretical Items ............................................................... 70

Table 7. Correlation Between the Theoretical Variables...................................................... 73

Table 8. Summary of the Multiple Regression Analysis for Predicting Physicians' Intention to Measure BMI using Direct Measures of Attitude and Subjective Norm ................................. 75 Table 9. Result of Multiple Regression Analysis for Predicting Intention using Direct Measures of Attitude and Subjective Norm ................................................................................... 76

Table 10. Summary of the Multiple Regression Analysis for Predicting Physicians' Intention to Measure BMI using Indirect Measures of Attitude and Subjective Norm .............................. 78 Table 11. Result of Multiple Regression Analysis for Predicting Intention using Indirect Measures of Attitude and Subjective Norm. .79

Table 12. Summary of Hierarchical Regression Analysis Depicting Utility of the Direct Measure of Perceived Behavioral Control in Predicting Intention Beyond the TRA Variables ................ 82 Table 13. Result of Hierarchical Regression Analysis Predicting Intention after Addition of the Direct Measure of Perceived Behavioral Control to the TRA Variables 83 Table 14. Summary of Hierarchical Regression Analysis Depicting Utility of the Indirect Measure of Perceived Behavioral Control in Predicting Intention Beyond the TRA Variables .. 85 Table 15. Result of Hierarchical Regression Analysis Predicting Intention After Addition of the Indirect Measure of Perceived Behavioral Control to the TRA Variables ............................... 86 Table 16. Utility of Past Behavior in Explaining Intention beyond the Direct Measures Theory of Planned Behavior (TPB) Model Constructs 88

Table 17. Result of the Hierarchical Regression Analysis Predicting Intention with Past Behavior and Direct Measures Theory of Planned Behavior (TPB) 89 Table 18. Utility of Past Behavior in Explaining Intention Beyond the Indirect Measures Theory of Planned Behavior (TPB) Model 91

Table 19. Result of the Hierarchical Regression Analysis Predicting Intention with Past Behavior and Indirect Measures Theory of Planned Behavior (TPB) Model ........................... 92 Table 20. Comparisons of Behavioral Beliefs Between Physicians who do not Intend, are Neutral, and Intend to Measure BMI in Pediatric and Adolescent Patients 95 Table 21. Comparisons of Normative Beliefs Between Physicians who do not Intend, are Neutral, and Intend to Measure BMI in Pediatric and Adolescent Patients ............................. 97 Table 22. Methods Used by Physicians to Identify Overweight Children and Adolescents ..... 100 Table 23. Methods Used by Physicians to Identify Overweight Children and Adolescents Based on State Childhood Obesity Prevalence Rates.... 101 Table 24. Family History Assessment of Overweight Children and Adolescents by Physicians103 Table 25. Family History Assessment of Overweight Children and Adolescents by Physicians Based on State Childhood Obesity Prevalence Rates ........................................................ 104 Table 26. Clinical Evaluation of Overweight Children and Adolescents by Physicians........... 106 
Table 27. Clinical Evaluation of Overweight Children and Adolescents by Physicians Based on State Childhood Obesity Prevalence Rates.......................................................................... 107 Table 28. Medical History and Physical Examination of Overweight Children and Adolescents

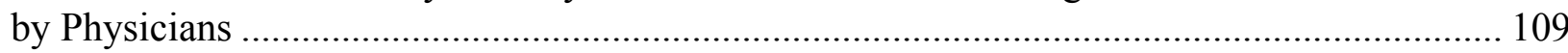
Table 29. Medical History and Physical Examination of Overweight Children and Adolescents by Physicians Based on State Childhood Obesity Prevalence Rates.......................................... 110 Table 30. Behavioral History Assessment of Overweight Children and Adolescents by Physicians 112

Table 31. Behavioral History Assessment of Overweight Children and Adolescents by Physicians Based on State Childhood Obesity Prevalence Rates. 113 


\section{LIST OF FIGURES}

Figure 1. Objective I theoretical model under investigation................................................ 13

Figure 2. Guidelines for preventive services in overweight children and adolescents: Expert

Committee recommendations (Reproduced with permission. Himes \& Dietz, 1994) ............... 26

Figure 3. Theory of Reasoned Action (Fishbein \& Ajzen, 1975).......................................... 32

Figure 4. Theory of Planned Behavior (Ajzen, 1985; Ajzen, 2006b) .................................... 35 


\section{LIST OF ABBREVIATIONS}

AAFP - American Academy of Family Physicians

AAP - American Academy of Pediatrics

BHS - Bogalusa Heart Study

BMI - Body Mass Index

CDC - Centers for Disease Control and Prevention

DHHS - Department of Health and Human Services

EMR - Electronic Medical Record

MCHB - Maternal and Child Health Bureau

SDB - Sleep Disordered Breathing

TPB - Theory of Planned Behavior

TRA - Theory of Reasoned Action

WHO - World Health Organization 


\section{CHAPTER ONE}

\section{INTRODUCTION}

\section{Obesity Prevalence and Cost Implications}

Over the past two decades, obesity has become a major public health issue worldwide. Considering the rapid increase in obesity prevalence across different nations, the World Health Organization (WHO) has declared obesity a global epidemic (WHO, 1998). The increase in the prevalence of obesity has affected all age groups. Worldwide, an estimated 1.1 billion adults and 155 million children are overweight or obese (Haslam \& James, 2005).

Obesity is a chronic disease (Bray, 2004), and as a disease, it acts as an underlying cause of multiple comorbid conditions such as impaired glucose tolerance, high blood pressure, hyperinsulinaemia, high-density lipoprotein cholesterol, dyslipidemia, asthma, and sleep disorders in children and adolescents (Caprio, Bronson, Sherwin, Rife, \& Tamborlane, 1996; Goran \& Gower, 1998; Lurbe, Alvarez, Liao, Tacons, Cooper, Cremades, Torro, \& Redon, 1998; Gupta, Mueller, Chan, \& Meininger, 2002; Sinha, Fisch, Teague, Tamborlane, Banyas, Allen, Savoye, Rieger, Taksali, Barbetta, Sherwin, \& Caprio, 2002; Mamun, Lawlor, Alati, O’callaghan, Williams, \& Najman, 2007; Thompson, Obarzanek, Franko, Barton, Morrison, Biro, Daniels, \& Striegel-Moore, 2007). In addition to medical complications, obesity in children and adolescents is associated with behavioral and psychosocial problems such as low self-esteem, aggressiveness, social withdrawal, and depression (Erermis, Cetin, Tamar, Bukusoglu, Akdeniz, \& Goksen, 2004; Sjoberg, Nilsson, \& Leppert, 2005). Overweight children and adolescents have lower health-related quality of life as compared to healthy children and 
adolescents, and similar quality of life to children and adolescents diagnosed with cancer (Schwimmer, Burwinkle, \& Varni, 2003).

Although the prevalence of childhood obesity has increased across different parts of the world, the rate of increase has been particularly high in the United States (US). The prevalence of obesity among children (age 6-11 years) and adolescents (age 12-19 years) has doubled and tripled, respectively, over the past two decades in the US (Baskin, Ard, Franklin, \& Allison, 2005). Data from the 2005 Youth Risk Behavior Surveillance (YRBS) showed that $13.1 \%$ of students in grades 9-12 are overweight, with another $15.7 \%$ at risk of being overweight (Eaton, Kann, Kinchen, Ross, Hawkins, Harris, Lowry, McManus, Chyen, Shanklin, Lim, Grunbaum, \& Wechsler, 2006).

With the increase in childhood and adolescent obesity, the healthcare expenditure associated with obesity at a young age has also increased in the US. The annual hospitalization costs related to childhood obesity increased by more than three times from 1979 to 1999 (Wang \& Dietz, 2002). Given that 77 percent of overweight children and adolescents carry their obesity into adulthood (Freedman, Khan, Dietz, Srinivasan, \& Berenson, 2001); the increasing prevalence of childhood obesity could negatively impact the overall obesity epidemic.

To control this epidemic of obesity, particularly childhood and adolescent obesity, and to increase the quality and years of health life of all people in the US, the US Department of Health and Human Services (US DHHS) set goals for the Healthy People 2010 initiative in January 2000 (US DHHS, 2000). Because of the major impact of obesity on public health and disability, it was listed as one of the target diseases. Objective 19-3c of the initiative calls for reducing the prevalence of obesity in children and adolescents to five percent by 2010 (US DHHS, 2000). To 
achieve this objective, there has to be a concerted and collaborative effort on the part of parents, schools, healthcare professionals, and policy makers.

Over the past several years, relevant organizations have published statements that address the scope of the problem of obesity and strategies to treat overweight children (Gidding, Leibel, Daniels, Rosenbaum, Van Horn, \& Marx, 1996; Barlow \& Dietz, 1998; American Academy of Pediatrics [AAP], 2001). In 1997, a committee of pediatric obesity experts convened by the Maternal and Child Health Bureau (MCHB), Health Resources and Services Administration (HRSA), and the DHHS put forth recommendations for health care professionals that described a management approach for overweight children (Barlow \& Dietz, 1998). More recently, the AAP came up with a policy statement that proposed strategies for prevention and early identification of overweight children (Krebs \& Jacobson, 2003).

The Pediatric Obesity Expert Committee recommendations (Barlow \& Dietz, 1998) are intended to guide pediatric health care providers, especially family physicians and pediatricians, in appropriately identifying and evaluating overweight children and adolescents. Prevention is easier than trying to cure for childhood obesity (Shephard, 2004); therefore, it is essential for family physicians and pediatricians, who are on the front line of providing health services to children and adolescents, to timely identify an overweight child using a valid screening tool. After an overweight child has been identified, a careful evaluation of that child should be performed by the physician to determine the presence of any underlying syndromes or co-morbid conditions (Barlow \& Dietz, 1998). Early identification and thorough evaluation of an overweight child could have a major bearing on success of the treatment strategy adopted. 


\section{Identification and Classification of Obesity in Children and Adolescents}

Obesity is generally defined as an excessive accumulation of fat in the body. One of the most widely accepted and convenient measure of an individual's weight status is the body mass index (BMI). BMI is a weight for height index, and is defined as weight in kilograms $(\mathrm{kg})$ over height in meters squared $\left(\mathrm{m}^{2}\right)$. In adults, BMI is widely accepted and recommended tool to identify obesity (Khosla \& Lowe, 1967; Keys, Fidanza, Karvonen, Kimura, \& Taylor, 1972; Garrow \& Webster, 1985; WHO, 1998). In 1997, the WHO convened the International Obesity Task Force (IOTF), which recommended a standard BMI classification system for adults (WHO, 1998). This classification system defines an adult with a BMI of 18.5 to $24.9 \mathrm{~kg} / \mathrm{m}^{2}$ as normal, a BMI of 25.0 to $29.9 \mathrm{~kg} / \mathrm{m}^{2}$ as overweight, and a BMI of greater than or equal to $30.0 \mathrm{~kg} / \mathrm{m}^{2}$ as obese.

In the US, the National Heart, Lung, and Blood Institute (NHLBI) adopted the BMI classification system recommended by the WHO (National Institute of Health [NIH], 1998). The use of BMI as a standard tool for obesity identification in adults was based on associations between adult BMI and risk of morbidity and mortality as shown in various observational and epidemiological studies (Rabkin, Mathewson, \& Hsu, 1977; Hubert, Feinleib, McNamara, \& Castelli, 1983; Hamm, Shekelle, \& Stamler, 1989; Lindsted, Tonstad, \& Kuzma, 1991; Chan, Rimm, Colditz, Stampfer, \& Willett, 1994; Colditz, Willett, Rotnitzky, \& Manson, 1995).

Though a few studies have debated the sensitivity and specificity of BMI (Dietz \& Robinson, 1998; Dietz \& Bellizzi, 1999; Ellis, Abrams, \& Wong, 1999), its use is recommended for identification of overweight children and adolescents (Himes \& Dietz, 1994; Barlow \& Dietz, 1998; Krebs \& Jacobson, 2003). These recommendations are based on the results of several studies which have documented the advantages of using BMI in children and adolescents. 
Besides the fact that BMI is relatively simple to calculate, studies have demonstrated a strong correlation (squared multiple correlation $\left[\mathrm{R}^{2}\right]=0.85$ and 0.89 for boys and girls, respectively) of BMI with total body fat in children and adolescents (Pietrobelli, Faith, Allison, Gallagher, Chiumello, \& Heymsfield, 1998). Studies have also demonstrated that a change in BMI is associated with clinically important improvements in insulin and lipid values and insulin sensitivity in children and adolescents (Reinehr, Kiess, Kapellen, \& Andler, 2004; Kirk, Zeller, Claytor, Santangelo, Khoury, \& Daniels, 2005).

Although BMI use is recommended in children and adolescents, the BMI classification system used in the adult population is not appropriate for children and adolescents, because BMI varies with age, gender, and stage of growth (Guo, Chumlea, Roche, \& Siervogel, 1997; Burniat, Cole, Lissau, \& Poskitt, 2002). Therefore, BMI cut-offs are age and gender specific in children and adolescents. Instead of a single BMI cutoff value to screen for obesity in adults, obesity in children is defined in terms of BMI percentile, which is age and gender specific. In the US, the Centers for Disease Control and Prevention (CDC) has developed BMI-for-age percentile growth charts and recommended the use of these charts in assessing the size and growth patterns of children and adolescents (Kuczmarski, Ogden, Guo, Grummer-Strawn, Flegal, Mei, Wei, Curtin, Roche, \& Johnson, 2002). Children and adolescents between the ages of two and eighteen years having a BMI greater than the $95^{\text {th }}$ percentile are categorized as overweight or obese, and those with BMI between the $85^{\text {th }}$ and $95^{\text {th }}$ percentile as at risk of being overweight (Himes \& Dietz, 1994; Barlow \& Dietz, 1998). Studies have shown the CDC BMI-cut-off points in overweight children to be strong predictors of obesity and risk factors for coronary heart disease in young adulthood (Janssen, Katzmarzyk, Srinivasan, Chen, Malina, Bouchard, \& Berenson, 2005). 


\section{Statement of the Problem}

Obesity is one of the major health challenges facing children and adolescents in the US (Hill \& Trowbridge, 1998). With rising obesity prevalence among this young age group, a bleak picture of future health is presented in terms of an increase in the prevalence of obesity-related medical conditions. Over the years, a number of interventions have been employed to tackle the problem of obesity in children and adolescents; however, these initiatives have met with little success (Boon \& Clydesdale, 2005). A crucial first step in the prevention of childhood and adolescent obesity is the early identification by physicians of children and adolescents who are overweight or at risk of being overweight.

Pediatricians and family physicians are key components of a successful prevention strategy. Although studies have shown physicians to be concerned about the growing problem of childhood obesity and its health effects on children (Story, Neumark-Stzainer, Sherwood, Holt, Sofka, Trowbridge, \& Barlow, 2002), the practice patterns of physicians related to identification and evaluation of overweight children and adolescents present a different picture.

Studies have documented low frequency of BMI use by physicians and inadequate medical evaluation of overweight children (Barlow, Dietz, Klish, \& Trowbridge, 2002; Jonides, Buschbacher, \& Barlow, 2002; Kolagotla \& Adams, 2004; Perrin, Flower, \& Ammerman, 2004; Dorsey, Wells, Krumholz, \& Concato, 2005). In addition, studies have reported use of other weight classification methods such as clinical impression, Rohrer Index (RI), and weight charts (Barlow et al., 2002; Kolagotla \& Adams, 2004; Perrin et al., 2004; Louthan, Lafferty-Oza, Smith, Homung, Franco, \& Theriot, 2005). 


\section{Conceptual Framework}

Since physicians are underutilizing the recommended obesity identification tool (BMI), interventions for improving physician BMI use could alleviate the problem of childhood obesity. An understanding of physician beliefs related to BMI use is essential to determine the reasons behind its lack of use for obesity identification. For practicing physicians, a number of beliefs and forces could influence their patterns of practice behavior, which makes it difficult for researchers to formulate a unifying theory of physician behavior change. Researchers have attempted to explain physician behavior in the clinical setting using a number of behavioral theories such as the Transtheoretical model, Social Cognitive theory, and others.

In this study, two related and well established behavioral models, the Theory of Reasoned Action (TRA) and the Theory of Planned Behavior (TPB) serve as the theoretical framework to study physician beliefs related to BMI use. Unlike other socio-behavioral models, these two theories provide an opportunity to understand the determinants of an individual's behavior (Ajzen \& Fishbein, 1980; Ajzen, 1985). According to the two theories, behavioral intention is the most important predictor of behavior. Intention reflects one's willingness to perform the behavior. Studies have shown that intention could be used as a useful proxy to actual behavior in building theory-based interventions (Bonetti, Eccles, Johnston, Steen, Grimshaw, Baker, Walker, \& Pitts, 2005).

\section{Theory of Reasoned Action (TRA)}

The underlying assumption of this theory is that all human beings are rational, that all available information is accounted for by them, and they consider the potential consequences of their actions (Fishbein \& Ajzen, 1975). According to the TRA, an individual's behavioral 
intention is the most immediate antecedent of a person's behavior (Ajzen \& Fishbein, 1980). Intention to perform a behavior is a function of two determinants, attitude and subjective norm. Attitude reflects a person's overall assessment of the behavior. Subjective norm refers to the societal pressure perceived by an individual to be on him or her to perform or not perform the behavior under investigation.

The predictive validity of the TRA is restricted to behaviors that are under one's control (Fishbein \& Ajzen, 1975; Ajzen \& Fishbein, 1977). The TRA is not adequate to predict those behaviors that require skills, resources, or opportunities (Fishbein, 1993). To address these limitations, TRA was modified by including another predictor of intention besides attitude and subjective norm (Ajzen, 1988, 1991).

\section{Theory of Planned Behavior (TPB)}

To address those behaviors that are not under one's control, a third component, perceived behavioral control, was added to the TRA model (Ajzen, 1985); the expanded model, with the perceived behavioral control component, is referred to as the Theory of Planned Behavior (TPB).

Perceived behavioral control reflects the ability of a person, as perceived by him or her, to perform the behavior under investigation. Addition of the perceived behavioral control component extends the use of the TRA beyond volitional behaviors. The TRA and the TPB are discussed in detail in chapter two.

This study determines the utility of these two behavioral models in explaining physician intention to measure BMI in children and adolescents through a mail survey of physicians practicing in four states. The TPB model was expanded by including the past behavior component. Role of past behavior in explaining physicians' intention to measure BMI over and 
above attitude, subjective norm, and perceived behavioral control was studied. In addition, this study assessed the current childhood obesity management practices of physicians.

\section{Purpose of the Study}

Although studies have been conducted to determine physician use of BMI (Barlow et al., 2002; Kolagotla \& Adams, 2004; Perrin et al., 2004; Gilbert \& Fleming, 2006), there is a lack of knowledge about the psychosocial factors that govern physician use of BMI. One purpose of this study was to increase our understanding of physician behavior and belief systems with respect to measuring BMI in children and adolescents. Using concepts derived from two behavioral models, the TRA and the TPB, predictors of physicians' intentions to measure BMI in children and adolescents were determined.

This study tests the predictive validity of the behavior choice models to increase understanding of beliefs that may influence physicians' intention to use BMI. The strength of the theoretical constructs in predicting physicians' intention to use BMI was examined. This study also provides updated information on how physicians currently evaluate overweight children and adolescents, including the screening methods used to identify obesity and medical conditions routinely assessed by them.

\section{Significance of the Study}

Using the TRA and the TPB, physician beliefs associated with BMI use can be identified. These beliefs can then be changed or reinforced to increase physicians' use of BMI. An instrument that classifies physicians into those intending and those not intending to use BMI could be useful. The results of this study can be used by policy makers, public, and professional 
healthcare agencies to develop communication strategies that are targeted towards improving physicians' use of BMI during well child visits. Interventions can be more effective in bringing about a behavior change by individualizing to physician's intention to use BMI. Updated information related to the frequency of medical evaluations performed by physicians can be used to modify the designs of educational interventions that provide professional training to physicians with the goal of improving management of overweight children.

\section{Study Objectives}

The study had three objectives. A detailed description of the three objectives of this study follows.

\section{Objective I}

The first objective of this study was to determine the utility of the TRA and the TPB model constructs in predicting intention (see Figure 1). The relationship of each of the three TPB constructs with their sub-determinants (i.e., the relationship between the direct and indirect measures of attitude, subjective norms, and perceived behavioral control, respectively) was investigated. The TRA is a model of social behavior that describes the relationship between attitude, subjective norms, and behavioral intention. This study attempts to determine the role, if any, of attitude and subjective norm in influencing behavioral intention. The TPB adds another construct, perceived behavioral control, to the TRA. The study determined if perceived behavioral control adds significantly beyond attitude and subjective norm in predicting physicians' intentions to measure BMI. Finally, the role of past behavior in predicting physicians' intentions to measure BMI was examined. 
Research Question 1: What is the relationship between the direct and indirect measures of attitude, subjective norms, and perceived behavioral control, respectively? Hypothesis 1.1a: Physician attitude towards measuring BMI in children and adolescents is not significantly correlated with the summated product of behavioral beliefs and evaluation of the outcomes.

Hypothesis 1.1b: Physician subjective norm about measuring BMI in children and adolescents is not significantly correlated with the summated product of normative belief and motivation to comply with a referent.

Hypothesis 1.1c: Physician's perceived behavioral control towards measuring BMI in children and adolescents is not significantly correlated with the product of control belief and influence of the specific control factor.

Research Question 2: What is the relationship between a physician attitude and subjective norms and his/her intention to measure BMI in children and adolescents?

Hypothesis 1.2: Attitude and subjective norm do not significantly predict physicians' intentions to measure BMI in children and adolescents.

Research Question 3: Does the addition of perceived behavioral control to attitude and subjective norm significantly increase the explained variance of physicians' intentions to measure BMI?

Hypothesis 1.3: Addition of perceived behavioral control over and above attitude and subjective norms will not add significantly to the prediction of physicians' intentions to measure BMI. 
Research Question 4: Does physician's past BMI measurement behavior increase the predictive ability of the TPB model?

Hypothesis 1.4: Addition of physician's past BMI measurement behavior to attitude, subjective norm, and perceived behavioral control does not significantly add to the prediction of his/her intention to measure BMI. 
Figure 1. Objective I theoretical model under investigation

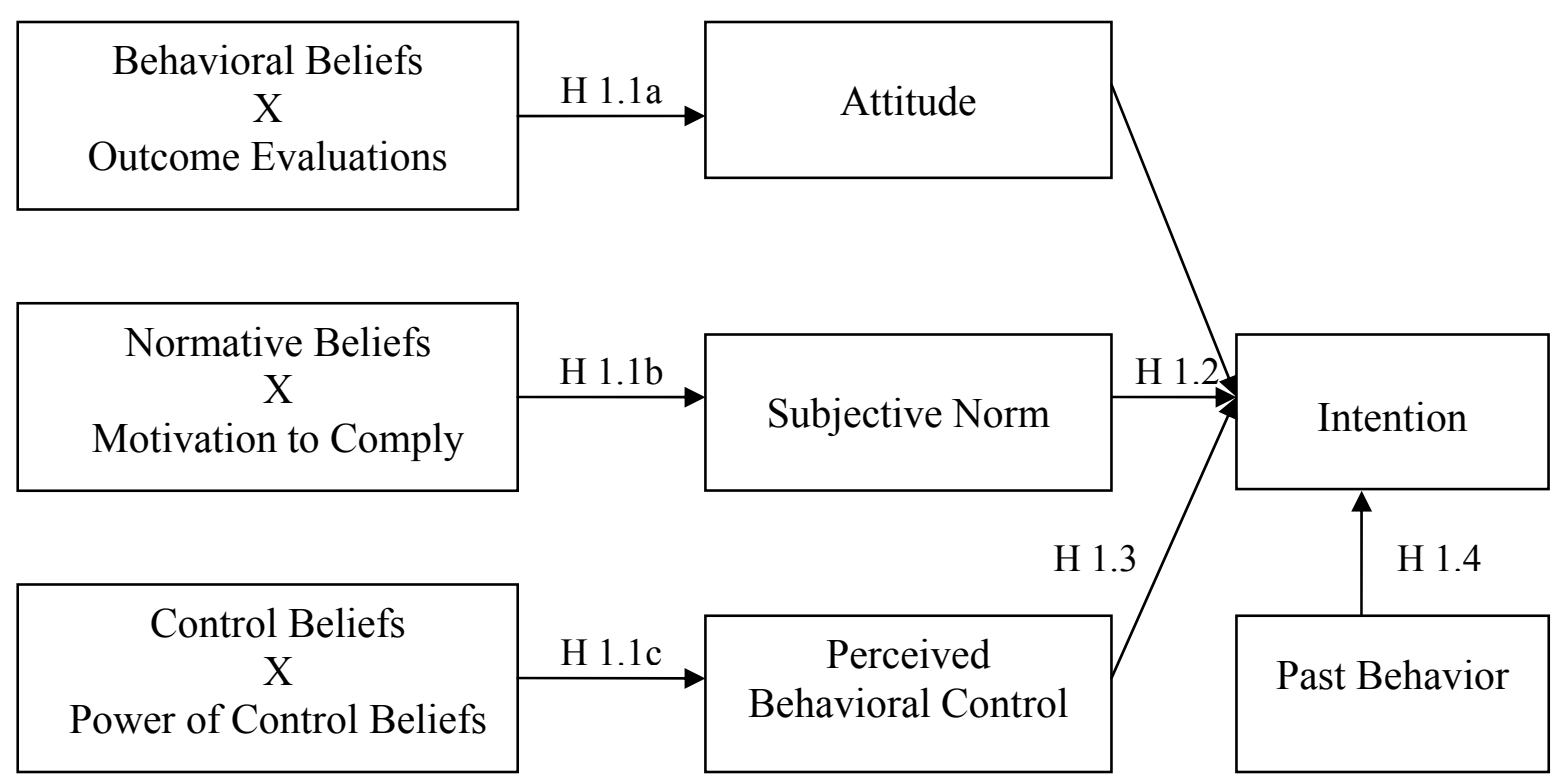




\section{Objective II}

The second objective of this study was to assess if there are any differences in physicians' beliefs based on their intention to measure BMI in children and adolescents. Salient behavioral and normative beliefs associated with intention were compared between physicians who intended to measure BMI and those who did not intended to measure BMI.

Hypothesis 2.1: There are no significant behavioral and normative belief differences between physicians who intend to measure BMI and those who do not intend to measure BMI.

\section{Objective III}

This part of the study describes physicians' practice concerning identification and evaluation of overweight children and adolescents. The frequency of use of different weight classification methods by physicians was described and their practice patterns related to medical evaluation of overweight children was assessed in relation to 1998 Pediatric Obesity Expert Committee recommendations.

\section{Study Assumptions}

The study is based on the assumptions that: 1) physicians accurately and honestly report their answers on the survey; 2) the study sample has been correctly identified from the physician list provided by SK\&A Information Services Inc., a private mailing list firm; and 3) the study sample provides regular care to the pediatric and/or adolescent populations.

The next chapter describes in detail the issue of childhood obesity and the theoretical models used for objective one the study. 


\section{CHAPTER TWO}

\section{LITERATURE REVIEW}

This chapter is divided into two sections. Section one discusses the issues surrounding obesity in children and adolescents: causes of obesity, implications of obesity on children's health, childhood obesity identification methods, and the role of physicians in obesity management. Section two discusses in detail the two theoretical models that were used in the study to test the Objective One hypotheses.

\section{Section I: Childhood Obesity}

\section{Causes of Obesity}

Obesity is a complex, multifactorial disease. A chronic disturbance of the energy balance results in obesity. This disturbance of the energy balance could be because of modifiable or nonmodifiable factors. Modifiable risk factors, such as lack of physical activity, sedentary behavior like television viewing, and unhealthy dietary habits, could alter the energy balance and cause obesity in children. In addition, non-modifiable risk factor like genetic make-up could also predispose a child to being overweight or obese.

Studies have shown that modifiable risk factors like dietary intake and physical activity account for a greater variance in changes in BMI of children as compared to non-modifiable risk factors (Klesges, R., Klesges, L., Eck, \& Shelton, 1995). Overall, the susceptibility towards obesity is determined by an interaction between genetic, behavioral, and environmental factors. The behavioral and environmental factors undergo a complex interaction to cause weight gain, 
while the genetic factors predispose a child towards weight gain. The role of each of these factors is discussed below.

\section{Role of Genetics}

A child's propensity towards obesity is partly determined by genetic factors. Studies have shown children of obese parents to have a much higher risk of obesity as compared to children of non-obese parents (Garn \& Clark, 1976). The likelihood of obesity is higher among identical twins of obese parents than those of non-obese parents (Borjeson, 1976). In addition, obese children with obese parents have a higher likelihood of being obese in their adulthood than obese children with thin parents (Epstein, Wing, \& Valoski, 1985). Several chromosomes associated with obese phenotypes have been identified by linkage studies (Comuzzie \& Allison, 1998). Studies of obese humans have found mutations and polymorphism of the genes of other neuropeptides and hormonal regulators of desire for food and weight control (Krude, Biebermann, Luck, Horn, Brabant, \& Gruters, 1998; Strobel, Issad, Camoin, Ozata, \& Strosberg, 1998). These studies suggest a genetic etiology to obesity in children.

At least five percent of moderately obese cases and a large percentage of extremely obese cases correspond to genetic predisposition (Loos \& Bouchard, 2003). The direct effect of genetics on childhood obesity is complex. Although the effect of genetics on weight-related chemical processes cannot be denied, genetics alone cannot account for the increasing prevalence of obesity among children and adolescents. Environmental and behavioral factors increase the risk of weight gain in children with a genetic predisposition towards obesity (Boutin \& Froguel, 2001). 


\section{Role of Environment, Behavior, and Psychological Factors}

The most common environmental factors affecting weight status in children and adolescents are physical activity, snacks and fast food consumption, television viewing, and duration of sleep (Andersen, Crespo, Bartlett, Cheskin, \& Pratt, 1998; Robinson, 1998; Berkey, Rockett, Field, Gillman, Frazier, Camargo, \& Colditz, 2000; Gupta et al., 2002). These factors could act individually or together to cause energy imbalance, thereby resulting in weight gain in children.

A physically active lifestyle could play a significant role in achieving appropriate growth and development in children and adolescents (Cooper, 1994; US DHHS, 1996). Over the years, numerous studies have reported the effect of physical activity on the weight status of children and adolescents (Andersen et al., 1998; Crespo, Smit, Troiano, Bartlett, Macera, \& Andersen, 2001; Eisenmann, Bartee, \& Wang, 2002; Gordon-Larsen, Adair, \& Popkin, 2002; Berkey, Rockett, Gillman, \& Colditz, 2003; Patrick, Norman, Calfas, Sallis, Zabinski, Rupp, \& Cella, 2004). These studies have consistently shown physical inactivity to be associated with higher BMI in children and adolescents. The last few years have seen a significant decline in physical activity among young people (Troiano, 2002), which could have contributed towards an increasing prevalence of obesity among this age group.

A decrease in physical activity and exercise among children and adolescents has been accompanied by an increase in sedentary behavior. Television viewing is the most prevalent sedentary behavior among children and adolescents. The American Academy of Pediatrics (AAP) recommends no more than two hours of screen viewing (television, video games, and internet) per day for children older than two years (AAP, 2001). However, more than one-fourth of children watch four or more hours of television per day (Andersen et al., 1998). Television 
viewing supplants physical activity and increases energy intake, and therefore could lead to obesity (Robinson, 1998; Epstein, Paluch, Consalvi, Riordan, \& Scholl, 2002). In addition, television viewing is associated with a child's overall food consumption pattern as well (Young \& Hetherington, 1996; Coon, Goldberg, Rogers, \& Tucker, 2001). An inverse relationship exists between television viewing and consumption of fruits and vegetables (Coon et al., 2001; Coon \& Tucker, 2002). The relationship between television viewing, physical activity and BMI has been well documented (Andersen et al., 1998; Eisenmann et al., 2002; Berkey et al., 2003). These studies highlight the role of television viewing in altering the energy balance in children and adolescents by increasing calorie intake and decreasing calorie expenditure.

The relationship between sleep duration and weight status in children and adolescents has also been investigated. Sleep duration is correlated with weight in children and adolescents (Gupta et al., 2002). This relationship could be because of the impact of sleep duration on the balance between energy intake and energy expenditure. Inadequate sleep leads to hormonal changes, which could lead to an increased consumption of calorific food (Taheri, 2006). Additionally, sleep deprivation could result in fatigue and decreased ability to perform physical activity. Gupta and colleagues (2002) reported that for every hour of sleep lost in adolescents, physical activity diminishes by three percent. As highlighted by these studies, lack of adequate sleep could contribute to obesity among children.

Of the different environmental factors, diet plays one of the most important roles in determining weight status of children and adolescents. Contrary to popular perception, over the years the total calories consumed as fat has decreased among children and adolescents (Cavadini, Siega-Riz, \& Popkin, 2000; Troiano, Briefel, Carroll, \& Bialostosky, 2000). However, calories consumed through healthy fruits and vegetables have been supplanted with calories associated 
with fast food. The relationship of carbonated drinks, fast food, and carbohydrate rich food with obesity is well recognized (Binkley, Eales, \& Jekanowski, 2000; French, Story, NeumarkSztainer, Fulkerson, \& Hannan, 2001; Ludwig, Peterson, \& Gortmaker, 2001). An increase in fast food consumption and accompanying decrease in physical activity has augmented the problem of obesity in children.

In addition, psychological factors, such as depression, dieting, and binge eating, could also cause excessive weight gain in children. Studies have shown that depressed children and adolescents have higher BMI during their adolescent and adult years of life (Pine, Goldstein, Wolk, \& Weissman, 2001; Goodman \& Whitaker, 2002). The odds of being obese are twice as high for depressed adolescents as compared to non-depressed adolescents (Goodman \& Whitaker, 2002). Weight control behaviors among children, such as dieting, induced vomiting, and use of appetite suppressants, could lead to weight gain rather than weight loss (Stice, Cameron, Killen, Hayward, \& Taylor, 1999). A few studies have reported eating disorders such as binge eating behavior as a potential risk factor for obesity in children and adolescents (McGuire, Wing, Klem, Lang, \& Hill, 1999; Stice et al., 1999).

Genetic, environmental, behavioral, and psychological factors interplay to cause a change in energy intake and energy expenditure in children. The relative influence of these factors varies among children. A child can have a healthy weight in a healthy eating environment accompanied by regular physical activity, despite being genetically predisposed to obesity. In comparison, a child without a genetic predisposition to obesity could still become overweight due to unhealthy-eating habits and lack of physical activity. It is important to highlight the role of environment and behavior in causing obesity, because unlike genes, these factors could be evaluated and targeted through interventions. 


\section{Health Implications of Childhood and Adolescent Obesity}

Obesity in children and adolescents could have detrimental short- and long-term health consequences. The short-term consequences of obesity could include an increased risk of chronic and other diseases, such as cardiovascular diseases, diabetes, asthma, sleep apnea, and certain psychological and behavioral problems (Daniels, 2006). These health consequences of childhood obesity are discussed in detail below. In the long-term, obese children and adolescents are more likely to become obese adults (Serdula, Ivery, Coates, Freedman, Williamson, \& Byers, 1993), and suffer from health problems associated with adult obesity. Obese adults have substantially lower life-expectancy due to an increase in early obesity-related mortality (Weiss, Dziura, Burgert, Tamborlane, Taksali, Yeckel, Allen, Lopes, Savoye, Morrison, Sherwin, \& Caprio, 2004).

\section{Cardiovascular Diseases}

Cardiovascular risk factors, such as elevated levels of systolic blood pressure, diastolic blood pressure, and triglyceride, cluster in overweight children and adolescents (Figueroa-Colon, Franklin, Lee, \& Aldridge, 1997; Freedman, Dietz, Srinivasan, \& Berenson, 1999). Results from one of the longest and most detailed study of cardiovascular disease risk factors in a biracial population of children, the Bogalusa Heart Study (BHS), showed a relationship between obesity and clustering of cardiovascular risk factors (Freedman et al., 1999). In the BHS, overweight (BMI greater than $95^{\text {th }}$ percentile) children and adolescents were more likely to have an elevated systolic blood pressure (odds ratio $[\mathrm{OR}]=4.5)$, diastolic blood pressure $(\mathrm{OR}=2.4)$, and triglycerides $(\mathrm{OR}=7.1)$ as compared to children and adolescents with a BMI less than the $85^{\text {th }}$ percentile (Freedman et al., 1999). 


\section{Diabetes}

Obesity in children has been shown to be a risk factor for Type 1 diabetes or insulindependent diabetes mellitus (IDDM) (Hypponen, Virtanen, Kenward, Knip, \& Akerblom, 2000). Hypponen and colleagues (2000) found that overweight children have more than a two-fold risk of developing IDDM. In addition to increasing the risk for Type 1 diabetes, studies have shown an increasing number of overweight children and adolescents presenting with Type 2 diabetes or non-insulin dependent diabetes mellitus (NIDDM) (Pinhas-Hamiel, Dolan, Daniels, Standiford, Khoury, \& Zeitler, 1996). The study by Pinhas-Hamiel and colleagues (1996) reported a ten fold increase in the number of Type 2 diabetes cases among adolescents between 1982 and 1994, which could be attributed to the increase in obesity prevalence among adolescents.

\section{Respiratory Disease}

Obesity is considered a risk factor for asthma (Shore, 2006). From 1980 to 1996, the prevalence of asthma increased by an average of $4.3 \%$ annually among children (Akinbami \& Schoendorf, 2002), and was accompanied by an increase in childhood obesity prevalence.

Studies have shown that overweight children have a higher risk of asthma (Castro-Rodriguez, Holberg, Morgan, Wright, \& Martinez, 2001; Mannino, Mott, Ferdinands, Camargo, Friedman, Greves, \& Redd, 2006). In addition to being prone to asthma, children and adolescents who are overweight or at risk of being overweight are more likely to experience severe asthma symptoms (Luder, Melnik, \& DiMaio, 1998; Belamarich, Luder, Kattan, Mitchell, Islam, Lynn, \& Crain, 2000). In children and adolescents with asthma, obesity is associated with more asthma symptoms, reduced peak expiratory flow rates, and higher healthcare utilization (Luder et al., 1998; Belamarich et al., 2000). 
Obesity in children and adolescents is also a risk factor for sleep apnea or sleepdisordered breathing (SDB) (Redline, Tishler, Schluchter, Aylor, Clark, \& Graham, 1999). Characteristics of SDB are upper airway obstruction, snoring, and daytime sleepiness. Studies have suggested that SDB may partly explain the relationship between obesity and asthma/wheezing in children and adolescents (Sulit, Storfer-Isser, Rosen, Kirchner, \& Redline, 2005).

\section{Psychosocial and Behavioral Problems}

Besides the clinical implications, obesity in children and adolescents has psychological, behavioral, and social ramifications. Overweight children tend to have more negative physical self-perceptions and lower general self-worth (Braet, Mervielde, \& Vandereycken, 1997). An analysis of the National Longitudinal Survey of Youth (NLSY) revealed that self-esteem decreases as obese children grow into obese adolescents (Strauss, 2000). Overweight children with low levels of self-esteem are more likely to engage in risky behaviors like smoking or consuming alcohol (Strauss, 2000). Other negative social and psychological ramifications of childhood obesity include being stigmatized, more bullied, and less liked by peers (Kraig \& Keel, 2001; Pearce, Boergers, \& Prinstein, 2002; Latner \& Stunkard, 2003; Janssen, Craig, Boyce, \& Pickett, 2004).

\section{Childhood Obesity Identification Methods}

In children, body fat can be accurately estimated using techniques such as dual-energy Xray absorbtiometry (DEXA), total body water, total-body electrical conductivity, total body potassium, underwater weighting, and computed tomography; however, the cost and complexity 
of these methods limits their use to only research settings (Fomon, Haschke, Ziegler, \& Nelson, 1982; Fiorotto, Cochran, Funk, Sheng, \& Klish, 1987; Goran, Kaskoun, Carpenter, Poehlman, Ravussin, \& Fontvieille, 1993; Schaefer, Georgi, Zieger, \& Scharer, 1994; Goran, Toth, \& Poehlman, 1998). In clinical settings, height and weight based indices such as BMI, weight-forheight, and the Rohrer index (RI) or anthropometric-based measurements such as skinfold thickness or circumference measurements are frequently used to identify overweight children and adolescents (WHO, 1995). In addition, physicians use clinical impression to identify overweight children in clinical settings (Barlow et al., 2002; Kolagotla \& Adams, 2004; Perrin et al., 2004; Louthan et al., 2005).

Use of weight classification methods such as clinical impression, weight-for-age, and weight-for-height percentile may lead to under diagnosis of children and adolescents who are overweight or at-risk of being overweight (Beeman, Levy, Hare, \& Stender, 2004; Louthan et al., 2005). Unlike BMI-for-age percentile charts, weight-for-stature charts that have been used in the past do not capture the change in the weight-height relation with age (Flegal, Wei, \& Ogden, 2002). The BMI is considered to be superior to other weight-for-height indices because of its ability to control the effect of sex, height, and age on weight (Cole, 1979). The BMI-for-age is better than the Rohrer Index (RI)-for-age (weight in kilogram/height in meters cubed) for predicting overweight and underweight children and adolescents (Mei, Grummer-Strawn, Pietrobelli, Goulding, Goran, \& Dietz, 2002). Another screening method that is sometimes used to assess weight-for-height proportion in children is the percentage of ideal body weight. However, compared with BMI, percentage of ideal body weight underestimates and overestimates the severity of malnutrition in children with short and tall stature, respectively (Zhang \& Lai, 2004). Another advantage of using BMI as a screening tool to identify 
overweight children is the continuity of assessment it could provide as a child grows. Since BMI is the recommended and widely accepted screening method for obesity identification in adults, periodic BMI measurement of children by physicians would also enable continuous monitoring of nutritional status of children and adolescents through adulthood.

\section{Role of Physicians in Assessment and Evaluation of Overweight Children and Adolescents}

Family physicians and pediatricians are well-placed to identify and appropriately manage overweight or at risk of being overweight children and adolescents. The increasing prevalence of obesity and its short-term and long-term implications necessitate greater participation of physicians in the prevention and treatment of overweight and obesity among their pediatric and adolescent patients.

Public health and professional organizations such as the Centers for Disease Control and Prevention (CDC), the American Academy of Pediatrics (AAP), and the American Academy of Family Physicians (AAFP) recommend the use of BMI to identify overweight children and adolescents. Identification of an overweight child should be followed by an in-depth medical evaluation. As recommended by the 1998 Pediatric Obesity Expert Committee (Barlow \& Dietz, 1998), appropriate medical evaluation of overweight children requires performance of certain clinical tests, medical history and physical examination, family history assessment, and behavioral history asssessment (see Figure 2). These evaluations correspond to the identification of causes and health conditions commonly associated with overweight children. A detailed medical evaluation of overweight children and adolescents should precede a weight control intervention (Barlow \& Dietz, 1998). Given that most of the obesity-related health conditions 
are asymptomatic in nature, and are unnoticeable for years, early screening and identification of these conditions is imperative. 
Figure 2. Guidelines for preventive services in overweight children and adolescents:

Expert Committee recommendations (Reproduced with permission. Himes \& Dietz, 1994)

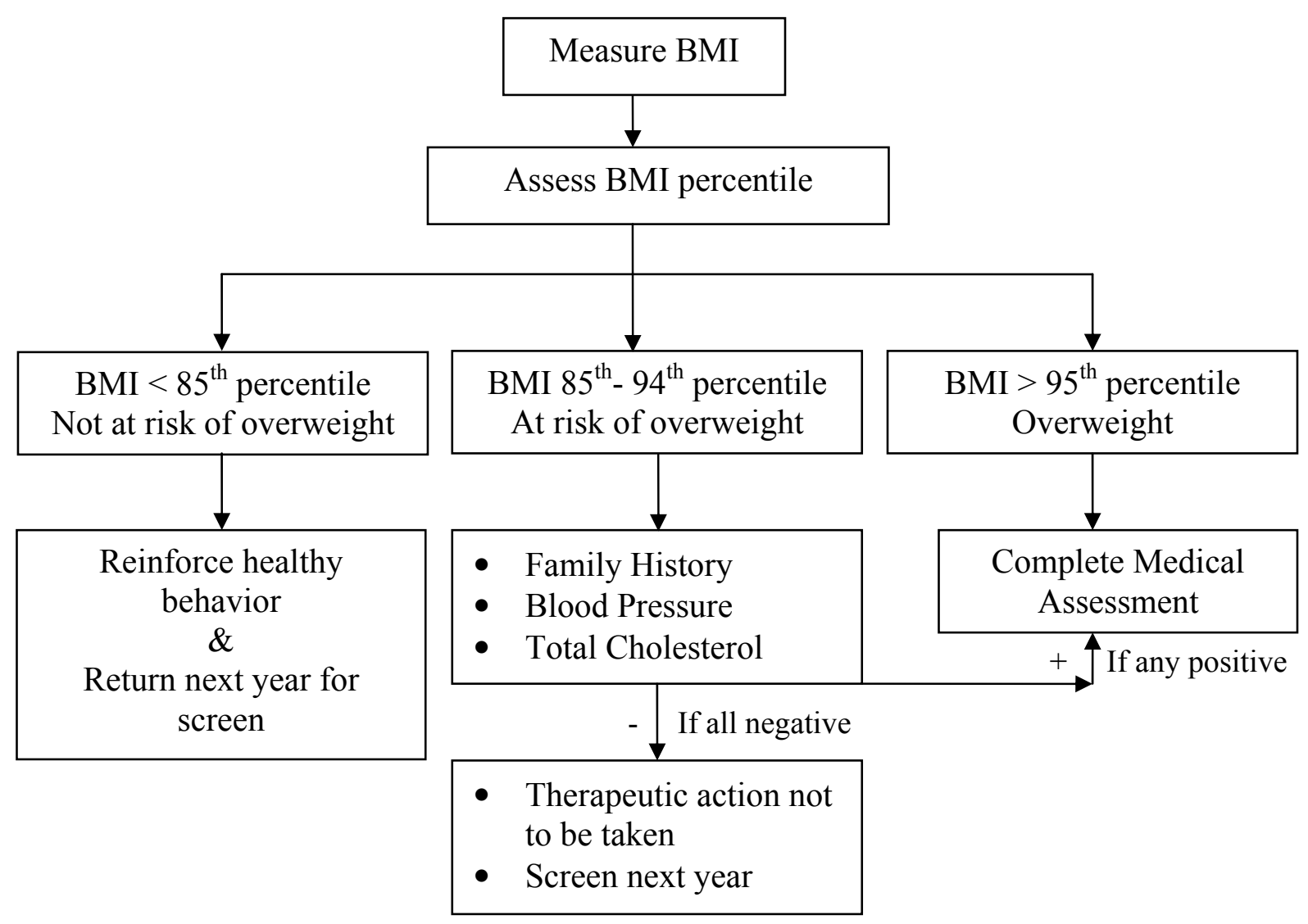


To date, few studies have reported physicians' practice patterns related to the assessment and evaluation of overweight children and adolescents. To draw focus to the childhood obesity assessment and evaluation practices of physicians, results from six articles have been summarized: Barlow and colleagues (2002), Jonides and colleagues (2002), Kolagotla and Adams (2003), Perrin and colleagues (2004), Dorsey and colleagues (2005), and Louthan and colleagues (2005). These summaries provide an insight into the obesity identification methods used by physicians, and the evaluation approach being followed by them in managing overweight children and adolescents.

Barlow and colleagues (2002) studied the childhood obesity assessment and evaluation practices of pediatric health care providers. The study determined physicians and other health care professionals' adherence to 1998 Pediatric Obesity Expert Committee recommendations on evaluation of overweight children and adolescents. The study results showed a frequent use of screening methods such as clinical impression, weight-for-age percentile, weight-for-height percent, weight-for-height percentile, and change in weight velocity by health care providers. Roughly $20 \%$ of pediatricians in the study used BMI and even fewer $(12.5 \%)$ used BMI percentile for obesity screening. Less than $10 \%$ of surveyed pediatricians routinely followed the Pediatric Obesity Expert Committee recommendations on medical evaluation of overweight children and adolescents. Pediatricians' adherence to the pediatric committee recommendations concerning clinical evaluations and family history assessment of overweight children was also low.

Kolagotla and Adams (2003) assessed family physicians and pediatricians adherence to Pediatric Obesity Expert Committee recommendations on evaluation of overweight children. Less than half of family physicians and roughly one-third of pediatricians reported using BMI in 
that study. A small percentage (13\%) of physicians routinely assessed all components (diabetes, hypertension, elevate cholesterol, obesity, cardiovascular disease, and gall bladder disease) of the family history assessment. With respect to medical history and physical examination of overweight children and adolescents, few physicians in that study reported that they routinely assessed overweight children for sleep disorder or pseudotumor cerebri. Sixty percent of physicians in that study reported that they routinely ask about diet history, and less than half frequently asked about depression and eating disorders. Overall, the study results showed low levels of physicians' adherence to the Pediatric Obesity Expert Committee recommendations. Jonides and colleagues (2002) assessed pediatric health care providers' psychological, emotional, and behavioral evaluation practices in overweight children and adolescents. Less than $75 \%$ of the pediatricians in that study reported conducting a routine assessment of the history of eating disorders and depression in overweight pediatric patients. However, more than $90 \%$ of pediatricians in that study routinely enquired about sedentary behavior and performance of organized physical activity.

Perrin and colleagues (2004) reported pediatricians' frequency of use of BMI and other methods of obesity identification in children. The most frequently used obesity screening tool among surveyed physicians was weight and height charts together. Physicians also reported using visual impression, weight-for-stature or weight-for-height charts to identify an overweight child. Eleven percent of surveyed physicians reported a frequent use of BMI as an obesity identification tool.

Dorsey and colleagues (2005) reviewed medical records of children and adolescents to determine physicians' use of BMI in obesity identification. Physicians recorded BMI in $0.5 \%$ of the medical records reviewed. The review of medical charts by the authors of that study revealed 
that roughly $80 \%$ of overweight children were undiagnosed and $83.1 \%$ were untreated. Of those overweight children who were treated, medical evaluation for the presence of comorbid diseases was performed in $3 \%$.

Louthan and colleagues (2005) reviewed medical charts of children to assess physicians' use of weight classification methods. The BMI was calculated and recorded in none of the medical charts of children that were reviewed by the authors. Charts review suggested that physicians were using clinical impression, weight-for-age percentile, and weight-for-height percentile. Despite the use of these screening methods, the study results showed that $71 \%$ of overweight children were undiagnosed.

Of the studies described above, the study by Barlow and colleagues (2002) and Kolagotla and Adams (2003) reported physicians practice related medical evaluation of overweight children in relation to 1998 Pediatric Obesity Expert Committee recommendations. However, both these studies were conducted in the early half of this decade, which was before the AAP released its policy statement recommending physicians use BMI for obesity identification. With the increasing emphasis being given to the issue of childhood obesity, it is possible that physicians practice would have changed over the years. This study attempts to provide the most recent update on physicians' adherence to Pediatric Obesity Expert Committee recommendations concerning evaluation of overweight children. 


\section{Section II: Socio-Behavioral Models}

To test hypotheses under Objective One, two related theoretical models, the Theory of Reasoned Action (TRA) and Theory of Planned Behavior (TPB), were used in the study. The two theoretical models are described in detail below.

\section{Theory of Reasoned Action (TRA)}

The TRA was first introduced in 1967, to serve the purpose of predicting and understanding an individual's behavior (Fishbein, 1967). Over the last few decades, TRA has established itself as one of the most credible models of social psychology. This model describes performance of behaviors that are under an individual's own control in terms of three cognitive elements: intentions, attitudes, and social norms. According to the TRA (Fishbein \& Ajzen, 1975; Ajzen \& Fishbein, 1980) (see Figure 3), intention is a predictor of an individual's behavior. Intention, in turn, is predicted by two components: 1) an attitudinal component, and 2) a social-normative component. Both of these components can be measured directly and indirectly.

Attitude reflects a person's beliefs related to performance of a behavior. The direct measure of attitude is based on a person's general evaluation of a behavior, wherein a person may judge the characteristic of a behavior on a semantic differential scale (e.g., beneficialharmful) (Francis, Johnston, Eccles, Grimshaw, \& Kaner, 2004a). The indirect measure of attitude is conceptualized as an individual's favorable or unfavorable evaluation of a behavior. A person's attitude towards a behavior is a function of his/her behavioral beliefs related to the consequences of performing the behavior weighted by the beliefs concerning the value attached to each consequence. The key relation between attitude $\left(\mathrm{A}_{\mathrm{b}}\right)$ and beliefs $\left(\mathrm{b}_{\mathrm{i}}\right)$ concerning 
outcomes associated with the performance of a behavior and evaluation $\left(\mathrm{e}_{\mathrm{i}}\right)$ of those outcomes is expressed by the following equation:

$$
\mathrm{A}_{\mathrm{b}}=\sum \mathrm{b}_{\mathrm{i}} \mathrm{e}_{\mathrm{i}}
$$

Similar to attitude, there are direct and indirect measures of subjective norm. The direct measure of subjective norm refers to a person's belief about whether important others want the person to perform the behavior in question or not. Important others or referents could be a person's friends, family, professional organizations, patients, etc. The indirect measure of subjective norm $\left(\mathrm{SN}_{\mathrm{b}}\right)$ is a function of normative beliefs $\left(\mathrm{nb}_{\mathrm{i}}\right)$, a person's beliefs regarding significant others views of a behavior, weighted by the person's motivation to comply $\left(\mathrm{mc}_{\mathrm{i}}\right)$ with the views of significant others. Mathematically, this relation can be represented as follows:

$$
\mathrm{SN}_{\mathrm{b}}=\sum(\mathrm{nb})_{\mathrm{i}}(\mathrm{mc})_{\mathrm{i}}
$$

Behavioral intention is the central determinant of behavior in the TRA. Intention refers to the perceived likelihood of performing a given behavior and indicates the effort people are willing to exert to perform the behavior (Ajzen, 1991). Multiple regression analysis can be used to test the hypothesized relations in the TRA model (Ajzen \& Fishbein, 1980). The relationship between the cognitive components of the TRA could be expressed algebraically as written below, where I is a person's intention to perform the behavior, $A_{b}$ is the person's attitude towards the behavior, $\mathrm{SN}_{\mathrm{b}}$ is the person's subjective norm related to the behavior, and $\mathrm{w}_{1}$ and $\mathrm{w}_{2}$ are the weights associated with attitude and subjective norm, respectively.

$$
\mathrm{I}=\mathrm{w}_{1}\left(\mathrm{~A}_{\mathrm{b}}\right)+\mathrm{w}_{2}\left(\mathrm{SN}_{\mathrm{b}}\right)
$$


Figure 3. Theory of Reasoned Action (Fishbein \& Ajzen, 1975)

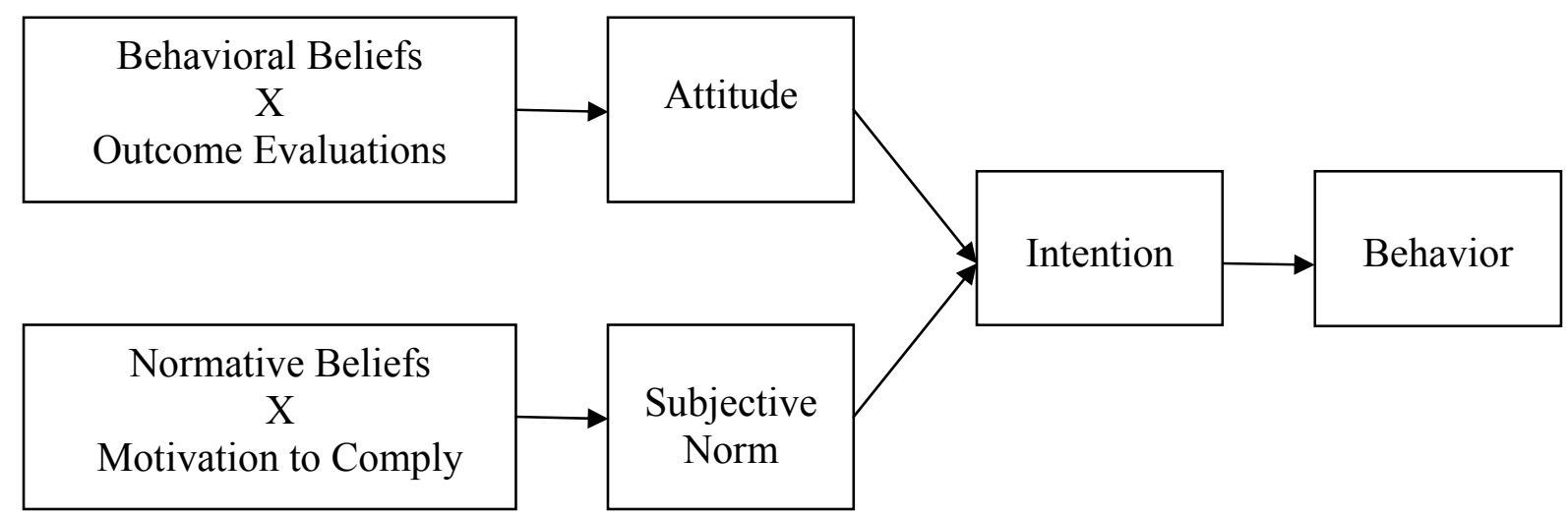




\section{Theory of Planned Behavior (TPB)}

The TRA was designed to explain behaviors over which an individual has complete control (Ajzen \& Fishbein, 1980). However, several behaviors require skills, resources or support from other people, which could limit the ability of the TRA model to predict performance of a behavior (Liska, 1984). For behaviors that are not under volitional control, Ajzen (1985) proposed a new model. The TPB (Ajzen, 1985) (see Figure 4) is an extension of the TRA and includes perceived behavioral control as a third predictor of intention. The addition of perceived behavioral control to attitude and subjective norm increases the predictive validity of the model for behaviors that are beyond an individual's control (Ajzen, 1991; Madden, Ellen, \& Ajzen, 1992). The TPB assumes that many behaviors are not within an individual's personal control and that nonmotivational aspects influence these behaviors.

As with attitude and subjective norm, perceived behavioral control can be measured both directly and indirectly. The direct measure of perceived behavioral control consists of three factors, the degree of control, confidence, and difficulty in performing a behavior (Ajzen \& Madden; 1986; Raats, Shepherd, \& Sparks, 1995; Terry \& O’Leary, 1995; Sparks, Guthrie, \& Shepherd, 1997; Armitage \& Connor, 1999; Ajzen, 2006a). Perceived confidence and perceived difficulty assesses a person's self-efficacy in performing a behavior. Perceived control assesses the degree of control a person has over a behavior. The indirect measure of perceived behavioral control $\left(\mathrm{PBC}_{\mathrm{b}}\right)$ is a function of control beliefs $\left(\mathrm{cb}_{\mathrm{i}}\right)$ weighted by the power of each of these control beliefs $\left(\mathrm{ec}_{\mathrm{i}}\right)$ in facilitating or inhibiting the performance of behavior under investigation (Ajzen \& Madden, 1986). The following equation represents the indirect measure of perceived behavioral control:

$$
\mathrm{PBC}_{\mathrm{b}}=\sum(\mathrm{cb})_{\mathrm{i}}(\mathrm{ec})_{\mathrm{i}}
$$


As with the TRA, the central construct in the TPB is behavioral intention. The relationship between the components of the TPB could be represented mathematically as mentioned below, where, I is a person's intention to perform the behavior, $A_{b}$ is the person's attitude towards performing the behavior, $\mathrm{SN}_{\mathrm{b}}$ is the person's subjective norm, $\mathrm{PBC}_{\mathrm{b}}$ is the person's perceived control over the behavior, and $\mathrm{w}_{1}, \mathrm{w}_{2}$, and $\mathrm{w}_{3}$ are the weights associated with attitude, subjective norm, and perceived behavioral control, respectively:

$$
\mathrm{I}=\mathrm{w}_{1}\left(\mathrm{~A}_{\mathrm{b}}\right)+\mathrm{w}_{2}\left(\mathrm{SN}_{\mathrm{b}}\right)+\mathrm{w}_{3}\left(\mathrm{PBC}_{\mathrm{b}}\right)
$$


Figure 4. Theory of Planned Behavior (Ajzen, 1985; Ajzen, 2006b)

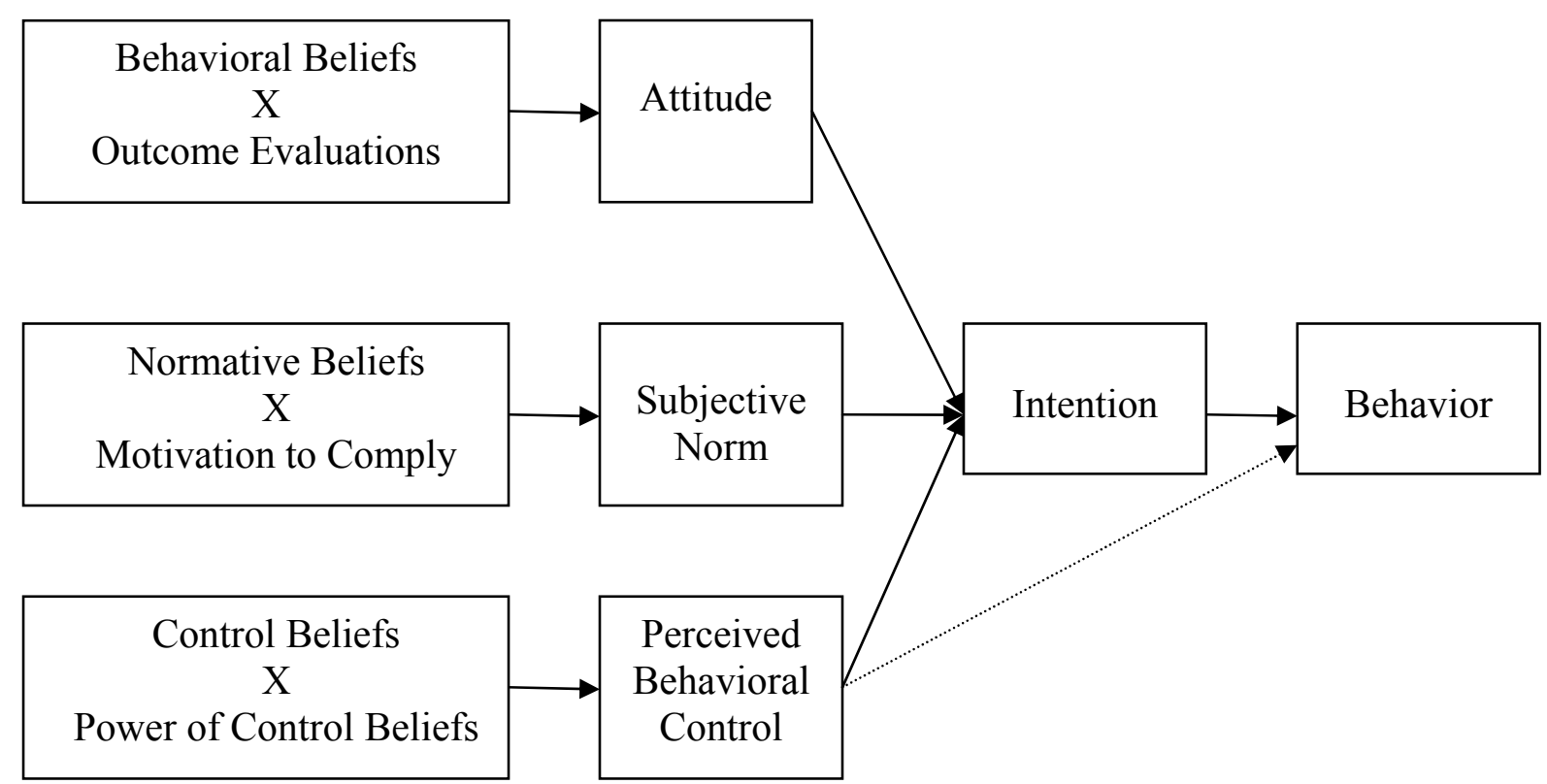




\section{Applications of the Theory of Reasoned Action and the Theory of Planned Behavior}

Several studies have tested the TRA and the TPB models in a variety of behaviors. Studies and meta-analyses have provided support for these two socio-behavioral models and have demonstrated the predictive ability of the two models across a wide range of behaviors (Sheppard, Hartwick, \& Warshaw, 1988; Ajzen, 1991; Connor \& Sparks, 1996; Godin \& Kok, 1996; Sheeran \& Taylor, 1999; Armitage \& Conner, 2001).

In a meta-analysis of 87 studies that had used the TRA model, Sheppard and colleagues (1988) found that the average correlation between intention and behavior was 0.53 and between attitude, subjective norm and intention was 0.66 . A review of empirical studies employing the TPB was performed by Ajzen (1991). The average multiple correlation of attitude, subjective norm, and perceived behavioral control with intention was 0.71 . A comparison of TRA and TPB by Madden and colleagues (1992) showed that the degree of perceived control over the behavior explained the magnitude of difference in prediction between the two models. For behaviors that were considered under volitional control, there was a small or no difference between the two models.

Godin and Kok (1996) conducted a meta-analysis of studies that had used the TPB and found that the addition of perceived behavioral control to attitude and subjective norm increased the intention variance explained by an average of $13 \%$. On average, the three TPB constructs, attitude, subjective norm, and perceived behavioral control explained $41 \%$ of the variance in intention. Armitage and Conner (2001) evaluated 185 studies that had employed the TPB in a variety of behaviors and found that perceived behavioral control increased the intention variance explained by an average of six percent after controlling for attitude and subjective norm. 
Both the TRA and the TPB have been used effectively in predicting intentions among physicians across different behavioral domains (Millstein, 1996; Lambert, Salmon, Stubbings, Gilomen-Study, Valuck, \& Kezlarian, 1997; Walker, Grimshaw, \& Armstrong, 2001; Beatty \& Beatty, 2004; Sable, Schwartz, Kelly, Libson, \& Hall, 2006). As has been demonstrated by some of these studies, the TRA and the TPB can be used to determine the particular beliefs associated with physicians' adherence to practice guidelines and recommendations. These studies and reviews have demonstrated the utility of the TRA and the TPB in understanding physicians' behavioral intentions and performance of the behavior.

In addition, several studies have attempted to increase the intention variance explained by making additions to the model. Studies have demonstrated that past behavior independently predicts both intention and behavior (Bagozzi \& Kimmel, 1995; Rutter, 2000). In their review of studies that had examined the impact of past behavior on TPB, Conner and Armitage (1998) found past behavior to be strongly correlated with intention $(\mathrm{r}=0.51)$. After accounting for attitude, subjective norm, and perceived behavioral control, past behavior increased the intention variance explained by an average of $7.2 \%$ in the studies that were reviewed by Conner and Armitage (1998).

This study uses the TRA, the TPB, and the modified TPB consisting of past behavior component to study physicians beliefs related to using BMI as a screening tool to identify overweight children and adolescents. Use of the TRA and the TPB model in understanding physician screening behavior, in relation to BMI use, would help us to understand the psychological channels through which attitudinal beliefs, normative beliefs, and control beliefs impact physicians BMI screening intentions.

The methodology employed in the study is discussed in the next chapter. 


\section{CHAPTER THREE}

\section{METHODOLOGY}

The study was conducted in two phases. Phase one of the study involved instrument development and phase two involved instrument administration. A detailed description of the two study phases is provided below.

\section{Phase I: Instrument Development}

To investigate the utility of the Theory of Reasoned Action (TRA) and the Theory of Planned Behavior (TPB) model, it was essential to determine the underlying beliefs that apply to physicians BMI measurement behavior. Considering that different beliefs are reported by different populations for similar behaviors (Kerner \& Grossman, 2001), studies recommend the construction of the TRA and the TPB questionnaire to be based on information provided by the population of interest (Ajzen \& Fishbein, 1980). Therefore, to determine the specific beliefs that are associated with physicians' use of BMI, a convenience sample of eight physicians (four family physicians and four pediatricians) were identified and contacted. Physicians for these elicitation interviews were identified randomly from the list of physicians practicing in the West Virginia University Hospital.

All eight physicians who were contacted agreed to participate in elicitation interviews. These physicians were interviewed face-to-face and were asked to identify the advantages and disadvantages associated with BMI measurement in children and adolescents, the individuals or groups influencing their decision to measure BMI, and the factors or circumstances that enable or make it difficult for them to measure BMI. These questions were based on recommendations 
for construction of TPB questionnaires (Francis, Eccles, Johnston, Walker, Grimshaw, Foy, Kaner, Smith, \& Bonetti, 2004b). Those beliefs that were commonly reported were converted into statements and included in section I of the survey. The theory based items are discussed in detail under instrumentation.

Section II of the questionnaire assessed the current obesity evaluation practices of physicians. Two researchers, Dr. Mary T. Story and Dr. Lakshmi Kolagotla, who had previously assessed physicians' management practices related to childhood obesity and their adherence to 1998 Pediatric Obesity Expert Committee recommendations, respectively, were contacted and requested to share the items they had used for their studies that related to physicians evaluation practices in overweight children in relation to Expert Committee recommendations (Story et al., 2002; Kolagotla \& Adams, 2004). Items under section II of the study instrument were based on 1998 Pediatric Obesity Expert Committee recommendations and the items from the surveys that were received from the two researchers mentioned above. Items used in section II of the questionnaire are discussed under instrumentation.

\section{Instrumentation}

\section{Section I}

There were three sections in the study instrument (see Appendix A). As previously described, Section I of the instrument consisted of items based on the TRA and the TPB model as applied to physician measurement of BMI in children and adolescents. The measurement and scoring of the theory constructs were conducted based on the recommendations of previous studies (Connor \& Sparks, 1995; Godin \& Kok, 1996). There were a total of 25 items in this section. Of the 25 items in this section, 24 items were related to the TRA and the TPB constructs 
and were measured on 7-point Likert scales. Studies recommend 7-point scales for items used for TPB studies (Francis et al., 2004b) instead of the typical 5-point measures. The constructs measured by these items were: a) intention, b) attitude, c) subjective norm, d) perceived behavioral control, and e) past behavior. The remaining item in this section assessed physicians past use of BMI using a staging algorithm. A description of measurement of each of these constructs follows.

\section{Intention}

An evaluation of a physician's intent relative to measuring BMI provided a measure of behavioral intention. The statement used to measure behavioral intention was: "I intend to measure the BMI of my pediatric and adolescent patients". The item was scored on a sevenpoint Likert scale with endpoints 1 (strongly disagree) and 7 (strongly agree).

\section{Attitude}

The direct measure of attitude of physicians towards BMI measurement in children and adolescents was assessed using the item: "Overall, I think that measuring the BMI of my pediatric and adolescent patients is beneficial". Ratings were made on a seven-point Likert scale having endpoints 1 (strongly disagree) and 7 (strongly agree).

The indirect measure of attitude was assessed using sum of the product of two subscales, behavioral beliefs and outcome evaluation. Results from the elicitation interviews were used to identify commonly held beliefs among physicians about the possible outcomes associated with measuring BMI in children and adolescents. Five behavioral beliefs that were common among the interviewed physicians were identified and included in the study. These beliefs were: 
measuring BMI lengthens the consultation time; BMI helps to identify underweight, overweight, or at risk of being overweight pediatric and adolescent patients; BMI leads to false labeling of muscular pediatric and adolescent patients as being overweight or at risk of being overweight; BMI provides an adequate measure of body fat in children and adolescents; and BMI can be used as an educational tool to motivate pediatric and adolescent patients to manage body weight.

Responses to behavioral belief items were measured on a seven-point scale with endpoints 1 (extremely unlikely) and 7 (extremely likely). To determine the outcome evaluation component of the indirect measure of attitude, respondents were asked how desirable or undesirable each of the five outcomes mentioned above were. Responses to outcome evaluation items ranged from 1 (extremely undesirable) to 7 (extremely desirable).

\section{Subjective Norm}

A single item was used to assess the direct measure of subjective norm. The item

"People who are important to me recommend that I should measure the BMI of my pediatric and adolescent patients", was used to measure physicians assessment of the extent to which important others supported or recommended BMI measurement in children and adolescents. A seven-point Likert scale with endpoints 1 (strongly disagree) and 7 (strongly agree) was used to measure the response.

The indirect measure of subjective norm was obtained by weighting participants' normative beliefs relative to particular referents by their motivation to comply with those referents. The specific referents identified from the elicitation interviews were: other practitioners, professional organizations (i.e., the American Academy of Pediatrics [AAP] and the American Academy of Family Physicians [AAFP]), and the Centers for Disease Control and 
Prevention (CDC). One of the normative belief item asked participants' if they think that other practitioners measure BMI of their pediatric and adolescent patients. The other two normative belief items asked participants' if specific referents (CDC, AAP/AAFP) recommend physicians to measure BMI. An additional three items assessed whether participants' consider it important to comply with other practitioners, the CDC, and the AAP/AAFP, respectively. Each normative belief and motivation to comply item was measured on a seven-point scale with endpoints 1 (strongly disagree) and 7 (strongly agree), respectively.

\section{Perceived Behavioral Control}

A direct measure of perceived behavioral control was obtained by averaging scores of three items, which measured participants' level of control, level of difficulty, and level of confidence in measuring BMI in pediatric and adolescent patients. Physicians' level of control over BMI measurement was derived using the item "Whether or not I measure the BMI of my pediatric and adolescent patients is entirely within my control." Level of difficulty was measured by the item "Measuring the BMI of my pediatric and adolescent patients is difficult for me." Physicians' confidence in their ability to measure BMI was assessed by the item "I feel confident that I can measure the BMI of my pediatric and adolescent patients if I wanted to." Each of the three items were measured on a seven-point Likert scale with endpoints ranging from 1 (strongly disagree) to 7 (strongly agree). The mean score of the three items was used to get the direct measure of perceived behavioral control. A higher score represented greater control of physicians over their ability to measure BMI.

The indirect measure of perceived behavioral control was obtained by weighing control belief strength by the power of that belief to influence the underlying behavior. Only one control 
belief was identified in the elicitation interviews. Control belief strength was measured using the item "I do not have adequate support staff (nurses, residents) to measure the height and weight of pediatric and adolescent patients". Control belief power was assessed using the item "How likely are you to measure the BMI of your pediatric and adolescent patients if you do not have adequate support staff to take height and weight measurements?" For both of these items, response ranged from 1 (extremely unlikely) to 7 (extremely likely).

\section{Past Behavior}

Past behavior was measured using a stage of change algorithm (Reed, Velicer, Prochaska, Rossi, \& Marcus, 1997). The single item consisted of five choices, with each choice representing a stage of change. The five stages were: maintenance "I have been measuring BMI in most of my patients for a long time (more than six months)," action "I have been measuring BMI in most of my patients for a while (less than six months)," preparation "I have not been measuring BMI in most of my patients, but I intend to start doing so in the near future (sometime in the next month)," contemplation "I have not been measuring BMI in most of my patients, but I intend to start doing so eventually (sometime in the next six months)," and precontemplation "I have not been measuring BMI in most of my patients and I do not intend to start any time in the foreseeable future."

Survey respondents were categorized into two groups based on their stage of change. Physicians who were in the action and maintenance stage and had been measuring BMI in most of their pediatric and adolescent patients were in group one. The second group consisted of physicians in the remaining three stages (precontemplation, contemplation, preparation) who had not being measuring BMI in their pediatric and adolescent patients. 


\section{$\underline{\text { Section II }}$}

Section II of the survey assessed physicians practice in relation to their screening and evaluation of overweight children and adolescents. There were a total of five items in this section. The first two questions were related to obesity identification. The remaining three questions evaluated physicians practice concerning evaluation of overweight children and adolescents.

\section{Obesity Identification}

The first item of section II asked participants about the tool they routinely use to identify overweight children and adolescents. There were five screening methods included in this item: clinical impression, weight-for-height percentile, weight-for-age percentile, BMI, and BMI percentile. The item also included an option of "other" for physicians who may not be using any of the five stated identification tools. Responses were coded as: never, rarely, sometimes, often, or always. The second item of this section asked participants to choose the cutoff value they use for BMI percentile, weight-for-height percentile, and weight-for-age percentile, to classify a child as overweight. For example, based on BMI-for-age classification system, children with BMI greater than the $95^{\text {th }}$ percentile are classified as overweight or obese (Himes \& Dietz, 1994; Barlow \& Dietz, 1998). To determine if participants were using the recommended BMI percentile cut-off to identify overweight children, there were four response sets included: greater than the $75^{\text {th }}$ percentile, greater than the $85^{\text {th }}$ percentile, greater than the $95^{\text {th }}$ percentile, and greater than the $99^{\text {th }}$ percentile. 


\section{Evaluation of Overweight Children and Adolescents}

Three items consisted of a list of components that related to family history, clinical evaluations, medical history and physical examination, and behavioral history assessment of overweight children and adolescents. For each evaluation component, physicians were required to choose from never, rarely, sometimes, often, or always, to determine their frequency of assessment of each component.

Physicians who responded that they always or often assessed the family history of overweight, diabetes mellitus, gallbladder disease, cardiovascular disease, hypertension, and elevated cholesterol in their overweight patients were considered adherent to 1998 Pediatric Obesity Expert Committee recommendations. Respondents who indicated that they always or often performed clinical evaluations for lipids and insulin were considered adherent to Expert Committee recommendations. Considering that hypothyroidism and hypercortisolism are rare in children (Rallison, Dobyns, Keating, Rall, \& Tyler, 1975; Magiakou, Mastorakos, Oldfield, Gomez, Doppman, Cutler, Nieman, Chrousos, 1994), physicians who responded that they never, rarely, or sometimes perform clinical evaluation for thyroid function and cortisol were considered as adherent to Expert Committee recommendations. With respect to medial history and physical examination of overweight children and adolescents, physicians who responded that they always, often, or sometimes assessed for signs and symptoms of pseudotumour cerebri and always or often assessed genetic disorders, sleep disorder, and blood pressure were considered adherent. As per behavioral history assessment, physicians who responded that they always or often assessed overweight children for diet, depression, eating disorder, tobacco use, television viewing, and exercise were considered as adherent to the Expert Committee recommendations. 


\section{$\underline{\text { Section III }}$}

\section{Demographic and Practice Information}

Five basic demographic and practice-related items were assessed in this section. These included: age, gender, number of years in practice, practice site, and the number of pediatric and adolescent patients seen per week. Age, gender, and practice site were measured on a categorical scale. Years in practice and the number of pediatric and adolescent patients seen per week were measured on a continuous scale.

\section{Instrument Validation}

Once the instrument was developed, faculty members from the West Virginia University School of Pharmacy and School of Medicine were approached to enhance the content and face validity of the instrument. Family physicians and pediatricians who had participated in the elicitation interviews were also approached to assess the relevance of the questions, instruction and question clarity, and readability levels. Some minor revisions were made to the questionnaire based on feedback from these physicians and faculty members.

\section{Phase II: Instrument Administration}

\section{Study Sample and Sample Size Determination}

The study used a cross-sectional survey design. The population of interest included family physicians and pediatricians. These two physician specialties were included because they are more likely to deal with the issue of childhood obesity in their day-to-day practice. Physicians practicing in four states, Alabama, Colorado, Massachusetts, and West Virginia were 
surveyed. The four states were chosen to get a fair representation of population dispersion and childhood obesity prevalence rates.

A list of family physicians and pediatricians practicing in the four states was obtained from SK\&A Information Services Inc., a private physician mailing list firm. SK\&A Information Services Inc. compiles the list of practicing physicians based on information acquired from state licensing boards, professional associations, government agencies, yellow page directories, and the internet. This list served as the sampling frame for the study. A total of 6,467 physicians (3,938 family physicians and 2,529 pediatricians) were available in the sampling frame for the four included states. The following formula was used to calculate the sample size required for this study (Kalton, 1987):

$$
\mathrm{n}=\frac{\mathrm{z}^{2} \times \mathrm{p} \times(1-\mathrm{p})}{\mathrm{c}^{2}}
$$

Where,

$\mathrm{n}=$ sample size

$\mathrm{z}=$ the number of standard errors away from the mean (1.96)

$\mathrm{p}=$ estimated proportion of physicians using BMI

$\mathrm{c}=$ confidence interval $(5 \%)$

The sample size for the study was determined with a $95 \%$ confidence level that the true proportion of the variable of interest in the population is within $\pm 5 \%$ of the population percentage (Kalton, 1987). The variable of interest for this study was the percentage of physicians using BMI for identification of overweight children. Over the past few years, different studies have reported different frequencies of BMI use by physicians (Barlow et al., 2002; Kolagotla \& Adams, 2004; Perrin et al., 2004; Dorsey et al., 2005; Louthan et al., 2005; 
Gilbert \& Fleming, 2006). However, for the current study, a true population proportion of 50\% was considered to have a higher sample size. A sample size of 340 physicians was determined by substituting the values in the above equation.

For the purpose of this study, a conservative physician response rate of $15 \%$ was estimated. Therefore,

$$
\text { Sample Size }=340 / 0.15=2,266
$$

Based on sampling analysis, a final sample of 2,590 physicians (1,427 family physicians and 1,163 pediatricians) was selected randomly from the sampling frame. The proportion of family physicians and pediatricians selected from each of the four states in the final sample, respectively, was relatively similar to their proportion in the sampling frame.

\section{Data Collection}

Prior to the study, the survey questionnaire and cover letter were approved by the West Virginia University Institutional Review Board (WVU-IRB). Data were collected over a period of two months from August to September 2006.

Physicians in the study sample were mailed a questionnaire (see Appendix A), cover letter (see Appendix B \& C), and a business reply envelope. The cover letter explained the purpose of the study and emphasized voluntary participation and confidentiality of responses. A self-addressed business reply envelope was provided for respondents to return the completed questionnaire. Surveys were coded, only for the purpose of tracking responses. A second mailing followed three weeks after the first mailing and was sent to only those physicians who failed to respond to the first mailing. Similar to the first mailing, the second mailing consisted of a cover letter, questionnaire, and a self-addressed business-reply envelope. 


\section{Data Analysis}

The Statistical Package for Social Sciences ${ }^{\circledR}$ (SPSS) for Windows, version 14.0 was used for analyzing the survey data. There was some missing information in the responses received. Surveys with greater than $15 \%$ of the total number of items missing were excluded from the analysis. General descriptive analysis of demographic and practice-related variables was performed. Means and standard deviations (SD) of theory-related variables (direct measure of attitude, direct measure of subjective norm, direct measure of perceived behavioral control, behavioral beliefs, normative beliefs, control beliefs, and intention) were examined. Psychometric evaluation of items related to the theoretical constructs was performed using Cronbach's coefficient alpha statistic.

Bivariate correlational analyses were conducted using Pearson product moment coefficients to examine if significant relationship existed between the dependent variable (intention) and independent variables (direct measure of attitude, indirect measure of attitude, direct measure of subjective norm, indirect measure of subjective norm, direct measure of perceived behavioral control, indirect measure of perceived behavioral control).

\section{Objective I}

Hypothesis 1.1a: Physician attitude towards measuring BMI in children and adolescents is not significantly correlated with the summated product of behavioral belief and evaluation of the outcomes.

This hypothesis was tested by examining the zero-order correlation between the direct and indirect measure (summated product of behavioral belief and evaluation of outcomes) of attitude. 
Hypothesis 1.1b: Physician subjective norm about measuring BMI in children and adolescents is not significantly correlated with the summated product of normative belief and motivation to comply with a referent.

Zero-order correlation between the direct and indirect measure (summated product of normative belief and motivation to comply) of subjective norm was examined to test this hypothesis.

Hypothesis 1.1c: Physician's perceived behavioral control towards measuring BMI in children and adolescents is not significantly correlated with the summated product of control belief and influence of the specific control factor.

Hypothesis testing was done by examining the zero-order correlation between the direct and indirect measure (summated product of control belief and influence of the specific control factor) of perceived behavioral control.

Hypothesis 1.2: Attitude and subjective norm do not significantly predict physicians' intention to measure BMI in children and adolescents.

To determine ability of the TRA model constructs, that is, attitude and subjective norm, in predicting physicians' intention to measure BMI, linear regression analysis was used. Two linear regression models were tested. In model one, the direct measures of attitude and subjective norm served as the independent variable with intention as the dependent variable. In model two, the indirect measures of attitude and subjective norm were used as independent variables. The regression equation tested for both models was:

$$
\text { Intention }=\alpha+b_{1}{ }^{*} \text { Attitude }+b_{2}{ }^{*} \text { Subjective norm }
$$


Where, $\alpha$ is a constant, $b_{1}$ is the coefficient of attitude and $b_{2}$ is the coefficient of subjective norm.

Hypothesis 1.3: Addition of perceived behavioral control over and above attitude and subjective norms will not add significantly to the prediction of physicians' intention to measure BMI.

To determine if the TPB model is better than the TRA model in explaining physicians intention to measure BMI, perceived behavioral control was added as a third predictor along with attitude and subjective norm in the regression equation. Hierarchical regression (also called sequential regression) models were built in order to determine the change in intention variance after addition of perceived behavioral control. The regression equation tested in this hypothesis was:

$$
\text { Intention }=\alpha+b_{1}{ }^{*} \text { Attitude }+b_{2}{ }^{*} \text { Subjective norm }+b_{3}{ }^{*} \text { Perceived behavioral control }
$$

Where, $\alpha$ is the constant, $b_{1}, b_{2}$, and $b_{3}$ are the regression coefficients for attitude, subjective norm, and perceived behavioral control, respectively.

There were two hierarchical models built to determine whether addition of perceived behavioral control to the TRA model significantly increases the intention variance explained. In model one, the direct measures of perceived behavioral control, attitude, and subjective norm served as the independent variable with intention as the dependent variable. The direct measure of perceived behavioral control was added as a third predictor in this regression model in the presence of direct measures of attitude and subjective norm.

In model two, the indirect measures of attitude, subjective norm, and perceived behavioral control were used as predictors. Behavioral intention was the dependent variable. The indirect measure of perceived behavioral control was added to the regression model to 
determine the increase in intention variance explained after accounting for indirect measures of attitude and subjective norm.

Hypothesis 1.4: Addition of physician's past BMI measurement behavior to attitude, subjective norm, and perceived behavioral control does not significantly add to the prediction of his/her intention to measure BMI.

To test Hypothesis 1.4, the variable past behavior was added in the presence of attitude, subjective norm, and perceived behavioral control to determine the increase in intention variance. Two hierarchical regression models were used to determine the contribution made by past behavior in increasing the intention variance explained after accounting for the variance explained by the TPB model. In model one the direct measures of attitude, subjective norm, and perceived behavioral control served as predictors in addition to past behavior. And in model two, past behavior was added as a predictor in the presence of the indirect measures of attitude, subjective norm, and perceived behavioral control. The regression equation looked like following:

$$
\text { Intention }=\alpha+b_{1}{ }^{*} \text { Attitude }+b_{2}{ }^{*} \text { Subjective norm }+b_{3} \text { Perceived behavioral control }+
$$

$\mathrm{b}_{4}{ }^{*}$ Past behavior

Where, $\alpha$ is the constant, $b_{1}, b_{2}, b_{3}$, and $b_{4}$ are the regression coefficients for attitude, subjective norm, perceived behavioral control, and past behavior, respectively.

\section{Objective II}

Hypothesis 2.1: There are no significant behavioral and normative belief differences between physicians who intend to measure BMI and those who do not intend to measure BMI. 
Physicians were classified into three groups: those who intend to measure BMI, those who are neutral, and those who do not intend to measure the BMI of their pediatric and adolescent patients. The three categories were formed based on physicians' response to the intention item. The three physician groups were compared based on their scores on each of the five behavioral beliefs using ANOVA. Similarly, the scores of the three groups of physicians were compared for each normative belief item using ANOVA. Because of unequal sample sizes of the three groups, post-hoc analyses were conducted using Hochberg's GT2 (Toothaker, 1993).

\section{Objective III}

Descriptive analyses were performed to determine the frequency of use of different weight classification methods and evaluation practices of surveyed physicians. The number of physicians frequently using BMI percentile and other weight classification methods was reported. In addition, the number of physicians who adhered to the 1998 Pediatric Obesity Expert Committee recommendations concerning evaluation of overweight children and adolescents were reported. Frequency of use of BMI percentile and evaluation practices of family physicians were compared to that of pediatricians using chi-square analysis. Physicians' identification and evaluation practices were also reported based on their state childhood obesity prevalence rates. Physicians practicing in four states were categorized into two groups based on whether childhood obesity prevalence rates in their state were above or below the national average. Chi-square analysis was used to compare family physicians and pediatricians in the two groups, respectively. 


\section{Power Analysis}

A priori power analyses was conducted to determine the minimum sample size required for regression analyses conducted under objective one of the study. When performing statistical power analyses, it is required to decide upon the probability of making a type I error (or alpha level), power to detect an effect, and effect size. Type I error or alpha level $(\alpha)$ is the probability of rejecting the null hypothesis, given the null hypothesis is true. Effect size measures the magnitude of treatment effect. Power analyses were performed using a program called G-Power (Erdfelder, Faul, \& Buchner, 1996).

Previous meta-analysis of studies utilizing the TPB have reported the average multiple correlation (R) of attitude, subjective norm, and perceived behavioral control with behavioral intention to be between 0.63 and 0.71 (Ajzen, 1991; Armitage \& Connor, 2001). To conduct power analysis for regression, an effect size index $\left(\mathrm{f}^{2}\right)$ is required (Cohen, 1977). In multiple regression $\mathrm{f}^{2}$ is equal to $\mathrm{R}^{2} / 1-\mathrm{R}^{2}$, where $\mathrm{R}^{2}$ is the coefficient of determination or the percentage of variance of the dependent variable explained by the model. At $R=0.63$, the variance $\left(R^{2}\right)$ explained by the model equals 0.39 and $\mathrm{f}^{2}$ equals $0.66(0.39 / 1-0.39)$. With a maximum of four predictors and an alpha level of 0.05 , a minimum sample size of 34 was needed to achieve a power of 0.95 to detect $\mathrm{R}=0.63$. 


\section{CHAPTER FOUR}

\section{RESULTS}

The purpose of this chapter is to provide an overview of the study results. Study response rate, non-response analysis, and general descriptive characteristics of the study sample are provided. Thereafter, the results for objective I, II, and III, respectively, are presented.

\section{Descriptive Statistics}

Response Rate

Of the 2,590 surveys mailed in the original sample, 44 had incorrect addresses. Therefore, 2,546 physicians were presumably reached by the mailings. A total of 622 responses were received after two mailings, giving a response rate of $24.4 \%$. Of the 622 responses, 39 surveys were not usable due to a large (more than 15\%) number of missing items and were excluded from the analysis. Thus, the usable responses rate was reduced to $22.8 \%$ (see Table 1). 
Table 1. Response Rate

\begin{tabular}{lc}
\hline & $\mathbf{N}(\mathbf{\%})$ \\
\hline Initial sample & 2,590 \\
Incorrect addresses & 44 \\
Final sample & $2,546(100.0)$ \\
Total surveys returned & $622(24.4)$ \\
Incomplete surveys (greater than $15 \%$ missing items) & 39 \\
Usable responses & $583(22.8)$ \\
\hline$\%=$ percentage &
\end{tabular}

$\%=$ percentage 


\section{Non-response Analysis}

To assess the potential for non-response bias, differences between physicians who responded to the first and second mailings were examined. Physicians who responded to the first mailing were considered as early responders and those who responded to the second mailing were considered as late responders. Studies have reported that participants who respond to second mailings of the survey could be considered similar to non-respondents (Pace, 1939), because in the absence of follow-up mailings the late responders would have been nonresponders. Therefore, early and late responders were compared using age, gender, number of years in practice, primary practice site, and number of pediatric and adolescent patients seen per week.

Of the total respondents, $69.5 \%$ responded to the first mailing. There were no significant differences between early and late responders with respect to age, gender, primary practice site, and number of years in practice. However, early responders were seeing significantly more pediatric and adolescent patients per week as compared to late responders (66 versus 53, $p<$ 0.05). Table 2 presents the characteristics of early and late responders. 
Table 2. Characteristics of Early and Late Responders

\section{Characteristic Early Responders Late Responders}

\begin{tabular}{ccc}
\hline Age group & & \\
$\leq 30$ years & $8(2.0 \%)$ & $5(2.8 \%)$ \\
$31-40$ years & $111(27.4 \%)$ & $60(33.7 \%)$ \\
$41-50$ years & $123(30.4 \%)$ & $55(30.9 \%)$ \\
$51-60$ years & $122(30.1 \%)$ & $41(23.0 \%)$ \\
$\geq 61$ years & $39(9.6 \%)$ & $16(9.0 \%)$
\end{tabular}

Gender

Male

Female

$$
209(51.6 \%)
$$$$
195(48.1 \%)
$$

14.7

$\pm 10.4$

ber of years in practice
SD

Mean

rimary practice site

Hospital based

Solo practice

Group practice

Other

$25(6.2 \%)$
$61(15.1 \%)$
$284(70.1 \%)$
$33(8.1 \%)$

$25(6.2 \%)$

$284(70.1 \%)$

$33(8.1 \%)$
$85(47.8 \%)$

$93(52.2 \%)$

12.9

$\pm 9.3$

$12(6.7 \%)$

$35(19.7 \%)$

$111(62.4 \%)$

$20(11.2 \%)$

Number of children and

adolescent patients/week

$\begin{array}{lrr}\text { Mean } & \\ \text { SD } & 66 & 53 \\ & \pm 47 & \pm 43\end{array}$

"Significant at $p<0.05 . \mathrm{SD}=$ Standard Deviation; $\leq=$ less than or equal to; $\geq=$ greater than or equal to; $\%=$ percentage 


\section{$\underline{\text { Sample Characteristics }}$}

Among the 583 respondents, $29.3 \%$ were 31 to 40 years old, $30.5 \%$ were 41 to 50 years old, and $28.0 \%$ were 51 to 60 years old. There was a fairly even distribution of gender, with a similar proportion of males $(50.4 \%)$ and females $(49.4 \%)$. The mean number of years in practice of physicians was 14.2 years ( $\mathrm{SD}= \pm 10.1$ years). Most $(67.8 \%)$ of the physicians in the sample were in group practice. The average number of pediatric and adolescent patients seen per week by the physicians was $61(\mathrm{SD}= \pm 46)$. Roughly $40 \%$ of the surveyed physicians were practicing in Massachusetts, with another 28\% in Colorado.

The demographic and practice-related distribution of the sample based on medical specialty revealed certain statistical differences between the two groups, that is, pediatricians and family physicians. Pediatricians were more likely to be in group practice $(74.0 \%$ versus $59.4 \%$, $p<0.01$ ), in practice for more number of years (15.4 years versus 12.3 years, $p<0.001$ ), and were seeing a greater number of pediatric and adolescent patients per week ( 88 versus $24, p<$ 0.001) than family physicians. The two specialty groups were similar with respect to age and gender.

Characteristics of the sample are also compared based on childhood obesity prevalence rates in physicians' state of practice. Based on 2005 Youth Risk Behavior Surveillance (YRBS) data (Eaton et al., 2006), physicians state of practice was categorized into two groups. One group consisted of those physicians who were practicing in states where childhood obesity prevalence rates, as reported in YRBS data, were above the national average (Alabama and West Virginia). The other group consisted of those physicians who were practicing in states where childhood obesity prevalence rates were below the national average (Colorado and Massachusetts). Family physicians practicing in states where childhood obesity prevalence rates 
were above national average were seeing significantly $(p<0.05)$ more number $(28$ versus 22$)$ of patients and were more likely to be in solo practice $(32.3 \%$ versus $14.5 \%, p<0.05)$ as compared to family physicians practicing in states with childhood obesity prevalence rates below the national average. Similarly, pediatricians were seeing significantly $(\mathrm{p}<0.05)$ a larger number of patients (101 versus 83$)$ and were more likely to be in solo practice $(23.2 \%$ versus $8.9 \%, p<$ 0.05) in states where childhood obesity prevalence was above national average as compared to those pediatricians who were practicing in states where obesity prevalence rates were below national average. Tables 3 and 4 presents the demographic and practice characteristics of physicians for all states combined and based on obesity prevalence rates in their state of practice, respectively. 
Table 3. Demographic and Practice Characteristics of the Sample

\begin{tabular}{|c|c|c|c|}
\hline Characteristic & $\begin{array}{c}\text { All Physicians } \\
\mathbf{N}=\mathbf{5 8 3}\end{array}$ & $\begin{array}{c}\text { Family Physicians } \\
n=241\end{array}$ & $\begin{array}{c}\text { Pediatricians } \\
n=342 \\
\end{array}$ \\
\hline \multicolumn{4}{|l|}{ Age group } \\
\hline$\leq 30$ years & $13(2.2 \%)$ & $6(2.5 \%)$ & $7(2.0 \%)$ \\
\hline $31-40$ years & $171(29.3 \%)$ & $73(30.3 \%)$ & $98(28.7 \%)$ \\
\hline $41-50$ years & $178(30.5 \%)$ & $81(33.6 \%)$ & $97(28.4 \%)$ \\
\hline $51-60$ years & $163(28.0 \%)$ & $66(27.4 \%)$ & $97(28.4 \%)$ \\
\hline$\geq 61$ years & $55(9.4 \%)$ & $13(5.4 \%)$ & $42(12.3 \%)$ \\
\hline Missing & $3(0.5 \%)$ & $2(0.8 \%)$ & $1(0.3 \%)$ \\
\hline \multicolumn{4}{|l|}{ Gender } \\
\hline Male & $294(50.4 \%)$ & $128(53.1 \%)$ & $166(48.5 \%)$ \\
\hline Female & $288(49.4 \%)$ & $112(46.5 \%)$ & $176(51.5 \%)$ \\
\hline Missing & $1(0.2 \%)$ & $1(0.4 \%)$ & $0(0.0 \%)$ \\
\hline \multicolumn{4}{|c|}{ Number of years in practice } \\
\hline Mean $^{* * *}$ & 14.2 & 12.3 & 15.4 \\
\hline $\mathrm{SD}$ & \pm 10.1 & \pm 9.4 & \pm 10.4 \\
\hline \multicolumn{4}{|c|}{ Primary practice site ${ }^{* *}$} \\
\hline Hospital based & $37(6.3 \%)$ & $16(6.6 \%)$ & $21(6.1 \%)$ \\
\hline Solo practice & $96(16.5 \%)$ & $52(21.6 \%)$ & $44(12.9 \%)$ \\
\hline Group practice & $395(67.8 \%)$ & $142(58.9 \%)$ & $253(74.0 \%)$ \\
\hline Other & $53(9.1 \%)$ & $29(12.0 \%)$ & $24(7.0 \%)$ \\
\hline Missing & $2(0.3 \%)$ & $2(0.8 \%)$ & $0(0.0 \%)$ \\
\hline \multicolumn{4}{|c|}{$\begin{array}{l}\text { Number of pediatric and } \\
\text { adolescent patients/week }\end{array}$} \\
\hline Mean $^{* * * *}$ & 61 & 24 & 88 \\
\hline SD & \pm 46 & \pm 22 & \pm 40 \\
\hline \multicolumn{4}{|l|}{ State of practice } \\
\hline Alabama & $85(14.6 \%)$ & $37(15.4 \%)$ & $48(14.0 \%)$ \\
\hline Colorado & $163(28.0 \%)$ & $90(37.3 \%)$ & $73(21.3 \%)$ \\
\hline Massachusetts & $229(39.3 \%)$ & $55(22.8 \%)$ & $174(50.9 \%)$ \\
\hline West Virginia & $106(18.2 \%)$ & $59(24.5 \%)$ & $47(13.7 \%)$ \\
\hline
\end{tabular}

${ }^{* * * *}$ Significant at $p<0.001$. ${ }^{* *}$ Significant at $p<0.01$. SD $=$ Standard Deviation; $\leq=$ less than or equal to; $\geq=$ greater than or equal to; $\%=$ percentage 
Table 4. Demographic and Practice Characteristics of Physicians by State Obesity Prevalence Rates

\begin{tabular}{|c|c|c|c|c|c|c|}
\hline \multirow[b]{2}{*}{ Characteristics } & \multicolumn{3}{|c|}{$\begin{array}{l}\text { States with Below National Average Childhood } \\
\text { Obesity Prevalence } \\
\text { (CO and MA) }\end{array}$} & \multicolumn{3}{|c|}{$\begin{array}{c}\text { States with Above National Average Childhood } \\
\text { Obesity Prevalence } \\
\text { (AL and WV) }\end{array}$} \\
\hline & $\begin{array}{l}\text { All Physicians } \\
\qquad(\mathrm{n}=\mathbf{3 9 2})\end{array}$ & $\begin{array}{l}\text { Family } \\
\text { Physicians } \\
(n=145)\end{array}$ & $\begin{array}{l}\text { Pediatricians } \\
\quad(n=247)\end{array}$ & $\begin{array}{l}\text { All Physicians } \\
\quad(\mathrm{n}=191)\end{array}$ & $\begin{array}{l}\text { Family } \\
\text { Physicians } \\
(\mathbf{n}=96)\end{array}$ & $\begin{array}{l}\text { Pediatricians } \\
\quad(\mathbf{n}=95)\end{array}$ \\
\hline \multicolumn{7}{|l|}{ Age group } \\
\hline$\leq 30$ years & $10(2.6 \%)$ & $6(4.1 \%)$ & $4(1.6 \%)$ & $3(1.6 \%)$ & $0(0.0 \%)$ & $3(3.2 \%)$ \\
\hline $31-40$ years & $116(29.6 \%)$ & $48(33.1 \%)$ & $68(27.5 \%)$ & $55(28.8 \%)$ & $25(26.0 \%)$ & $30(31.6 \%)$ \\
\hline $41-50$ years & $121(30.9 \%)$ & $51(35.2 \%)$ & $70(28.3 \%)$ & $57(29.8 \%)$ & $30(31.3 \%)$ & $27(28.4 \%)$ \\
\hline $51-60$ years & $111(28.3 \%)$ & $34(23.4 \%)$ & $77(31.2 \%)$ & $52(27.2 \%)$ & $32(33.3 \%)$ & $20(21.1 \%)$ \\
\hline$\geq 61$ years & $31(7.9 \%)$ & $4(22.8 \%)$ & $27(10.9 \%)$ & $24(12.6 \%)$ & $9(9.4 \%)$ & $15(15.8 \%)$ \\
\hline Missing & $3(0.8 \%)$ & $2(1.4 \%)$ & $1(0.4 \%)$ & $0(0.0 \%)$ & $0(0.0 \%)$ & $0(0.0 \%)$ \\
\hline \multicolumn{7}{|l|}{ Gender } \\
\hline Male & $192(49.0 \%)$ & $75(51.7 \%)$ & $117(47.4 \%)$ & $102(53.4 \%)$ & $53(55.2 \%)$ & $49(51.6 \%)$ \\
\hline Female & $199(50.8 \%)$ & $69(47.6 \%)$ & $130(52.6 \%)$ & $89(46.6 \%)$ & $43(44.8 \%)$ & $46(48.4 \%)$ \\
\hline Missing & $1(0.3 \%)$ & $1(0.7 \%)$ & $0(0.0 \%)$ & $0(0.0 \%)$ & $0(0.0 \%)$ & $0(0.0 \%)$ \\
\hline \multicolumn{7}{|c|}{ Number of years in practice } \\
\hline Mean & 14.2 & 11.6 & 15.7 & 14.1 & 13.4 & 14.8 \\
\hline $\mathrm{SD}$ & \pm 10.0 & \pm 8.8 & \pm 10.3 & \pm 10.4 & \pm 10.0 & \pm 10.8 \\
\hline \multicolumn{7}{|l|}{ Primary practice site } \\
\hline Hospital based & $30(7.7 \%)$ & $12(8.3 \%)$ & $18(7.3 \%)$ & $7(3.7 \%)$ & $4(4.2 \%)$ & $3(3.2 \%)$ \\
\hline Solo practice Group & $43(11.0 \%)$ & $21(14.5 \%)$ & $22(8.9 \%)$ & $53(27.7 \%)$ & $31(32.3 \%)^{\S}$ & $22(23.2 \%)^{*}$ \\
\hline practice & $281(71.7 \%)$ & $91(62.8 \%)$ & $190(76.9 \%)$ & $114(59.7 \%)$ & $51(53.1 \%)$ & $63(66.3 \%)$ \\
\hline Other & $36(9.2 \%)$ & $19(13.1 \%)$ & $17(6.9 \%)$ & $17(8.9 \%)$ & $10(10.4 \%)$ & $7(7.4 \%)$ \\
\hline Missing & $2(0.5 \%)$ & $2(1.4 \%)$ & $0(0.0 \%)$ & $0(0.0 \%)$ & $0(0.0 \%)$ & $0(0.0 \%)$ \\
\hline \multicolumn{7}{|l|}{$\begin{array}{l}\text { Number of pediatric and } \\
\text { adolescent patients/week }\end{array}$} \\
\hline Mean & 61 & 22 & 83 & 64 & $28^{\S}$ & $101^{*}$ \\
\hline $\mathrm{SD}$ & \pm 44 & \pm 19 & \pm 38 & \pm 522 & \pm 26 & \pm 44 \\
\hline
\end{tabular}

${ }^{\S}$ Significant at $p<0.05$ between family physicians in the two groups. "Significant at $p<0.05$ between pediatricians in the two groups.

${ }^{a}$ Prevalence based on Youth Risk Behavior Surveillance (Eaton et al., 2006). SD = Standard Deviation; $\leq=$ less than or equal to; $\geq=$ greater than or equal to; $\%=$ percentage; $\mathrm{AL}=$ Alabama; $\mathrm{CO}=$ Colorado; $\mathrm{MA}=$ Massachusetts; $\mathrm{WV}=\mathrm{West}$ Virginia 


\section{Objective I}

Means and Standard Deviation (SD) of the Theoretical Variables

The means and standard deviations of the theoretical variables were calculated. They were: intention, direct attitude, direct subjective norm, direct perceived behavioral control, indirect attitude, indirect subjective norm, indirect perceived behavioral control, behavioral beliefs, outcome evaluations, normative beliefs, motivation to comply, control beliefs, and power of control beliefs.

The behavioral intention measure used in the study was a direct measure of physician's intention to measure BMI in pediatric and adolescent patients. The mean behavioral intention score was $5.84(\mathrm{SD}= \pm 1.45)$. Roughly $44 \%$ of the physicians reported that they strongly intend to measure BMI in pediatric and adolescent patients (score of 7 on a scale of 1 [strongly disagree] to 7 [strongly agree]).

The mean score for the direct measure of attitude was $5.73(\mathrm{SD}= \pm 1.29)$. As discussed in an earlier section, to calculate the indirect measure of attitude, the behavioral belief and the corresponding outcomes evaluation items were multiplied and summed. Of the five behavioral belief items, two were negatively worded and were reversed so that higher scores represent more favorable and lower scores represent less favorable behavioral beliefs. The two items that were reverse scored were: "Measuring BMI lengthens the consultation time" and "Using BMI for weight classification can lead to false labeling of muscular pediatric and adolescent patients as being overweight or at risk of being overweight." After reverse scoring, the mean response for the two items was $4.73(\mathrm{SD}= \pm 1.91)$ and $4.03(\mathrm{SD}= \pm 1.59)$, respectively, reflecting that physicians were neutral with regards to the two beliefs. 
The mean response to the item "BMI measurement will provide an adequate measure of body fat in pediatric and adolescent patients" was $4.52(\mathrm{SD}= \pm 1.39)$, which indicated a neutral opinion of physicians. For the remaining two behavioral beliefs, "BMI will help me identify those pediatric and adolescent patients who are underweight, overweight, or at risk of being overweight" and "BMI can be used as an educational tool to motivate pediatric and adolescent patients to manage body weight," mean responses were $5.78(\mathrm{SD}= \pm 1.36)$ and $5.42(\mathrm{SD}=$ \pm 1.32 ), respectively, indicating that physicians believed these consequences of measuring BMI as "somewhat-very likely".

In terms of outcome evaluations, physicians' responses indicated that "Lengthening consultation time with pediatric and adolescent patient" is considered "somewhat undesirable" $(3.15[\mathrm{SD}= \pm 1.43])$. The mean responses to the items "Identifying pediatric and adolescent patients who are underweight, overweight, or at risk of being overweight" and "Having pediatric and adolescent patients who are motivated to manage their body weight" were $6.28(\mathrm{SD}= \pm 0.81)$ and $6.54(\mathrm{SD}= \pm 0.67)$, respectively, indicating that physicians considered these outcomes "veryextremely desirable." The item "Falsely classifying muscular pediatric and adolescent patients as overweight or at risk of being overweight" was reverse scored during data analysis so that a higher score represents a more favorable outcome belief. After reverse scoring, the mean response for the item was $5.29(\mathrm{SD}= \pm 1.29)$, which showed that physicians do not consider false labeling of muscular children as a desirable outcome. Physicians considered "Having an adequate measure of body fat in pediatric and adolescent patients," mean response $5.70(\mathrm{SD}=$ $\pm 0.99)$, as a "somewhat-very desirable" outcome of BMI measurement in pediatric and adolescent patients. 
Each behavioral belief score was multiplied with the corresponding outcome evaluation score and the scores were summed. Based on the five behavioral beliefs and corresponding outcome evaluation items, the indirect measure of attitude could have a minimum score of 5 and maximum score of 245. A higher score represented more favorable attitude towards BMI measurement. For example, if a physician scored 1 on all five behavioral belief items (from 1 [extremely unlikely] to 7 [extremely likely]) and corresponding outcome evaluation items (from 1 [extremely undesirable] to 7 [extremely desirable]), then the physician would have a score of 5 for the indirect measure of attitude. Overall, the mean indirect measure of attitude was 134.69 $(\mathrm{SD}= \pm 30.51)$

The mean response to the direct measure of subjective norm item was $4.76(\mathrm{SD}= \pm 1.78)$, indicating that physicians "slightly agreed" to the statement that important others recommend physicians to measure BMI. Scores from the normative belief items were multiplied with the corresponding motivation to comply statements and summed to get the indirect measure of subjective norm. Therefore, the indirect measure of attitude could have a minimum score of 3 and a maximum score of 147 .

The overall mean response for the indirect measure of subjective norm was 89.68 ( $\mathrm{SD}=$ $\pm 26.63)$. The mean response to the items "The American Academy of Pediatrics and/or the American Academy of Family Physicians recommend that I should measure the BMI of my pediatric and adolescent patients" and "The Centers for Disease Control and Prevention (CDC) recommends that I should measure the BMI of my pediatric and adolescent patients" were 6.05 $(\mathrm{SD}= \pm 1.08)$ and $5.79(\mathrm{SD}= \pm 1.18)$, respectively, indicating that physicians "somewhat agreed" that these referents recommend BMI measurement. However, physicians' responses were 
neutral, on average, for the item "Other practitioners measure the BMI of their pediatric and adolescent patients" $(4.32[\mathrm{SD}= \pm 1.37])$.

The mean response to the motivation to comply items indicated that physicians "somewhat agreed" to comply with what the American Academy of Pediatrics (AAP) and/or the American Academy of Family Physicians (AAFP) (5.89 [SD = $=1.09])$ and the Centers for Disease Control and Prevention (CDC) (5.78 [SD = \pm 1.16$])$ recommends. In contrast, physicians' response was "neutral" for the item "Doing what other practitioners do is important to me" $(4.41[\mathrm{SD}= \pm 1.50])$.

As mentioned under instrumentation, the mean of three items assessing physicians' level of control, difficulty, and confidence, respectively, was used to assess the direct measure of perceived behavioral control. Score for the item assessing physicians' level of control over their BMI measurement behavior was reversed so that a higher overall mean score of the three perceived behavioral control items together represents a greater control over BMI measurement and a lower score represents a lesser control. The direct measure of perceived behavioral control could have a minimum response of 1 and a maximum response of 7 .

The mean response to the direct measure of perceived behavioral control was $6.02(\mathrm{SD}=$ $\pm 1.00)$. The response indicated that physicians consider having control over BMI measurement. The indirect measure of perceived behavioral control was measured by multiplying the control belief item with the power of control belief item. Thus, the indirect measure of perceived behavioral control could have a minimum of 1 and a maximum of 49 . The results showed that the mean score for the indirect measure of perceived behavioral control was $6.58(\mathrm{SD}= \pm 5.96)$. The low score indicated the strong influence of the control factor. The control belief item used in the study, "I do not have adequate support staff (nurses, residents) to measure the height and 
weight of pediatric and adolescent patients" had a mean score of $1.85(\mathrm{SD}= \pm 1.43)$ reflecting that physicians do not believe that they have an inadequate support staff. The mean score for the power of control belief item, "How likely are you to measure the BMI of your pediatric and adolescent patients if you do not have adequate support staff to take height and weight measurements?" was 3.79 ( $\mathrm{SD}= \pm 2.02$ ), indicating that physicians were "somewhat unlikely" to measure BMI in the absence of adequate support staff. Table 5 summarizes the means and standard deviations of the theoretical variables. 
Table 5. Descriptive Statistics for Theoretical Variables $(\mathrm{N}=\mathbf{5 8 3})$

\begin{tabular}{|c|c|c|}
\hline & Mean & SD \\
\hline Intention & 5.84 & 1.45 \\
\hline Attitude & 5.73 & 1.29 \\
\hline Indirect attitude $^{\mathrm{a}}$ & 134.69 & 30.51 \\
\hline \multicolumn{3}{|l|}{ Behavioral beliefs } \\
\hline - Lengthens consultation time ${ }^{*}$ & 4.73 & 1.91 \\
\hline $\begin{array}{l}\text { Identifies overweight, underweight, } \\
\text { or at risk of being overweight patients }\end{array}$ & 5.78 & 1.36 \\
\hline - Leads to false labeling ${ }^{*}$ & 4.03 & 1.59 \\
\hline - Provides adequate measure of body fat & 4.52 & 1.39 \\
\hline$\square$ Motivates patients & 5.42 & 1.32 \\
\hline \multicolumn{3}{|l|}{ Outcome evaluations } \\
\hline$\square$ Consultation time & 3.15 & 1.43 \\
\hline $\begin{array}{l}\text { Identifying overweight, underweight, } \\
\text { or at risk of being overweight patients }\end{array}$ & 6.28 & 0.81 \\
\hline - False labeling* ${ }^{*}$ & 5.29 & 1.29 \\
\hline - Having adequate measure of body fat & 5.70 & 0.99 \\
\hline - Motivated patients & 6.54 & 0.67 \\
\hline Subjective norm & 4.76 & 1.78 \\
\hline Indirect subjective norm ${ }^{\mathrm{b}}$ & 89.68 & 26.63 \\
\hline \multicolumn{3}{|l|}{ Normative beliefs } \\
\hline - Other practitioners & 4.32 & 1.37 \\
\hline - AAP/AAFP & 6.05 & 1.08 \\
\hline$\square \mathrm{CDC}$ & 5.79 & 1.18 \\
\hline \multicolumn{3}{|l|}{ Motivation to comply } \\
\hline$\square \quad$ Other practitioners & 4.41 & 1.50 \\
\hline - AAP/AAFP & 5.89 & 1.09 \\
\hline$\therefore \mathrm{CDC}$ & 5.78 & 1.16 \\
\hline Perceived behavioral control & 6.02 & 1.00 \\
\hline$\square$ Confidence & 6.42 & 0.95 \\
\hline - Control & 5.75 & 1.59 \\
\hline 口 Difficult ${ }^{*}$ & 5.88 & 1.47 \\
\hline Indirect perceived behavioral control $^{\mathrm{c}}$ & 6.58 & 5.96 \\
\hline \multicolumn{3}{|l|}{ Control beliefs } \\
\hline - Not adequate support staff & 1.85 & 1.43 \\
\hline \multicolumn{3}{|l|}{ Power of control beliefs } \\
\hline - Effect of support staff & 3.79 & 2.02 \\
\hline
\end{tabular}

"Scores reversed; ${ }^{\mathrm{a} O n}$ a scale 5 (low)-245 (high); ${ }^{\mathrm{b}}$ On a scale 3 (low)-147 (high); ${ }^{\mathrm{c}}$ On a scale 1 (low)-49 (high); All other scores on a scale of 1-7. AAP = American Academy of Pediatrics; AAFP $=$ American Academy of Family Physicians; $\mathrm{CDC}=$ Centers for Disease Control and Prevention 


\section{Psychometric Evaluation of Section I of the Instrument}

Cronbach's alpha $(\alpha)$ coefficient was used to establish the internal reliability of the theoretical items (indirect attitude, indirect subjective norm, and direct perceived behavioral control). The direct attitude, direct subjective norm, indirect perceived behavioral control, and intention were assessed using a single item, respectively, and therefore no reliability analysis was conducted.

The indirect measure of attitude was calculated by multiplying and summing the five behavioral beliefs and associated outcome evaluation items. The reliability of the scale was 0.55 , which is less than the acceptable Cronbach's alpha level of 0.60 (Robinson, Shaver, \& Wrightsman, 1991) and indicates a moderate consistency between the product of the responses to the items measuring behavioral beliefs and associated outcome evaluations. According to Francis et al. (2004b), Theory of Planned Behavior (TPB) constructs like attitude are not necessarily internally consistent; because the belief based items measuring the domain of attitude could be measuring two contrasting facets of the same domain. That is, individuals may hold both positive and negative beliefs about any particular behavior, leading to low internal consistency among the products of items measuring behavioral belief and outcome evaluation.

The indirect measure of subjective norm was assessed by multiplying the three normative belief items with the corresponding motivation to comply items and summing the scores. The coefficient alpha for these three products was 0.79 , indicating a strong internal consistency.

The direct measure of perceived behavioral control was assessed using three items. The coefficient alpha for the three items was 0.57 , which is close to the acceptable level of 0.60 . The results of the reliability analysis are presented in Table 6. 
Table 6. Reliability Results for Theoretical Items

\begin{tabular}{lcc}
\hline Construct & Number of Items & Cronbach's Alpha \\
\hline Indirect attitude & 5 & 0.55 \\
Indirect subjective norm & 3 & 0.79 \\
Direct perceived behavioral control & 3 & 0.57 \\
\hline
\end{tabular}


Research Question 1: What is the relationship between the direct and indirect measures of attitude, subjective norms, and perceived behavioral control, respectively?

All zero-order correlations between the theory variables were significant $(\mathrm{r}=0.11-0.66, p$ $<0.01)$. Intention was strongly correlated with the direct measure of attitude $(\mathrm{r}=0.66, p<0.01)$, followed by indirect measure of subjective norm $(\mathrm{r}=0.52, p<0.01)$ and direct measure of subjective norm $(\mathrm{r}=0.50, p<0.01)$. Indirect attitude $(\mathrm{r}=0.43, p<0.01)$, direct perceived behavioral control $(\mathrm{r}=0.35, p<0.01)$, and indirect perceived behavioral control $(\mathrm{r}=0.23, p<$ 0.01) were also significantly correlated with intention. Table 7 shows the correlation between the theoretical variables.

Hypothesis 1.1a: Physician attitude towards measuring BMI in children and adolescents is not significantly correlated with the summated product of behavioral beliefs and evaluation of the outcomes

The zero-order correlation between the direct and the indirect measure of attitude was $0.61(p<0.01)$. Based on the strong and significant correlation between the direct measure of attitude and the indirect measure of attitude (summated product of the behavioral beliefs and associated outcome evaluation items), Hypothesis 1.1 was rejected.

Hypothesis 1.1b: Physician subjective norm about measuring BMI in children and adolescents is not significantly correlated with the summated product of normative belief and motivation to comply with a referent.

The result of correlation analysis showed that there was a significant $(p<0.01)$ correlation between the direct and the indirect measure of subjective norm $(\mathrm{r}=0.52)$. Therefore, Hypothesis $1.1 \mathrm{~b}$ was rejected. 
Hypothesis 1.1c: Physician's perceived behavioral control towards measuring BMI in children and adolescents is not significantly correlated with the product of control belief and influence of the specific control factor.

The direct measure of perceived behavioral control was significantly $(p<0.01)$ correlated with the indirect measure of perceived behavioral control $(r=0.29)$, leading to the rejection of Hypothesis 1.1c. 
Table 7. Correlation Between the Theoretical Variables

\begin{tabular}{lcccccc}
\hline Variable & $\mathbf{2}$ & $\mathbf{3}$ & $\mathbf{4}$ & $\mathbf{5}$ & $\mathbf{6}$ & $\mathbf{7}$ \\
\hline 1. Intention & 0.66 & 0.50 & 0.35 & 0.43 & 0.52 & 0.23 \\
2. Attitude & - & 0.43 & 0.29 & 0.61 & 0.45 & 0.22 \\
3. Subjective norm & & - & 0.29 & 0.29 & 0.52 & 0.11 \\
4. Perceived behavioral control & & - & 0.27 & 0.28 & 0.29 \\
5. Indirect attitude & & & - & 0.38 & 0.25 \\
6. Indirect subjective norm & & & & - & & \\
7. Indirect perceived behavioral control & & & & & &
\end{tabular}

All correlations are significant at $p<0.01$ 
Research Question 2: What is the relationship between a physician attitude and subjective norms and his/her intention to measure BMI in children and adolescents?

Hypothesis 1.2: Attitude and subjective norm do not significantly predict physicians' intention to measure BMI in children and adolescents.

Two models of multiple regression analyses were constructed to determine utility of the Theory of Reasoned Action (TRA) in predicting physicians' intention to measure BMI. Model one used the direct measures of TRA constructs (i.e., direct measures of attitude and subjective norm), while the second model used the indirect measures of attitude and subjective norm as predictors. In both the models, intention to measure BMI served as the dependent variable. Given the significant correlation between attitude and subjective norm, multicollinearity diagnostics were performed by requesting variance inflation statistics for the regression analyses. Multicollinearity was ruled out in the regression models, since the variance inflation factor was less than the recommended level of ten (Hair, Anderson, Tatham, \& Black, 1998).

Model 1: Using Direct Measures of Attitude and Subjective Norm to Predict Intention In model one, utility of the TRA in explaining physician intention to measure BMI was determined using the direct measures of attitude and subjective norm. The model was statistically significant $(\mathrm{F}=288.834, p=0.000)$, and together the two predictor variables explained $49.9 \%$ (adjusted $\left.\mathrm{R}^{2}=0.497\right)$ of the variance in intention. Both attitude $(\mathrm{B}=0.620, p=$ $0.000)$ and subjective norm $(\mathrm{B}=0.215, p=0.000)$ made strong and significant contributions in predicting intention. Tables 8 and 9 present the results of the regression analysis. For the direct measures TRA model the regression equation takes the following form:

$$
(\text { Intention })^{\prime}=1.263+0.620(\text { Direct Attitude })+0.215(\text { Direct Subjective Norm) }
$$


Table 8. Summary of the Multiple Regression Analysis for Predicting Physicians' Intention to Measure BMI using Direct Measures of Attitude and Subjective Norm

\begin{tabular}{ccccc}
\hline $\mathbf{R}^{2}$ & Adjusted $\mathbf{R}^{2}$ & $\mathbf{R}^{2}$ Change & F Change & Model F \\
\hline 0.499 & 0.497 & 0.499 & $288.834^{* * *}$ & $288.834^{* * *}$ \\
${ }^{* * * *}$ Significant at $p=0.000$. & Dependent variable: Intention; Predictors: & (Constant), Direct
\end{tabular}
Attitude, Direct Subjective Norm 
Table 9. Result of Multiple Regression Analysis for Predicting Intention using Direct Measures of Attitude and Subjective Norm

\begin{tabular}{|c|c|c|c|}
\hline Predictors & $\begin{array}{l}\text { Unstandardized } \\
\text { Coefficients (B) }\end{array}$ & Std. Error & $\begin{array}{c}\text { Standardized } \\
\text { Coefficients (Beta) }\end{array}$ \\
\hline $\mathrm{ATT}_{\mathrm{D}}$ & $0.620^{* * *}$ & 0.037 & 0.552 \\
\hline $\mathrm{SN}_{\mathrm{D}}$ & $0.215^{* * *}$ & 0.027 & 0.263 \\
\hline
\end{tabular}


Model 2: Using Indirect Measures of Attitude and Subjective Norm to Predict Intention

In model two, indirect measures of attitude and subjective norm were used as predictors to determine intention to measure BMI. The model was statistically significant $(\mathrm{F}=146.447, p=$ $0.000)$, with both the indirect measure of attitude $(\mathrm{B}=0.013, p=0.000)$ and the indirect measure of subjective norm $(\mathrm{B}=0.022, p=0.000)$ making significant contributions to predicting intention. The two variables together explained $33.6 \%$ (adjusted $\mathrm{R}^{2}=0.333$ ) of the variance in intention. The result of multiple regression analysis with indirect measures of attitude and subjective norm as predictors and intention as the dependent variable is presented in Tables 10 and 11. For the indirect measures TRA model, the regression equation can be written as: $(\text { Intention })^{\prime}=2.035+0.013$ (Indirect Attitude) +0.022 (Indirect Subjective Norm) As seen in model one, direct measures of attitude and subjective norm significantly predicted intention. And in model two, indirect measures of attitude and subjective norm were significant predictors of intention. The results of multiple regression analyses demonstrated utility of attitude and subjective norm in predicting intention. Therefore, Hypothesis 1.2 was rejected. 
Table 10. Summary of the Multiple Regression Analysis for Predicting Physicians' Intention to Measure BMI using Indirect Measures of Attitude and Subjective Norm

\begin{tabular}{ccccc}
\hline $\mathbf{R}^{2}$ & Adjusted $\mathbf{R}^{2}$ & $\mathbf{R}^{2}$ Change & F Change & Model F \\
\hline 0.336 & 0.333 & 0.336 & $146.447^{* * *}$ & $146.447^{* * *}$ \\
\hline
\end{tabular}

${ }^{* * *}$ Significant at $p=0.000$. Dependent variable: Intention; Predictors: (Constant), Indirect Attitude, Indirect Subjective Norm 
Table 11. Result of Multiple Regression Analysis for Predicting Intention using Indirect Measures of Attitude and Subjective Norm

\begin{tabular}{lccc}
\hline Predictors & $\begin{array}{c}\text { Unstandardized } \\
\text { Coefficients (B) }\end{array}$ & Std. Error & $\begin{array}{c}\text { Standardized } \\
\text { Coefficients (Beta) }\end{array}$ \\
\hline $\mathrm{ATT}_{\mathrm{I}}$ & $0.013^{* * *}$ & 0.002 & 0.280 \\
$\mathrm{SN}_{\mathrm{I}}$ & $0.022^{* * *}$ & 0.002 & 0.411 \\
\hline
\end{tabular}

${ }^{* * *}$ Significant at $p=0.000 . \mathrm{ATT}_{\mathrm{I}}=$ indirect attitude; $\mathrm{SN}_{\mathrm{I}}=$ indirect subjective norm; Std. Error $=$ Standard Error 
Research Question 3: Does the addition of perceived behavioral control to attitude and subjective norm significantly increase the explained variance of physicians' intentions to measure BMI?

Hypothesis 1.3: Addition of perceived behavioral control over and above attitude and subjective norms will not add significantly to the prediction of physicians' intention to measure BMI.

To test utility of the Theory of Planned Behavior (TPB) in predicting physicians intention to measure BMI, the construct of perceived behavioral control was added as a third predictor besides attitude and subjective norm. As discussed under methodology, two hierarchical regression models were constructed to test whether the addition of perceived behavioral control accounts for a significant increase in the intention variance explained beyond the TRA variables. In model one, the direct measure of perceived behavioral control was added over and above the direct measures of attitude and subjective norm to determine if the intention variance explained is significantly increased. And in model two, the indirect measure of perceived behavioral control was added to the indirect measures of attitude and subjective norm to determine the increase in intention variance explained. Because of the significant correlations between attitude, subjective norm, and perceived behavioral control, multicollinearity diagnostics were performed using variance inflation factor. The variance inflation factor value of less than ten indicated a lack of multicollinearity between the independent variables.

Model 1: Utility of the Direct Measure of Perceived Behavioral Control in Explaining Intention In hierarchical regression analysis, the direct measures of attitude and subjective norm were added together as predictors in the first step, and the direct measure of perceived behavioral control was added in a separate, last step. 
The change in intention variance explained after addition of the direct measure of perceived behavioral control over and above the direct measures of attitude and subjective norm was small but significant $\left(\mathrm{R}^{2}\right.$ change $\left.=0.013, p=0.000\right)$. The total variance in intention explained by the three predictors (direct attitude, direct subjective norm, and direct perceived behavioral control) was $51.2 \%$. The significant predictors in the final step were attitude $(\mathrm{B}=$ $0.592, p=0.000)$, subjective norm $(\mathrm{B}=0.194, p=0.000)$, and perceived behavioral control $(\mathrm{B}=$ $0.178, p=0.000)$. The results of model one hierarchical regression analysis are presented in Tables 12 and 13. The regression equation for the direct measures TPB model can be written as: $(\text { Intention })^{\prime}=0.455+0.592($ Direct Attitude $)+0.194($ Direct Subjective Norm) +0.178 (Direct Perceived Behavioral Control) 
Table 12. Summary of Hierarchical Regression Analysis Depicting Utility of the Direct Measure of Perceived Behavioral Control in Predicting Intention Beyond the TRA Variables

\begin{tabular}{cccccc}
\hline Step & $\mathbf{R}^{2}$ & Adjusted $\mathbf{R}^{2}$ & $\mathbf{R}^{2}$ Change & F Change & Model F \\
\hline 1 & 0.499 & 0.497 & 0.499 & $288.834^{* * *}$ & $288.834^{* * *}$ \\
2 & 0.512 & 0.510 & 0.013 & $15.652^{* * *}$ & $202.638^{* * *}$ \\
\hline
\end{tabular}

${ }^{* * *}$ Significant at $p=0.000$. Dependent variable: Intention; Step 1 Predictors: (Constant), Direct Attitude, Direct Subjective Norm; Step 2 Predictors: (Constant), Direct Attitude, Direct Subjective Norm, Direct Perceived Behavioral Control 
Table 13. Result of Hierarchical Regression Analysis Predicting Intention after Addition of the Direct Measure of Perceived Behavioral Control to the TRA Variables

\begin{tabular}{|c|c|c|c|c|c|c|}
\hline \multirow[b]{2}{*}{ Predictors } & \multicolumn{3}{|c|}{ Step 1} & \multicolumn{3}{|c|}{ Step 2} \\
\hline & $\begin{array}{l}\text { Unstandardized } \\
\text { Coefficients } \\
\text { (B) }\end{array}$ & $\begin{array}{c}\text { Std. } \\
\text { Error }\end{array}$ & $\begin{array}{l}\text { Standardized } \\
\text { Coefficients } \\
\text { (Beta) }\end{array}$ & $\begin{array}{c}\text { Unstandardized } \\
\text { Coefficients } \\
\text { (B) }\end{array}$ & $\begin{array}{l}\text { Std. } \\
\text { Error }\end{array}$ & $\begin{array}{c}\text { Standardized } \\
\text { Coefficients } \\
\text { (Beta) }\end{array}$ \\
\hline $\mathrm{ATT}_{\mathrm{D}}$ & $0.620^{* * *}$ & 0.037 & 0.552 & $0.592^{* * *}$ & 0.037 & 0.527 \\
\hline $\mathrm{SN}_{\mathrm{D}}$ & $0.215^{* * *}$ & 0.027 & 0.263 & $0.194^{* * *}$ & 0.027 & 0.238 \\
\hline $\mathrm{PBC}_{\mathrm{D}}$ & & & & $0.178^{* * *}$ & 0.045 & 0.123 \\
\hline
\end{tabular}

\footnotetext{
${ }^{* * *}$ Significant at $p=0.000 . \mathrm{ATT}_{\mathrm{D}}=$ direct attitude; $\mathrm{SN}_{\mathrm{D}}=$ direct subjective norm; $\mathrm{PBC}_{\mathrm{D}}=$ direct perceived behavioral
} control; Std. Error $=$ Standard Error 
Model 2: Utility of the Indirect Measure of Perceived Behavioral Control in Explaining

Intention

The indirect measures of attitude and subjective norm were added in step one of the hierarchical regression model, and the indirect measure of perceived behavioral control was added in a separate, last step of the regression model.

The change in the intention variance explained after addition of the indirect measure of perceived behavioral control in the second step was significant $\left(\mathrm{R}^{2}\right.$ change $\left.=0.013, p<0.01\right)$. All three psychosocial constructs, indirect measure of attitude $(\mathrm{B}=0.011, p=0.000)$, indirect measure of subjective norm $(\mathrm{B}=0.022, p=0.000)$, and indirect measure of perceived behavioral control $(\mathrm{B}=0.012, p<0.01)$ were significant predictors of intention in the final step. Tables 14 and 15 demonstrate the utility of adding the indirect measure of perceived behavioral control to the TRA variables in explaining intention. The indirect measures TPB regression equation can be written as following:

$$
(\text { Intention })^{\prime}=1.952+0.011(\text { Indirect Attitude })+0.022(\text { Indirect Subjective Norm })+
$$

0.012 (Indirect Perceived Behavioral Control)

Results of model one and two hierarchical regression analyses depict a small but significant increase in intention variance explained after addition of perceived behavioral control beyond the TRA variables (attitude and subjective norm). Therefore, Hypothesis 1.3 was rejected. 
Table 14. Summary of Hierarchical Regression Analysis Depicting Utility of the Indirect Measure of Perceived Behavioral Control in Predicting Intention Beyond the TRA Variables

\begin{tabular}{cccccc}
\hline Step & $\mathbf{R}^{2}$ & Adjusted $\mathbf{R}^{2}$ & $\mathbf{R}^{2}$ Change & F Change & Model F \\
\hline 1 & 0.336 & 0.333 & 0.336 & $146.447^{* * *}$ & $146.447^{* * *}$ \\
2 & 0.349 & 0.345 & 0.013 & $11.796^{* *}$ & $103.381^{* * *}$ \\
\hline
\end{tabular}

${ }^{* * *}$ Significant at $p<0.01{ }^{* * * *}$ Significant at $p=0.000$. Dependent variable: Intention; Step 1 Predictors: (Constant), Indirect Attitude, Indirect Subjective Norm; Step 2 Predictors:

(Constant), Indirect Attitude, Indirect Subjective Norm, Indirect Perceived Behavioral Control 
Table 15. Result of Hierarchical Regression Analysis Predicting Intention After Addition of the Indirect Measure of Perceived Behavioral Control to the TRA Variables

\begin{tabular}{lcccccc}
\hline Predictors & $\begin{array}{c}\text { Step 1 } \\
\text { Unstandardized } \\
\text { Coefficients } \\
(\mathbf{B})\end{array}$ & $\begin{array}{c}\text { Std. } \\
\text { Error }\end{array}$ & $\begin{array}{c}\text { Standardized } \\
\text { Coefficients } \\
\text { (Beta) }\end{array}$ & $\begin{array}{c}\text { Snstandardized } \\
\text { Coefficients } \\
\text { (B) }\end{array}$ & $\begin{array}{c}\text { Std. } \\
\text { Error }\end{array}$ & $\begin{array}{c}\text { Standardized } \\
\text { Coefficients } \\
\text { (Beta) }\end{array}$ \\
\hline $\mathrm{ATT}_{\mathrm{I}}$ & $0.013^{* * *}$ & 0.002 & 0.280 & $0.011^{* * *}$ & 0.002 & 0.251 \\
$\mathrm{SN}_{\mathrm{I}}$ & $0.022^{* * *}$ & 0.002 & 0.411 & $0.022^{* * *}$ & 0.002 & 0.406 \\
$\mathrm{PBC}_{\mathrm{I}}$ & & & $0.012^{* *}$ & 0.004 & 0.119
\end{tabular}

${ }^{* *}$ Significant at $p<0.01 .{ }^{* * *}$ Significant at $p=0.000 . \mathrm{ATT}_{\mathrm{I}}=$ indirect attitude; $\mathrm{SN}_{\mathrm{I}}=$ indirect subjective norm; $\mathrm{PBC}_{\mathrm{I}}=$ indirect perceived behavioral control; Std. Error $=$ Standard Error 
Research Question 4: Does physician past BMI measurement behavior increase the predictive ability of the TPB model?

Hypothesis 1.4: Addition of physician's past BMI measurement behavior to attitude, subjective norm, and perceived behavioral control does not significantly add to the prediction of his/her intention to measure BMI.

To determine if inclusion of past behavior increases predictive ability of the TPB model, two hierarchical regression models were used. Being a categorical variable, past behavior was coded as 1 (indicating past use of BMI) or 0 (indicating BMI not used in the past) for both the models.

Model 1: Addition of Past Behavior to the Direct Measures of Attitude, Subjective Norm, and Perceived Behavioral Control

In model one, the direct measure of attitude, subjective norm, and perceived behavioral control were added in the first step of the regression model, followed by past behavior in the second, last step. Addition of past behavior to the direct measures of attitude, subjective norm, and perceived behavioral control improved the intention variance explained by $7.6 \%$. With the addition of past behavior, the total variance in intention explained was $58.2 \%$ (adjusted $\mathrm{R}^{2}=$ 0.579). Overall, past behavior ( $\mathrm{B}=0.992, p=0.000)$, attitude $(\mathrm{B}=0.505, p=0.000)$, subjective norm $(\mathrm{B}=0.129, p=0.000)$, and perceived behavioral control $(\mathrm{B}=0.116, p=0.000)$ significantly predicted intention. Tables 16 and 17 depict the results of the regression model. The regression equation with the addition of past behavior to direct measures TPB model is: $(\text { Intention })^{\prime}=0.942+0.505($ Direct Attitude $)+0.129($ Direct Subjective Norm $)+0.116$ (Direct Perceived Behavioral Control) +0.992 (Past Behavior) 
Table 16. Utility of Past Behavior in Explaining Intention beyond the Direct Measures Theory of Planned Behavior (TPB) Model Constructs

\begin{tabular}{cccccc}
\hline Step & $\mathbf{R}^{2}$ & Adjusted $\mathbf{R}^{2}$ & $\mathbf{R}^{2}$ Change & F Change & Model F \\
\hline 1 & 0.506 & 0.503 & 0.506 & $195.189^{* * *}$ & $195.189^{* * *}$ \\
2 & 0.582 & 0.579 & 0.076 & $103.522^{* * *}$ & $198.511^{* * *}$ \\
\hline
\end{tabular}

${ }^{* * *}$ Significant at $p=0.000$. Dependent variable: Intention; Step 1 Predictors: (Constant), Direct Attitude, Direct Subjective Norm, Direct Perceived Behavioral Control; Step 2

Predictors: (Constant), Direct Attitude, Direct Subjective Norm, Direct Perceived Behavioral Control, Past Behavior 
Table 17. Result of the Hierarchical Regression Analysis Predicting Intention with Past Behavior and Direct Measures Theory of Planned Behavior (TPB)

\begin{tabular}{|c|c|c|c|c|c|c|}
\hline \multirow[b]{2}{*}{ Predictors } & \multicolumn{3}{|c|}{ Step 1} & \multicolumn{3}{|c|}{ Step 2} \\
\hline & $\begin{array}{l}\text { Unstandardized } \\
\text { Coefficients } \\
\text { (B) }\end{array}$ & $\begin{array}{c}\text { Std. } \\
\text { Error }\end{array}$ & $\begin{array}{l}\text { Standardized } \\
\text { Coefficients } \\
\text { (Beta) }\end{array}$ & $\begin{array}{l}\text { Unstandardized } \\
\text { Coefficients } \\
\text { (B) }\end{array}$ & $\begin{array}{c}\text { Std. } \\
\text { Error }\end{array}$ & $\begin{array}{c}\text { Standardized } \\
\text { Coefficients } \\
\text { (Beta) }\end{array}$ \\
\hline $\mathrm{ATT}_{\mathrm{D}}$ & $0.582^{* * *}$ & 0.037 & 0.516 & $0.505^{* * *}$ & 0.035 & 0.448 \\
\hline $\mathrm{SN}_{\mathrm{D}}$ & $0.196^{* * *}$ & 0.027 & 0.242 & $0.129^{* * *}$ & 0.026 & 0.159 \\
\hline $\mathrm{PBC}_{\mathrm{D}}$ & $0.183^{* * *}$ & 0.045 & 0.128 & $0.116^{* * *}$ & 0.042 & 0.081 \\
\hline $\mathrm{PB}$ & & & & $0.992^{* * *}$ & 0.098 & 0.314 \\
\hline
\end{tabular}


Model 2: Addition of Past Behavior to the Indirect Measures of Attitude, Subjective Norm, and Perceived Behavioral Control

In model two, past behavior was added as an independent variable into the regression model in the presence of the indirect measures of attitude, subjective norm, and perceived behavioral control. Addition of past behavior as a predictor to the TPB model increased the intention variance explained to $48.2 \%$ (adjusted $\mathrm{R}^{2}=0.478$ ). Past behavior increased the variance explained by $13.7 \%$. Indirect attitude $(\mathrm{B}=0.001, p=0.000)$, indirect subjective norm $(\mathrm{B}=0.016, p=0.000)$, and past behavior $(\mathrm{B}=1.280, p=0.001)$ were the significant predictors of intention in the final step. Tables 18 and 19 present the results of the regression model. The regression equation with the addition of past behavior to the indirect measures TPB model looks like following:

$$
(\text { Intention })^{\prime}=2.105+0.001(\text { Indirect Attitude })+0.016(\text { Indirect Subjective Norm })+
$$

\subsection{0 (Past Behavior)}

As seen in model one and two, addition of past behavior to the TPB variables significantly increased the intention variance explained. Therefore, Hypothesis 1.4 was rejected. 
Table 18. Utility of Past Behavior in Explaining Intention Beyond the Indirect Measures Theory of Planned Behavior (TPB) Model

\begin{tabular}{cccccc}
\hline Step & $\mathbf{R}^{2}$ & Adjusted $\mathbf{R}^{2}$ & $\mathbf{R}^{2}$ Change & F Change & Model F \\
\hline 1 & 0.345 & 0.342 & 0.345 & $100.400^{* * *}$ & $100.400^{* * *}$ \\
2 & 0.482 & .478 & 0.137 & $150.850^{* * *}$ & $132.739^{* * *}$ \\
\hline
\end{tabular}

*** Significant at $p=0.000$. Dependent variable: Intention; Step 1 Predictors: (Constant), Indirect Attitude, Indirect Subjective Norm, Indirect Perceived Behavioral Control; Step 2 Predictors: (Constant), Indirect Attitude, Indirect Subjective Norm, Indirect Perceived Behavioral Control, Past Behavior 
Table 19. Result of the Hierarchical Regression Analysis Predicting Intention with Past Behavior and Indirect Measures Theory of Planned Behavior (TPB) Model

\begin{tabular}{lcccccc}
\hline Predictors & $\begin{array}{c}\text { Step 1 } \\
\text { Unstandardized } \\
\text { Coefficients } \\
(\mathbf{B})\end{array}$ & $\begin{array}{c}\text { Std. } \\
\text { Error }\end{array}$ & $\begin{array}{c}\text { Standardized } \\
\text { Coefficients } \\
\text { (Beta) }\end{array}$ & $\begin{array}{c}\text { Unstandardized } \\
\text { Coefficients } \\
(\mathbf{B})\end{array}$ & $\begin{array}{c}\text { Std. } \\
\text { Error }\end{array}$ & $\begin{array}{c}\text { Standardized } \\
\text { Coefficients } \\
\text { (Beta) }\end{array}$ \\
\hline $\mathrm{ATT}_{\mathrm{I}}$ & $0.011^{* * *}$ & 0.002 & 0.250 & $0.001^{* * *}$ & 0.002 & 0.198 \\
$\mathrm{SN}_{\mathrm{I}}$ & $0.022^{* * *}$ & 0.002 & 0.404 & $0.016^{* * *}$ & 0.002 & 0.301 \\
$\mathrm{PBC}_{\mathrm{I}}$ & $0.012^{* *}$ & 0.004 & 0.121 & 0.001 & 0.003 & 0.046 \\
$\mathrm{~PB}$ & & & & $1.280^{* * *}$ & 0.104 & 0.405
\end{tabular}

${ }^{* *}$ Significant at $p<0.01 .{ }^{* * *}$ Significant at $p=0.000 . \mathrm{ATT}_{\mathrm{I}}=$ Indirect attitude; $\mathrm{SN}_{\mathrm{I}}=$ Indirect subjective norm; $\mathrm{PBC}_{\mathrm{I}}=$ Indirect perceived behavioral control; $\mathrm{PB}=$ past behavior; Std. Error $=$ Standard Error 


\section{Objective II}

Hypothesis 2.1: There are no significant behavioral and normative belief differences between physicians who intend to measure BMI and those who do not intend to measure BMI.

The study compared the behavioral and normative beliefs of surveyed physicians who responded that they intend, do not intend, or are neutral with respect to measuring BMI in pediatric and adolescent patients. The results of this comparison are described below.

\section{Salient Beliefs and Intention to Measure BMI}

Physicians were divided into three groups on the basis of their expressed intention to measure BMI. Based on the response to the statement "I intend to measure the BMI of my pediatric and adolescent patients" on a scale of 1 (strongly disagree) to 7 (strongly agree), physicians were classified as non-intenders $(\mathrm{N}=46)$ if their response was from 1 to 3 , neutral ( $=37)$ if the response was 4 , and intenders $(N=500)$ if the response was from 5 to 7 . Scores on each of the behavioral belief and normative belief items were compared between the three groups using ANOVA. For each belief, a significant overall $\mathrm{F}$ for ANOVA was followed by post-hoc analyses using Hochberg's GT2.

The overall $\mathrm{F}$ test was significant for all but one of the behavioral belief items, respectively. The overall $\mathrm{F}$ was not significant for the belief item, "Using BMI for weight classification can lead to false labeling of muscular pediatric and adolescent patients as being overweight or at risk of being overweight". Therefore, post-hoc analyses were conducted to compare the three groups of physicians on each of the remaining four behavioral belief items. Intenders were significantly more likely than non-intenders to believe that measuring BMI does not lengthen the consultation time $(p<0.01)$; BMI helps in identifying underweight, overweight, 
or at risk of being overweight pediatric and adolescent patients $(p<0.001)$; BMI provides an adequate measure of body fat in pediatric and adolescent patients $(p<0.001)$; and BMI can be used as an educational tool to motivate pediatric and adolescent patients to manage body weight $(p<0.001)$. Compared with intenders, those physicians who were neutral were significantly $(p<$ 0.001) less likely to believe that BMI helps in identifying underweight, overweight, or at risk of being overweight pediatric and adolescent patients. Physicians who were neutral were significantly more likely than non-intenders to believe that BMI can be used as an education tool to motivate pediatric and adolescent patients to manage body weight $(p<0.01)$. Table 20 presents the results of the comparison of behavioral beliefs between the three groups. 
Table 20. Comparisons of Behavioral Beliefs Between Physicians who do not Intend, are Neutral, and Intend to Measure BMI in Pediatric and Adolescent Patients

\begin{tabular}{lccc} 
Consequence & Non-Intenders & Neutral & Intenders \\
\hline $\begin{array}{l}\text { Behavioral beliefs } \\
\text { - Lengthen consultation time }\end{array}$ & & & \\
- Helps in identifying overweight, & $4.02 \pm 1.90$ & $4.16 \pm 1.97$ & $4.84 \pm 1.89^{* *}$ \\
$\quad \begin{array}{l}\text { underweight, or at risk of being } \\
\quad \text { overweight patients }\end{array}$ & $4.38 \pm 1.77$ & $4.70 \pm 1.54^{\dagger \dagger \dagger}$ & $5.99 \pm 1.18^{* * *}$ \\
- Leads to false labeling & & & \\
- Provides adequate measure of body & $3.86 \pm 1.55$ & $4.45 \pm 1.53$ & $4.01 \pm 1.60$ \\
$\quad$ fat & & & \\
- Motivates patients & $3.95 \pm 1.56$ & $4.62 \pm 1.47$ & $4.56 \pm 1.36^{*}$ \\
& $4.19 \pm 1.60^{\S \S}$ & $5.13 \pm 1.31$ & $5.56 \pm 1.23^{* * *}$ \\
\hline
\end{tabular}

${ }^{*}$ Significant at $p<0.05$ for intenders vs. non-intenders. ${ }^{* *}$ Significant at $p<0.01$ for intenders vs. non-intenders. ${ }^{* * *}$ Significant at $p<0.001$ for intenders vs. non-intenders. ${ }^{\dagger \dagger}$ Significant at $p<$ 0.001 for intenders vs. neutral. ${ }^{\S}$ Significant at $p<0.01$ for neutral vs. non-intenders. ${ }^{\mathrm{a}}$ Scores were reversed. Note: Possible scores for behavioral beliefs ranged from 1 (extremely unlikely) to 7 (extremely likely). 
As with the behavioral beliefs, comparisons of normative belief items also revealed significant group differences. The overall $\mathrm{F}$ was significant for each of the three normative belief items. Therefore, post hoc analyses were conducted to compare responses of the three groups of physicians on each of three normative belief items.

In comparison to non-intenders, intenders were significantly more likely to believe that other practitioners measure BMI $(p<0.001)$, the AAP and/or the AAFP recommend BMI measurement $(p<0.001)$, and the CDC recommends BMI measurement $(p<0.001)$. In comparison to intenders, physicians who were neutral were significantly less likely to believe that other practitioners measure BMI $(p<0.01)$, the AAP and/or the AAFP recommend BMI measurement $(p<0.001)$, and the CDC recommends BMI measurement $(p<0.001)$. There were no significant normative belief differences between non-intenders and physicians with neutral intentions. Table 21 presents the results of the comparison of normative beliefs between the three groups. The above results reflect significant behavioral and normative belief differences between physicians who intend and those who do not intend to measure BMI.

As seen from the results, there were significant behavioral and normative belief differences between intenders and non-intenders. Therefore, Hypothesis 2.1 was rejected. 
Table 21. Comparisons of Normative Beliefs Between Physicians who do not Intend, are Neutral, and Intend to Measure BMI in Pediatric and Adolescent Patients

\begin{tabular}{lccc} 
Referent & Non-Intenders & Neutral & Intenders \\
\hline $\begin{array}{l}\text { Normative beliefs } \\
\text { - Other practitioners }\end{array}$ & $3.50 \pm 1.49$ & $3.70 \pm 1.37^{\dagger \dagger}$ & $4.44 \pm 1.32^{* * *}$ \\
- American Academy of Pediatrics & & & \\
$\quad \begin{array}{l}\text { and/or the American Academy of } \\
\quad \text { Family Physicians }\end{array}$ & $4.93 \pm 1.46$ & $5.35 \pm 0.97^{\dagger \dagger \dagger}$ & $6.21 \pm 0.97^{* * *}$ \\
- $\begin{array}{l}\text { Centers for Disease Control and } \\
\quad \text { Prevention }\end{array}$ & $4.90 \pm 1.24$ & $5.00 \pm 1.05^{\dagger \dagger \dagger}$ & $5.93 \pm 1.13^{* * *}$ \\
\hline
\end{tabular}

${ }^{* * *}$ Significant at $p<0.001$ for intenders vs. non-intenders. ${ }^{\dagger}$ Significant at $p<0.01$ for intenders vs. neutral. ${ }^{\dagger \dagger}$ Significant at $p<0.001$ for intenders vs. neutral. Note: Possible scores for normative beliefs ranged from 1 (extremely unlikely) to 7 (extremely likely). 


\section{Objective III}

The frequency of use of different weight classification methods and evaluation practices of surveyed physicians were reported in this study. Comparison was made between family physicians and pediatricians, respectively, based on childhood obesity prevalence rates in their state. Additional analyses were also conducted to determine which physician demographic and practice-related characteristics predicted their adherence to 1998 Pediatric Obesity Expert Committee recommendations. Logistic regression analyses were used to examine those predictors. The following independent variables were used in the logistic regression models: gender, years in practice, number of pediatric and adolescent patients seen per week, practice site (categorized into solo, group, and hospital/other), and state of practice (categorized into two groups based on Youth Risk Behavior Surveillance [YRBS] results [Eaton et al., 2006]- states with childhood obesity prevalence rates above national average [Alabama and West Virginia] and states with childhood obesity prevalence rates below national average [Colorado and Massachusetts]). To avoid possible multicollinearity between age and the number of years in practice, age was not included as a predictor.

\section{Method of Obesity Identification}

Most of the physicians reported the use of multiple methods to identify overweight pediatric and adolescent patients. A majority of physicians frequently used clinical impression (76.7\%), weight for height percentile (65.4\%), and weight for age percentile (60.1\%). Roughly $65 \%$ of physicians frequently used BMI, and approximately $57 \%$ used BMI percentile. Of those physicians who used BMI percentile, $60.2 \%$ used a BMI cut-off value of greater than the $95^{\text {th }}$ percentile to classify patients as overweight. 
More than $71 \%$ of the pediatricians frequently used BMI and a similar percentage (72.8\%) used BMI percentile to identify overweight children and adolescents; however, less than $55 \%$ and $35 \%$ of family physicians frequently used BMI and BMI percentile for obesity identification, respectively. More pediatricians used BMI percentile to identify overweight pediatric and adolescent patients than family physicians $(72.8 \%$ versus $34.4 \%, p<0.001)$. Table 22 shows the distribution of physicians by the screening methods used by them to identify overweight children.

Comparison of BMI percentile use between physicians' practicing in states with above average childhood obesity prevalence rates (Alabama and West Virginia) and below average childhood obesity prevalence rates (Colorado and Massachusetts) revealed certain important differences. More pediatricians practicing in states with below average childhood obesity prevalence rates were using BMI percentile than pediatricians in states with above average childhood obesity prevalence rates $(84.6 \%$ versus $51.7 \%, p<0.001)$. However, there was no statistical difference in BMI percentile use between family physicians practicing in states with above average childhood obesity prevalence rates and states with below average childhood obesity prevalence rates $(33.7 \%$ versus $38.7 \%, p>0.05)$. Distribution of physicians' use of screening methods by their state of practice is shown in Table 23 . 
Table 22. Methods Used by Physicians to Identify Overweight Children and Adolescents

\begin{tabular}{lccc}
\hline \multicolumn{1}{c}{ Method } & $\begin{array}{c}\text { All Physicians } \\
(\mathbf{n}=\mathbf{5 8 3})\end{array}$ & $\begin{array}{c}\text { Family Physicians }^{\mathrm{a}} \\
(\mathbf{n}=\mathbf{2 4 1})\end{array}$ & $\begin{array}{c}\text { Pediatricians }^{\mathbf{a}} \\
(\mathbf{n}=\mathbf{3 4 2})\end{array}$ \\
\hline Clinical impression & $447(76.7 \%)$ & $203(84.2 \%)$ & $244(71.3 \%)$ \\
Weight for height percentile & $381(65.4 \%)$ & $183(75.9 \%)$ & $198(57.9 \%)$ \\
Weight for age percentile & $350(60.1 \%)$ & $168(69.7 \%)$ & $182(53.2 \%)$ \\
BMI & $376(64.5 \%)$ & $132(54.8 \%)$ & $244(71.3 \%)$ \\
BMI percentile & $332(56.9 \%)$ & $83(34.4 \%)$ & $249(72.8 \%)$ \\
\hline
\end{tabular}

${ }^{a}$ Physicians who replied always or often. BMI: body mass index; $\%=$ percentage 
Table 23. Methods Used by Physicians to Identify Overweight Children and Adolescents Based on State Childhood Obesity Prevalence Rates

\begin{tabular}{|c|c|c|c|c|c|c|}
\hline \multirow{2}{*}{ Method } & \multicolumn{3}{|c|}{$\begin{array}{c}\text { States with Below National Average } \\
\text { Childhood Obesity Prevalence }{ }^{\mathrm{a}} \\
\text { (CO and MA) }\end{array}$} & \multicolumn{3}{|c|}{$\begin{array}{l}\text { States with Above National Average } \\
\text { Childhood Obesity Prevalence }{ }^{\mathrm{a}} \\
\text { (AL and WV) }\end{array}$} \\
\hline & $\begin{array}{c}\text { All } \\
\text { Physicians }^{b} \\
(\mathbf{n}=\mathbf{3 9 2})\end{array}$ & $\begin{array}{l}\text { Family } \\
\text { Physicians } \\
(\mathbf{n}=\mathbf{1 4 5})\end{array}$ & $\begin{array}{l}\text { Pediatricians }^{b} \\
\quad(n=247)\end{array}$ & $\begin{array}{l}\text { All } \\
\text { Physicians }^{b} \\
(n=191)\end{array}$ & $\begin{array}{l}\text { Family } \\
\text { Physicians } \\
(\mathrm{n}=96)\end{array}$ & $\begin{array}{c}\text { Pediatricians }^{b} \\
\quad(n=95)\end{array}$ \\
\hline Clinical Impression & $292(76.2 \%)$ & $120(83.9 \%)$ & $172(71.7 \%)$ & $155(82.9 \%)$ & $83(88.3 \%)$ & $72(77.4 \%)$ \\
\hline $\begin{array}{l}\text { Weight for height } \\
\text { percentile }\end{array}$ & $244(64.6 \%)$ & $107(75.4 \%)$ & $137(58.1 \%)$ & $137(74.1 \%)$ & $76(81.7 \%)$ & $61(66.3 \%)$ \\
\hline $\begin{array}{l}\text { Weight for age } \\
\text { percentile }\end{array}$ & $218(57.8 \%)$ & $98(69.0 \%)$ & $120(51.1 \%)$ & $132(72.5 \%)$ & $70(76.1 \%)$ & $62(68.9 \%)^{*}$ \\
\hline BMI & $276(71.3 \%)$ & $81(56.3 \%)$ & $195(80.2 \%)$ & $100(54.1 \%)$ & $51(53.7 \%)$ & $49(54.4 \%)^{*}$ \\
\hline BMI percentile & $257(68.0 \%)$ & $53(38.7 \%)$ & $204(84.6 \%)$ & $75(42.6 \%)$ & $30(33.7 \%)$ & $45(51.7 \%)^{*}$ \\
\hline
\end{tabular}

"Significant at $p<0.05$ between pediatricians in the two groups. ${ }^{a}$ Prevalence based on Youth Risk Behavior Surveillance (Eaton et al., 2006); ${ }^{\mathrm{b}}$ Physicians who replied always or often. BMI: body mass index; $\%=$ percentage; $\mathrm{AL}=\mathrm{Alabama}$; $\mathrm{CO}=\mathrm{Colorado}$; $\mathrm{MA}=$ Massachusetts; WV $=$ West Virginia 


\section{Family History Assessment}

Among the surveyed physicians, a majority reported that they frequently ask about a family history of obesity, diabetes mellitus, cardiovascular disease, hypertension, and elevated cholesterol. Fewer physicians reported frequently asking about a family history of gallbladder disease among overweight patients. Approximately 15\% of the total sample adhered to 1998 Pediatric Obesity Expert Committee recommendations by assessing all the components of family history.

In comparison to family physicians, pediatricians more frequently assessed family history of obesity $(76.0 \%$ versus $61.0 \%, p<0.001)$ and elevated cholesterol $(88.3 \%$ versus $82.2 \%, p<$ 0.05) in their overweight pediatric and adolescent patients. Physicians who have been practicing for longer duration were slightly more likely (Odds ratio $[\mathrm{OR}]=1.05,95 \% \mathrm{CI}=[1.03,1.08])$ to follow the Expert Committee recommendations for family history assessment. Physicians who were practicing in states where the childhood obesity prevalence rates were above national average were more than twice as likely $(\mathrm{OR}=2.34,95 \% \mathrm{CI}=[1.42,3.86])$ to adhere to recommendations. Table 24 shows the number and percentage of physicians who frequently assess the different components of family history.

Significantly $(p<0.05)$ more family physicians $(26.0 \%$ versus $11.9 \%)$ practicing in states where childhood obesity prevalence rates were higher than the national average were following the Expert Committee recommendations. Similarly, significantly $(p<0.05)$ more pediatricians (20.2\% versus $11.1 \%)$ practicing in states where childhood obesity prevalence rates were higher than the national average were following Expert Committee recommendations. Table 25 shows the family history assessment practices of physicians based on obesity prevalence rates in their state of practice. 
Table 24. Family History Assessment of Overweight Children and Adolescents by Physicians

\begin{tabular}{lccc}
\hline \multicolumn{1}{c}{ Condition } & $\begin{array}{c}\text { All Physicians } \\
(\mathbf{n}=\mathbf{5 8 3})\end{array}$ & $\begin{array}{c}\text { Family Physicians }^{\mathrm{a}} \\
(\mathbf{n}=\mathbf{2 4 1})\end{array}$ & $\begin{array}{c}\text { Pediatricians }^{\mathbf{a}} \\
(\mathbf{n}=\mathbf{3 4 2})\end{array}$ \\
\hline Overweight & $407(69.8 \%)$ & $147(61.0 \%)$ & $260(76.0 \%)$ \\
Diabetes mellitus & $530(90.9 \%)$ & $220(91.3 \%)$ & $310(90.7 \%)$ \\
Gallbladder disease & $103(17.7 \%)$ & $50(20.8 \%)$ & $53(15.5 \%)$ \\
Cardiovascular disease & $508(87.2 \%)$ & $206(85.5 \%)$ & $302(88.3 \%)$ \\
Hypertension & $503(86.3 \%)$ & $207(85.9 \%)$ & $296(86.5 \%)$ \\
Elevated cholesterol & $500(86.2 \%)$ & $198(82.2 \%)$ & $302(88.3 \%)$ \\
Recommended practice ${ }^{\mathrm{b}}$ & $88(15.1 \%)$ & $42(17.4 \%)$ & $46(13.5 \%)$ \\
\hline
\end{tabular}

${ }^{a}$ Physicians who replied always or often; ${ }^{b}$ Physicians who adhered to 1998 Pediatric Obesity Expert Committee recommended practice. $\%=$ percentage 
Table 25. Family History Assessment of Overweight Children and Adolescents by Physicians Based on State Childhood

Obesity Prevalence Rates

\begin{tabular}{|c|c|c|c|c|c|c|}
\hline \multirow[b]{2}{*}{ Condition } & \multicolumn{3}{|c|}{$\begin{array}{l}\text { States with Below National Average } \\
\text { Childhood Obesity Prevalence }{ }^{\mathrm{a}} \\
\text { (CO and MA) }\end{array}$} & \multicolumn{3}{|c|}{$\begin{array}{l}\text { States with Above National Average } \\
\text { Childhood Obesity Prevalence }{ }^{\mathrm{a}} \\
\text { (AL and WV) }\end{array}$} \\
\hline & $\begin{array}{c}\text { All } \\
\text { Physicians }^{b} \\
(\mathrm{n}=\mathbf{3 9 2})\end{array}$ & $\begin{array}{c}\text { Family } \\
\text { Physicians }^{b} \\
(\mathrm{n}=145) \\
\end{array}$ & $\begin{array}{l}\text { Pediatricians }^{b} \\
\quad(n=247)\end{array}$ & $\begin{array}{c}\text { All } \\
\text { Physicians }^{b} \\
(n=191)\end{array}$ & $\begin{array}{c}\text { Family } \\
\text { Physicians }^{b} \\
(\mathbf{n}=96)\end{array}$ & $\begin{array}{c}\text { Pediatricians }^{b} \\
\quad(n=95)\end{array}$ \\
\hline Overweight & $267(68.5 \%)$ & $80(55.6 \%)$ & $187(76.0 \%)$ & $140(74.1 \%)$ & $67(69.8 \%)^{\S}$ & $73(78.5 \%)$ \\
\hline Diabetes mellitus & $354(90.5 \%)$ & $132(91.0 \%)$ & $222(90.2 \%)$ & $176(92.1 \%)$ & $88(91.7 \%)$ & $88(92.6 \%)$ \\
\hline Gallbladder disease & $51(13.2 \%)$ & $20(13.9 \%)$ & $31(12.8 \%)$ & $52(27.4 \%)$ & $30(31.6 \%)^{\S}$ & $22(23.2 \%)^{*}$ \\
\hline $\begin{array}{l}\text { Cardiovascular } \\
\text { disease }\end{array}$ & $337(86.6 \%)$ & $120(83.3 \%)$ & $217(88.6 \%)$ & $171(89.5 \%)$ & $86(89.6 \%)$ & $85(89.5 \%)$ \\
\hline Hypertension & $334(85.6 \%)$ & $121(83.4 \%)$ & $213(86.9 \%)$ & $169(88.9 \%)$ & $86(89.6 \%)$ & $83(88.3 \%)$ \\
\hline Elevated cholesterol & $336(86.4 \%)$ & $113(78.5 \%)$ & $223(91.0 \%)$ & $164(85.9 \%)$ & $85(88.5 \%)$ & $79(83.2 \%)$ \\
\hline $\begin{array}{l}\text { Recommended } \\
\text { practice }^{c}\end{array}$ & $44(11.4 \%)$ & $17(11.9 \%)$ & $27(11.1 \%)$ & $44(23.2 \%)$ & $25(26.0 \%)^{\S}$ & $19(20.2 \%)^{*}$ \\
\hline
\end{tabular}

${ }^{\S}$ Significant at $p<0.05$ between family physicians in the two groups. ${ }^{*}$ Significant at $p<0.05$ between pediatricians in the two

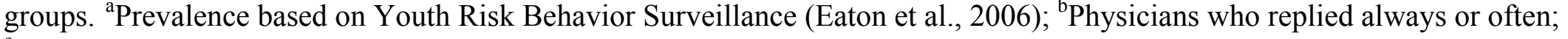
${ }^{c}$ Physicians who adhered to 1998 Pediatric Obesity Expert Committee recommended practice. \% $\%$ percentage; AL = Alabama; $\mathrm{CO}=$ Colorado; $\mathrm{MA}=$ Massachusetts; $\mathrm{WV}=$ West Virginia 


\section{Clinical Evaluations}

More than $60 \%$ of physicians frequently performed a clinical evaluation to assess dyslipidemia in overweight pediatric and adolescent patients; however, less than $20 \%$ of physicians routinely checked insulin. Although thyroid test is rarely required in overweight children, more than half (54.4\%) of the physicians were frequently conducting the test. As with thyroid test, cortisol test is also rarely required in overweight children. A small percentage (4.2\%) of physicians frequently requested tests for cortisol levels. Less than $5 \%$ of all physicians clinically evaluated overweight children based on the Expert Committee recommendations.

More pediatricians were frequently performing a clinical test to assess dyslipidemia in overweight children and adolescents than family physicians $(73.7 \%$ versus $43.6 \%, p<0.001)$. Also, more pediatricians were checking insulin in overweight patients than family physicians (30.1\% versus $4.9 \%, p<0.001)$. Physicians who were seeing more pediatric and adolescent patients per week were slightly more likely $(\mathrm{OR}=1.01,95 \% \mathrm{CI}=[1.00,1.02])$ to follow recommendations. However, physicians who were practicing in states with childhood obesity prevalence rates above the national average were less likely $(\mathrm{OR}=0.17,95 \% \mathrm{CI}=[0.04,0.77])$ to adhere to recommendations concerning clinical evaluations of overweight children. Table 26 shows the number and percentage of physicians frequently assessing each component of clinical evaluations.

As mentioned earlier, thyroid function test is not frequently required in overweight children. However, significantly $(p<0.05)$ more pediatricians $(62.1 \%$ versus $47.5 \%)$ practicing in states where obesity prevalence was above national average were conducting thyroid test. Table 27 shows the clinical evaluation of overweight children and adolescents by physicians based on obesity prevalence rates in their state of practice. 
Table 26. Clinical Evaluation of Overweight Children and Adolescents by Physicians

\begin{tabular}{|c|c|c|c|}
\hline Clinical Test & $\begin{array}{l}\text { All Physicians }{ }^{a} \\
\quad(n=583)\end{array}$ & $\begin{array}{c}\text { Family Physicians } \\
\text { (n }=241)\end{array}$ & $\begin{array}{l}\text { Pediatricians }^{a} \\
\quad(n=342)\end{array}$ \\
\hline Lipid profile & $357(61.3 \%)$ & $105(43.6 \%)$ & $252(73.7 \%)$ \\
\hline Insulin & $115(19.7 \%)$ & $12(4.9 \%)$ & $103(30.1 \%)$ \\
\hline Cortisol $^{b}$ & $24(4.1 \%)$ & $8(3.3 \%)$ & $16(4.7 \%)$ \\
\hline Thyroid function $^{\mathrm{b}}$ & $317(54.4 \%)$ & $142(58.9 \%)$ & $175(51.2 \%)$ \\
\hline Recommended practice ${ }^{c}$ & $25(4.3 \%)$ & $1(0.4 \%)$ & $24(7.0 \%)$ \\
\hline
\end{tabular}


Table 27. Clinical Evaluation of Overweight Children and Adolescents by Physicians Based on State Childhood Obesity

Prevalence Rates

\begin{tabular}{|c|c|c|c|c|c|c|}
\hline \multirow[b]{2}{*}{ Clinical Test } & \multicolumn{3}{|c|}{$\begin{array}{c}\text { States with Below National Average } \\
\text { Childhood Obesity Prevalence }{ }^{\mathrm{a}} \\
\text { (CO and MA) }\end{array}$} & \multicolumn{3}{|c|}{$\begin{array}{l}\text { States with Above National Average } \\
\text { Childhood Obesity Prevalence } \\
\text { (AL and WV) }\end{array}$} \\
\hline & $\begin{array}{c}\text { All } \\
\text { Physicians }^{b} \\
(\mathrm{n}=392) \\
\end{array}$ & $\begin{array}{c}\text { Family } \\
\text { Physicians } \\
(\mathrm{n}=145)\end{array}$ & $\begin{array}{l}\text { Pediatricians }^{b} \\
\quad(n=247)\end{array}$ & $\begin{array}{c}\text { All } \\
\text { Physicians }^{b} \\
(\mathbf{n}=191)\end{array}$ & $\begin{array}{l}\text { Family } \\
\text { Physicians } \\
(\mathbf{n}=96)\end{array}$ & $\begin{array}{l}\text { Pediatricians } s^{b} \\
\quad(n=95)\end{array}$ \\
\hline Lipid profile & $244(62.4 \%)$ & $57(39.3 \%)$ & $187(76.0 \%)$ & $113(59.2 \%)$ & $48(50.0 \%)$ & $65(68.4 \%)$ \\
\hline Insulin & $87(23.0 \%)$ & $5(3.6 \%)$ & $82(34.3 \%)$ & $28(15.4 \%)$ & $7(7.5 \%)$ & $21(23.6 \%)$ \\
\hline Cortisol $^{\mathrm{c}}$ & $14(3.8 \%)$ & $3(2.1 \%)$ & $11(4.7 \%)$ & $10(5.5 \%)$ & $5(5.3 \%)$ & $5(5.3 \%)$ \\
\hline $\begin{array}{l}\text { Thyroid } \\
\text { function }^{c}\end{array}$ & $194(49.9 \%)$ & $78(53.8 \%)$ & $116(47.5 \%)$ & $123(64.4 \%)$ & $64(66.7 \%)$ & $59(62.1 \%)^{*}$ \\
\hline $\begin{array}{l}\text { Recommended } \\
\text { practice }^{d}\end{array}$ & $23(5.9 \%)$ & $1(0.7 \%)$ & $22(9.1 \%)$ & $2(1.1 \%)$ & $0(0.0 \%)$ & $2(2.1 \%)$ \\
\hline
\end{tabular}

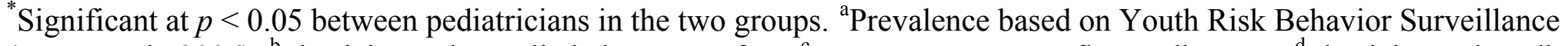
(Eaton et al., 2006); ${ }^{\mathrm{b}}$ Physicians who replied always or often; ${ }^{\mathrm{c}}$ Lower percentage reflects adherence; ${ }^{\mathrm{d}} \mathrm{Physicians}$ who adhered to 1998 Pediatric Obesity Expert Committee recommended practice. $\%=$ percentage; $\mathrm{AL}=\mathrm{Alabama} ; \mathrm{CO}=\mathrm{Colorado}$; $\mathrm{MA}=$ Massachusetts; WV = West Virginia 


\section{Medical History and Physical Examination}

Most (92.4\%) of respondent physicians frequently checked blood pressure in overweight children and adolescents. In contrast, roughly $5 \%$ of physicians routinely assessed for signs and symptoms of pseudotumour cerebri. One-fifth of physicians routinely assessed genetic disorders and approximately $43 \%$ frequently assessed sleep disorders in overweight children and adolescents. Of the total sample, $6.0 \%$ frequently assessed all the components of medical history and physical exam.

In comparison to family physicians, more pediatricians routinely assessed overweight children and adolescents for signs and symptoms of sleep disorders (49.7\% versus $32.4 \%, p<$ $0.001)$ and pseudotumour cerebri $(7.1 \%$ versus $2.5 \%, p<0.05)$. Female physicians $(\mathrm{OR}=2.69$, $95 \% \mathrm{CI}=[1.14,6.32])$ and physicians practicing in states with childhood obesity prevalence rates above national average $(\mathrm{OR}=2.50,95 \% \mathrm{CI}=[1.14,5.45])$ were more likely to adhere to the Expert Committee's recommendations. Table 28 shows the number and percentage of physicians for each component of medical history and physical exam.

A comparison of medical history and physical examination practices of family physicians based on the childhood obesity prevalence rates in their location of practice revealed no significant differences. However, significantly $(p<0.05)$ more pediatricians $(15.8 \%$ versus 4.5\%) practicing in states where the childhood obesity prevalence rates were above national average were following the Expert Committee's recommendations. Table 29 shows the medical history and physical evaluation of overweight children and adolescents by physicians based on obesity prevalence rates in their state of practice. 
Table 28. Medical History and Physical Examination of Overweight Children and Adolescents by Physicians

\begin{tabular}{lccc}
\hline \multicolumn{1}{c}{ Component } & $\begin{array}{c}\text { All Physicians } \\
(\mathbf{n}=\mathbf{5 8 3})\end{array}$ & $\begin{array}{c}\text { Family Physicians }^{\mathrm{a}} \\
(\mathbf{n}=\mathbf{2 4 1})\end{array}$ & $\begin{array}{c}\text { Pediatricians }^{\mathbf{a}} \\
(\mathbf{n}=\mathbf{3 4 2})\end{array}$ \\
\hline Pseudtumour cerebri & $30(5.1 \%)$ & $6(2.5 \%)$ & $24(7.1 \%)$ \\
Genetic disorders & $119(20.4 \%)$ & $49(20.4 \%)$ & $70(20.4 \%)$ \\
Sleep disorder & $248(42.5 \%)$ & $78(32.4 \%)$ & $170(49.7 \%)$ \\
Blood pressure & $539(92.4 \%)$ & $216(89.6 \%)$ & $323(94.4 \%)$ \\
Recommended practice ${ }^{\mathrm{b}}$ & $35(6.0 \%)$ & $9(3.7 \%)$ & $26(7.6 \%)$ \\
\hline${ }^{\mathrm{a}}$ Physicians who replied always or often; ${ }^{\mathrm{b}}$ Physicians who adhered to 1998 Pediatric Obesity \\
Expert Committee recommended practice. $\%=$ percentage
\end{tabular}


Table 29. Medical History and Physical Examination of Overweight Children and Adolescents by Physicians Based on State

Childhood Obesity Prevalence Rates

\begin{tabular}{|c|c|c|c|c|c|c|}
\hline \multirow[b]{2}{*}{ Component } & \multicolumn{3}{|c|}{$\begin{array}{l}\text { States with Below National Average } \\
\text { Childhood Obesity Prevalence }{ }^{\mathrm{a}} \\
\text { (CO and MA) }\end{array}$} & \multicolumn{3}{|c|}{$\begin{array}{l}\text { States with Above National Average } \\
\text { Childhood Obesity Prevalence }{ }^{\mathrm{a}} \\
\text { (AL and WV) }\end{array}$} \\
\hline & $\begin{array}{c}\text { All } \\
\text { Physicians }^{b} \\
(n=392) \\
\end{array}$ & $\begin{array}{l}\text { Family } \\
\text { Physicians } \\
(\mathrm{n}=145)\end{array}$ & $\begin{array}{l}\text { Pediatricians }^{b} \\
\quad(n=247)\end{array}$ & $\begin{array}{l}\text { All } \\
\text { Physicians }^{b} \\
(\mathrm{n}=\mathbf{1 9 1})\end{array}$ & $\begin{array}{l}\text { Family } \\
\text { Physicians } \\
(n=96)\end{array}$ & $\begin{array}{c}\text { Pediatricians }^{b} \\
\quad(n=95)\end{array}$ \\
\hline $\begin{array}{l}\text { Pseudtumour } \\
\text { cerebri }\end{array}$ & $19(5.0 \%)$ & $2(1.4 \%)$ & $17(7.1 \%)$ & $11(5.8 \%)$ & $4(4.3 \%)$ & $7(7.4 \%)$ \\
\hline Genetic disorders & $76(19.6 \%)$ & $30(20.7 \%)$ & $46(19.0 \%)$ & $43(22.6 \%)$ & $19(20.0 \%)$ & $24(25.3 \%)$ \\
\hline Sleep disorder & $170(43.4 \%)$ & $44(30.3 \%)$ & $126(51.0 \%)$ & $78(40.8 \%)$ & $34(35.4 \%)$ & $44(46.3 \%)$ \\
\hline Blood pressure & $365(93.6 \%)$ & $128(89.5 \%)$ & $237(96.0 \%)$ & $174(91.1 \%)$ & 88 (91.7\%) & $86(90.5 \%)$ \\
\hline $\begin{array}{l}\text { Recommended } \\
\text { practice }^{c}\end{array}$ & $15(3.9 \%)$ & $4(2.8 \%)$ & $11(4.5 \%)$ & $20(10.5 \%)$ & $5(5.3 \%)$ & $15(15.8 \%)^{*}$ \\
\hline
\end{tabular}

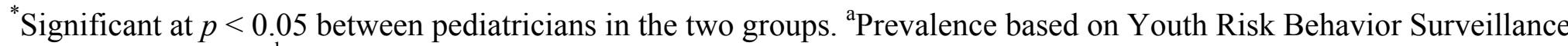
(Eaton et al., 2006); ${ }^{b}$ Physicians who replied always or often; ${ }^{\mathrm{c} P h y s i c i a n s}$ who adhered to 1998 Pediatric Obesity Expert Committee recommended practice. $\%=$ percentage; $\mathrm{AL}=$ Alabama; $\mathrm{CO}=$ Colorado; $\mathrm{MA}=$ Massachusetts; $\mathrm{WV}=\mathrm{West}$ Virginia 


\section{Behavioral History}

With respect to assessing the behavioral history of overweight children and adolescents, more than $90 \%$ of physicians routinely asked about exercise and diet (93.2\%). A similar percentage of physicians assessed television viewing/screen time (77.8\%) and tobacco use (77.7\%) in overweight pediatric and adolescent patients. A majority of physicians frequently asked about depression (54.3\%) and eating disorders (55.6\%). One-third of the total sample frequently asked about all of the behavioral assessment components.

More pediatricians than family physicians routinely obtained diet history $(97.1 \%$ versus $87.6 \%, p<0.001)$, history of television viewing and screen time $(86.6 \%$ versus $65.5 \%, p<$ $0.001)$, and history of exercise $(97.4 \%$ versus $93.7 \%, p<0.001)$. However, more family physicians routinely obtained history of eating disorders $(61.0 \%$ versus $51.8 \%, p<0.05)$ and history of tobacco use $(87.2 \%$ versus $71.1 \%, p<0.001)$ as compared to pediatricians. Female physicians were more likely $(\mathrm{OR}=1.98,95 \% \mathrm{CI}=[1.35,2.90])$ to adhere to Expert Committee recommendations. Physicians who were practicing in states with childhood obesity prevalence rates above national average were less likely $(\mathrm{OR}=0.57,95 \% \mathrm{CI}=[0.38,0.86])$ to adhere to Expert Committee's recommendations. Table 30 shows the number and percentage of physicians who frequently assess each component of behavioral assessment.

There were no significant differences between family physicians and pediatricians, respectively, practicing in states where childhood obesity prevalence rates were above national average as compared to those practicing in states where childhood obesity prevalence rates were below national average in terms of following the Expert Committee's recommendations. Table 31 shows the behavioral history practices of physicians based on obesity prevalence rates in their state of practice. 
Table 30. Behavioral History Assessment of Overweight Children and Adolescents by Physicians

\begin{tabular}{lccc}
\hline \multicolumn{1}{c}{ Component } & $\begin{array}{c}\text { All Physicians } \\
(\mathbf{n}=\mathbf{5 8 3})\end{array}$ & $\begin{array}{c}\text { Family }^{\text {Physicians }} \mathbf{~}^{\mathrm{a}} \\
(\mathbf{n}=\mathbf{2 4 1})\end{array}$ & $\begin{array}{c}\text { Pediatricians }^{\mathbf{a}} \\
(\mathbf{n}=\mathbf{3 4 2})\end{array}$ \\
\hline Diet history & $543(93.2 \%)$ & $211(87.6 \%)$ & $332(97.1 \%)$ \\
Depression & $317(54.3 \%)$ & $142(58.9 \%)$ & $175(51.2 \%)$ \\
Eating disorder & $324(55.6 \%)$ & $147(61.0 \%)$ & $177(51.8 \%)$ \\
Tobacco use & $353(77.7 \%)$ & $210(87.2 \%)$ & $243(71.1 \%)$ \\
Television/screen time & $454(77.8 \%)$ & $158(65.5 \%)$ & $296(86.6 \%)$ \\
Exercise & $559(95.9 \%)$ & $226(93.7 \%)$ & $333(97.4 \%)$ \\
Recommended practice ${ }^{\mathrm{b}}$ & $193(33.1 \%)$ & $80(33.2 \%)$ & $113(33.0 \%)$ \\
\hline
\end{tabular}

${ }^{a}$ Physicians who replied always or often; ${ }^{b}$ Physicians who adhered to 1998 Pediatric Obesity Expert Committee recommended practice. 
Table 31. Behavioral History Assessment of Overweight Children and Adolescents by Physicians Based on State Childhood

Obesity Prevalence Rates

\begin{tabular}{|c|c|c|c|c|c|c|}
\hline \multirow{2}{*}{ Component } & \multicolumn{3}{|c|}{$\begin{array}{c}\text { States with Below National Average } \\
\text { Childhood Obesity Prevalence }{ }^{\mathrm{a}} \\
\text { (CO and MA) }\end{array}$} & \multicolumn{3}{|c|}{$\begin{array}{c}\text { States with Above National Average } \\
\text { Childhood Obesity Prevalence }{ }^{\mathrm{a}} \\
\text { (AL and WV) }\end{array}$} \\
\hline & $\begin{array}{c}\text { All } \\
\text { Physicians }^{b} \\
(\mathbf{n}=\mathbf{3 9 2}) \\
\end{array}$ & $\begin{array}{c}\text { Family } \\
\text { Physicians }^{b} \\
(\mathrm{n}=\mathbf{1 4 5}) \\
\end{array}$ & $\begin{array}{l}\text { Pediatricians }^{b} \\
\quad(n=247)\end{array}$ & $\begin{array}{c}\text { All } \\
\text { Physicians }^{b} \\
(n=191)\end{array}$ & $\begin{array}{l}\text { Family } \\
\text { Physicians } \\
(\mathbf{n}=96)\end{array}$ & $\begin{array}{c}\text { Pediatricians } \\
\quad(n=95)\end{array}$ \\
\hline Diet history & $375(96.2 \%)$ & $133(93.0 \%)$ & $242(98.0 \%)$ & $168(88.4 \%)$ & $78(81.3 \%)^{\S}$ & $90(95.7 \%)$ \\
\hline Depression & $225(57.4 \%)$ & $90(62.1 \%)$ & $135(54.7 \%)$ & $92(48.7 \%)$ & $52(54.7 \%)$ & $40(42.6 \%)$ \\
\hline Eating disorder & $221(56.4 \%)$ & $91(62.8 \%)$ & $130(52.6 \%)$ & $103(53.9 \%)$ & $56(58.3 \%)$ & $47(49.5 \%)$ \\
\hline Tobacco use & $311(79.5 \%)$ & $127(88.2 \%)$ & $184(74.5 \%)$ & $142(74.3 \%)$ & $83(86.5 \%)$ & $59(62.1 \%)^{*}$ \\
\hline $\begin{array}{l}\text { Television/screen } \\
\text { time }\end{array}$ & $324(82.9 \%)$ & $102(70.8 \%)$ & $222(89.9 \%)$ & $130(68.1 \%)$ & $56(58.3 \%)$ & $74(77.9 \%)^{*}$ \\
\hline Exercise & $383(98.7 \%)$ & $139(97.9 \%)$ & $244(99.2 \%)$ & $176(93.1 \%)$ & $87(90.6 \%)^{\S}$ & $89(95.7 \%)$ \\
\hline $\begin{array}{l}\text { Recommended } \\
\text { practice }^{\text {c }}\end{array}$ & $144(37.1 \%)$ & $55(39.0 \%)$ & $89(36.0 \%)$ & $49(25.8 \%)$ & $25(26.0 \%)$ & $24(25.5 \%)$ \\
\hline
\end{tabular}

${ }^{\S}$ Significant at $p<0.05$ between family physicians in the two groups. ${ }^{*}$ Significant at $p<0.05$ between pediatricians in the two

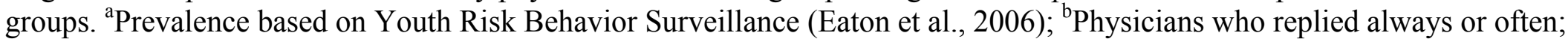
${ }^{\mathrm{c}}$ Physicians who adhered to 1998 Pediatric Obesity Expert Committee recommended practice. $\mathrm{AL}=\mathrm{Alabama}$; $\mathrm{CO}=\mathrm{Colorado}$; MA = Massachusetts; WV = West Virginia 


\section{CHAPTER FIVE}

\section{DISCUSSION AND CONCLUSIONS}

This chapter discusses the results obtained in this study and draws conclusions based on those results. Limitations of the study and recommendations made for future research are addressed.

\section{Discussion for Objective I}

According to the Theory of Planned Behavior (TPB), an individual's intention to perform a behavior is predicted by his/her attitude toward the behavior, perceived societal pressure to perform the given behavior, and perceived degree of control over the behavior. There are both direct and indirect measures for each of three constructs of the TPB. The direct measures are generic in nature, and are applicable across different behaviors. In contrast, indirect measures are belief based and are behavior specific. Correlation between the direct and indirect measures can be used to establish convergent validity between the two measures for each construct (Francis et al., 2004b).

This study tested the relation between the direct and the indirect measures of attitude, subjective norm, and perceived behavioral control, respectively, using correlation analyses. The null hypotheses $1.1 \mathrm{a}, 1.1 \mathrm{~b}$, and $1.1 \mathrm{c}$ were rejected based on the statistically significant correlations observed between the direct and the indirect measures of attitude, subjective norm, and perceived behavioral control, respectively. These results demonstrate that: a) physician attitude towards measuring BMI was determined both by their beliefs that measuring BMI results in a given set of outcomes and their beliefs concerning evaluations of those outcomes, b) 
subjective norms was influenced by physicians beliefs related to whether specific others (Centers for Disease Control and Prevention [CDC], American Academy of Pediatrics [AAP], and American Academy of Family Physicians [AAFP]) wanted them to measure BMI in children and adolescents and their motivation to comply with those specific others, and c) perceived behavioral control was determined jointly by physicians control belief and power of that control belief in influencing behavior.

Over the past few years, professional and policy groups have emphasized the need to measure BMI in children and adolescents in routine primary care. However, $40 \%$ of the surveyed physicians believed that the use of BMI results in false-positive results when used to determine weight status in muscular patients and $22.3 \%$ believed that BMI is not an adequate measure of body fat in children and adolescents. As with all screening methods, it is likely that BMI leads to a few false-positive results, wherein certain tall and muscular children have a high BMI but not an excess body fat (Young, 2005). Studies have shown the CDC overweight classification criteria based on BMI to have high sensitivity and specificity (Zimmermann, Gubeli, Puntener, \& Molinari, 2004). Moreover, studies have shown a close association of BMI with percentage body fat, total body fat, and abdominal fat mass in children (Dencker, Thorsson, Linden, Wollmer, Andersen, \& Karlsson, 2007). Results of these studies emphasize that BMI is a valid and fairly accurate screening tool; however, it is important to consider that BMI is not a diagnostic tool, and any concerns physicians have about the false-positive results associated with BMI use in muscular children could be alleviated by performing skinfold thickness measurements.

Roughly one-third of physicians believed that measuring BMI will lengthen the consultation time. The issue of lack of time could be resolved with the use of electronic medical 
record (EMR), which automatically calculates BMI. Focus groups of healthcare providers (including family physicians and pediatricians) conducted by Flower, Perrin, Viadro, and Ammerman (2007) highlighted that providers consider EMR as a facilitator of BMI use. As physicians practice transitions towards an EMR system, the use of BMI would become easier and less time intensive.

With respect to their normative beliefs, physicians strongly agreed to the fact that the $\mathrm{CDC}$ and the AAP/AAFP endorse the use of BMI in identifying overweight children and adolescents. Given that the surveyed physicians were strongly motivated to comply with these public and professional organizations, policy statement endorsing the use of BMI, like the one issued by the AAP (Krebs \& Jacobson, 2003) is a step in the right direction.

The study also highlighted the importance of support staff in physicians' intention to use BMI. Approximately $55 \%$ of physicians reported that they are unlikely to measure BMI in the absence of adequate support staff. Support staff constitutes an important component of a physicians' office. A lack of adequate support staff could impede physicians' adherence to general guidelines and recommendations. For example, lack of support staff has been cited as a barrier by family physicians and pediatricians in their domestic violence screening behavior (Erickson, Hill, \& Siegel, 2001). Though interventions cannot impact the adequacy of support staff in a physician office, they could be targeted towards increasing administrative and office staff involvement in physicians' use of BMI. Greater involvement of support staff has been effective in physician counseling for smoking cessation (Duncan, Stein, \& Cummings, 1991), and could be helpful in increasing physicians' use of BMI.

The Theory of Reasoned Action (TRA) and the Theory of Planned Behavior (TPB) model successfully predicted physicians' intentions to measure BMI. These models were able to 
explain up to $51.2 \%$ of the variance in behavioral intention, resulting in the rejection of null Hypothesis 1.2 and 1.3, respectively. As explained by the theory, all three theoretical constructs, attitude, subjective norm, and perceived behavioral control were significant predictors of intention in this study.

The two constructs of TRA, attitude and subjective norm, explained up to $49.7 \%$ of the variance in behavioral intention. Addition of the perceived behavioral control construct led to a significant but small increase in intention variance explained. Ajzen (1985) hypothesized little difference between the TRA and TPB for behaviors that are under volitional control. A review of ten different behaviors by Madden and colleagues (1992) highlighted that the addition of perceived behavioral control increased the intention variance $\left(\mathrm{R}^{2}\right)$ by 0.01 for behaviors under high volitional control and 0.28 for behaviors under less volitional control. The addition of perceived behavioral control increased the intention variance $\left(\mathrm{R}^{2}\right)$ by 0.013 in this study. The magnitude of difference in the variance in intention explained by the TRA and TPB was small. This finding suggests that measuring BMI is perceived by physicians to be under high volitional control and that control factors have a small impact on physicians' intentions to measure BMI.

Among the three constructs, attitude, subjective norm, and perceived behavioral control in the direct measures TPB model, attitude was the strongest predictor of intention. However, in the indirect measures TPB model, subjective norm had the strongest influence on intention. This result is in contrast to most TPB studies, which have found subjective norm to have less important influence on intention as compared to attitude or perceived behavioral control (Godin \& Kok, 1996). It is possible that not all behavioral and control beliefs associated with physicians BMI measurement behavior were identified during elicitation interviews, thereby resulting in lower influence of these constructs on intention. The increasing emphasis on the use of BMI by 
professional and public agencies could also explain the greater role of referents on physician intentions to measure BMI. The strong influence of subjective norm on intention could be attributed to the behavior under investigation. Though several organizations endorse the use of BMI in children and adolescents, its use remains controversial (Lindsay, Hanson, Roumain, Ravussin, Knowler, \& Tataranni, 2001). As is the case with using BMI, studies have suggested that subjective norm might be more influential in predicting intention when the behavior in question is controversial (Puffer \& Rashidian, 2004).

According to the TPB, the intention variance explained should not significantly increase with the inclusion of additional variables. However, over the past few years, several studies have made additions to the TPB model to increase its predictive ability. The inclusion of past behavior has received considerable attention in this regard (Conner \& Armitage, 1998). Studies have demonstrated the usefulness of past behavior in predicting physicians' intention to perform a given behavior (Millstein, 1996; Faulkner \& Biddle, 2001; Walker et al, 2001). Similar results were obtained in this study, wherein addition of past behavior significantly increased the proportion of variance explained by the TPB model, and led to the rejection of Hypothesis 1.4. In both the direct and the indirect measures TPB model in this study, respectively, addition of past behavior significantly increased the intention variance.

Physicians who had been measuring BMI in the past had higher intention scores than those who had not been measuring BMI. This suggests that previous experience with BMI measurement may be an important predictor of future intentions. Development of an automatic cognitive response to an environmental stimulus could partly explain this association between past behavior and intention (Ronis, Yates, \& Kirscht, 1989; Ouellette \& Wood, 1998). Physicians routinely use screening methods to identify weight status of patients, which could 
cause cognitive processes which guide decision-making related to the use of a particular obesity identification screening tool to become automatic.

\section{Discussion for Objective II}

The study highlighted significant behavioral and normative belief differences between intenders and non-intenders, which lead to the rejection of Hypothesis 2.1. Belief differences between intenders and non-intenders have also been reported in previous studies that have used the TPB model (Walker et al., 2001). Walker and colleagues (2001) used the TPB model to determine physicians' intention to prescribe antibiotics. The differences between the intenders and non-intenders in this study are noteworthy and could be used to develop strategies for changing physicians' beliefs about using BMI.

It was not surprising that intenders held more positive beliefs about the outcomes of measuring BMI than non-intenders. Intenders had significantly higher scores than non-intenders for all except one of the behavioral beliefs. There was no difference between intenders and nonintenders in terms of their belief that using BMI could lead to false-positive results. As has been discussed in the previous section, physicians generally considered BMI to have low specificity, which could explain this lack of difference between intenders and non-intenders. This perception is contrary to the result of studies that have shown BMI to have high specificity (Malina \& Katzmarzyk, 1999). For weight classification in muscular children, physicians could use other screening methods in addition to BMI.

Similar to behavioral beliefs, there were significant differences between intenders and non-intenders with respect to normative beliefs. In contrast to non-intenders, physicians who intended to measure BMI strongly believed that the CDC and the AAP/AAFP endorse the use of 
BMI for identifying overweight children and adolescents. Based on this result, it could be implied that non-intenders were unaware of the fact that the $\mathrm{CDC}$, the AAP, and the AAFP endorse the use of BMI. In their study, Flower and colleagues (2007) found that physicians were unaware of AAP recommendations to assess BMI on a yearly basis. To increase physicians' use of BMI, it is essential that physicians' awareness of policy statements like the one issued by the AAP that recommends periodic BMI use is increased through communication programs.

\section{Discussion for Objective III}

The study also identified physicians' practice related to identification and evaluation of overweight children and adolescents. Similar to the results reported in previous studies (Barlow et al., 2002; Kolagotla \& Adams, 2004; Perrin et al., 2004; Louthan et al., 2005), this study found a lack of any systematic approach toward obesity identification, with physicians using multiple screening methods to identify overweight children and adolescents. In their study, Louthan and colleagues (2005) showed that the use of weight classification methods like clinical impression, weight-for-age, and weight-for-height percentile by physicians leads to an underdiagnosis of overweight children. Despite their disadvantages (Barlow et al., 2002), clinical impression, weight-for-height percentile, and weight-for-age percentile were the commonly used methods of obesity identification among this study sample.

Among the surveyed physicians, only 31.2\% reported "always" using, 25.7\% reported "often" using, and 9.6\% reported "never" using BMI percentile to identify overweight children and adolescents. Of those physicians who frequently (always or often) used BMI percentile, $33 \%$ used a cut-off value of greater than $75^{\text {th }}$ percentile or greater than $85^{\text {th }}$ percentile for sex and age to classify a child as overweight. Based on BMI-for-age percentile charts, children with 
BMI greater than the $95^{\text {th }}$ percentile are classified as overweight (Himes \& Dietz, 1994; Barlow \& Dietz, 1998). Therefore, physicians were classifying their pediatric and adolescent patients as overweight, when in fact they were not. This misclassification of healthy and at risk of being overweight children as overweight can be reduced by increasing physician awareness of the appropriate cut-off values.

As compared to family physicians, more pediatricians were frequently using BMI as an obesity identification tool. This is in contrast to the result reported by Kolagotla and Adams (2004), wherein more family physicians were using BMI than pediatricians. In contrast to this study, Kolagotla and Adams (2004) conducted a national survey of physicians, which could explain the difference in results between the two studies. This difference in BMI use between family physicians and pediatricians could also be explained by the position of their referent professional organizations with respect to using BMI. Although both the AAP and the AAFP endorse the use of BMI as a screening tool to identify overweight children and adolescents (Moyer, Klein, Ockene, Teutsch, Johnson, \& Allan, 2005), only the AAP has a written policy statement to that effect. The AAP released a policy statement in 2003 on the prevention of pediatric obesity, wherein periodic BMI use is recommended for childhood obesity identification (Krebs \& Jacobson, 2003). This study did not identify any such policy statement from the AAFP, which could explain the lower frequency of BMI use by family physicians.

Another interesting finding was the higher frequency of BMI use by pediatricians in this study as compared to the previously reported use of BMI by pediatricians (Barlow et al., 2002; Kolagotla \& Adams, 2004; Perrin et al., 2004; Louthan et al., 2005; Gilbert \& Fleming, 2006). Higher frequency of BMI use by pediatricians in this study as compared to previous studies could be attributed to the fact that all except one of these studies were conducted before the 
release of the AAP policy statement. The most recent data regarding frequency of BMI use by pediatricians was provided in the study by Gilbert and Fleming (2006). Only a third of the pediatricians in that study reported plotting BMI on a routine basis as compared to $72.8 \%$ in this study. The low frequency of BMI use by pediatricians in the Gilbert and Fleming (2006) study could be attributed to its low sample size (24 respondents).

One of the most common causes of insulin resistance in children and adolescents is obesity (Ornstein \& Jacobson, 2006), but less than $20 \%$ of physicians in the study frequently evaluated insulin levels in overweight children and adolescents. In terms of medical history and physical examination, the majority of physicians routinely checked blood pressure in overweight children; however, only one-fifth of physicians routinely assessed overweight children for genetic disorders. Studies have shown genetics to play an important role in the etiology of childhood obesity (Loos \& Bouchard, 2003). In order to appropriately treat an overweight child, physicians need to identify the underlying cause of obesity. Without adequate assessment of an obese child, the treatment strategy adopted may have minimal effects.

A majority of physicians routinely assessed history of diet, exercise, television viewing, and tobacco use in overweight children. However, less than $60 \%$ of physicians frequently assessed overweight children for history of depression and eating disorders. Depression can be both a cause of obesity and an associated condition in overweight children (Sjoberg et al., 2005; Pine et al., 2001; Goodman \& Whitaker, 2002). Abnormal eating behaviors in adolescents such as dietary restraint, self-labeled dieting, and appetite suppressant use could also result in weight gain (Stice et al., 1999). It is therefore essential that physicians consider the role of these psychological aspects while evaluating an overweight child. 
A very notable result of the study was the variation in childhood obesity identification and evaluation practices between physicians practicing in states with below national average childhood obesity prevalence rates (Colorado and Massachusetts) and those practicing in states with above national average childhood obesity prevalence rates (Alabama and West Virginia). Researchers have debated the geographic variation in physicians practice patterns (Wennberg, 1998). This variation in practice by state could be attributed to reasons such as physician training and insurance coverage.

Differences in physicians' education and training could lead to a variation in their BMI percentile chart use and evaluation of overweight children. However, in the absence of any documented evidence, the role of physician training on their identification and evaluation practices in overweight children and adolescents needs to be verified. Variation in insurance coverage could also influence physicians' decision to use BMI. Anecdotal evidence suggests that physician's reimbursement for well child visits is increasingly being tied to preventive measures, like use of BMI. Differences in physicians' reimbursement rates could influence their decision to use BMI percentile charts and their evaluation practices. It will be interesting to look at the urban-rural variation and the influence of patient demographics on physicians' childhood obesity management practice.

Finally, the low levels of adherence of physicians to the 1998 Pediatric Obesity Expert Committee recommendations on evaluation of overweight children seen in this study could be because of their lack of awareness of these recommendations. In the study conducted by Kolagotla and Adams (2004), physicians reported unfamiliarity with the 1998 Pediatric Obesity Expert Committee recommendations on evaluation of an overweight child. Though not assessed 
in this study, it is possible that physicians are still unaware of those recommendations, which could serve as a barrier to their evaluation practices in overweight children and adolescents.

\section{Conclusions}

Given the limited success of interventions in controlling childhood obesity, an increasing role of physicians in early identification and evaluation of overweight children is warranted. This study highlights the usefulness of two behavioral models, Theory of Reasoned Action (TRA) and Theory of Planned Behavior (TPB), in understanding physicians' beliefs related to their use of BMI in identifying overweight children. A theoretically based understanding of physicians' beliefs related to BMI use as a childhood obesity screening tool can guide and reinforce appropriate interventions directed towards increasing physicians' management of childhood obesity.

The study highlighted a low frequency of BMI use by physicians, which could result in underdiagnosis of an overweight child. Low levels of BMI use by physicians could impede the childhood obesity prevention efforts being implemented by the states that were studied.

Moreover, the study highlights the variation in physicians practice based on state obesity prevalence rates. To improve obesity treatment, physicians need to do more than just timely identify an overweight child. Physicians need to thoroughly evaluate an overweight child. The results of this study suggest that physicians are not adequately adhering to the 1998 Pediatric Obesity Expert Committee recommendations. The information collected in this study could be used in designing and delivering an effective childhood obesity management strategy based on physician specialty and location of practice. 


\section{Study Limitations}

There were certain limitations associated with this study. These limitations are discussed below:

A self-administered mail survey was used to collect the desired information. The limitations inherent of any mail surveys such as lower response rate, respondents misinterpreting the instructions or items, and difference between respondents and non-respondents could have affected the study results.

Physicians from only four states, Alabama (AL), Colorado (CO), Massachusetts (MA), and West Virginia (WV), were surveyed. Therefore, the study results cannot be generalized to physicians practicing in other states.

Elicitation interviews were conducted to identify physicians' belief related to BMI measurement. However, the low internal consistency among theory based items on the questionnaire suggested an absence of complete range of attitudinal and control beliefs.

As is a limitation with TRA and TPB studies, social desirability and acquiescence of the survey responders could have introduced a bias into the study results. Physicians' responses on the questionnaire could have been influenced by self-reporting bias. It is possible that physicians might have falsely reported that they intend to measure BMI and that they frequently perform medical evaluations in overweight children in order to appear socially desirable. Based on sample size, the study had adequate power (greater than 0.9 ) for all the regression analyses that were conducted to explain physicians intention to measure BMI. However, the intentions of physicians in the sample may not be representative of the actual intention levels of physicians. 


\section{Recommendations for Future Research}

One of the limitations of the study was the low internal consistency among theory based items. Future studies could conduct elicitation interviews of more physicians and also conduct focus groups to elicit behavioral and control beliefs associated with physicians' use of BMI.

The study highlighted the role of past behavior in predicting intention. However, given the cross-sectional design of the study, the role of past behavior in predicting future performance of the behavior under investigation could not be determined. A prospective analysis could be conducted to determine whether past behavior predicts future behavior.

It is likely that theoretical constructs affect physicians' intention to measure BMI through interconnected pathways. Future studies could use path analysis to detect these pathways and their significance in predicting intention.

Although the TRA and the TPB served as useful models to study physician intentions to measure BMI, they do not consider the role of economic or environmental barriers in physicians' use of BMI. Future studies could identify these barriers and determine their influence on intentions.

This study used a self-administered questionnaire to determine physicians practice. Moreover, physicians' intention to use BMI as a screening tool for obesity identification may not always translate into actual behavior. To reduce the effect of social desirability in physicians' response and to assess whether intention translates into behavior, medical charts could be reviewed in addition to using a self-administered questionnaire.

Physicians in only four states were surveyed in this study. Future studies could study difference in physicians practice patterns across the nation and determine the impact of patient demographics on physicians practice. 


\section{BIBLIOGRAPHY}

American Academy of Pediatrics (AAP). (2001). Children, adolescents, and television. Pediatrics, 107, 423-426.

Ajzen, I. (1985). From intentions to actions: A theory of planned behavior. In: Action control: From cognition to behavior, J. Kuhl \& J. Beckman, eds. Springer-Verlag: Herdelberg, 1139, 200-301.

Ajzen, I. (1988). Attitudes, personality, and behavior. Milton-Keynes, England: Open University Press \& Chicago, IL: Dorsey Press.

Ajzen, I. (1991). The theory of planned behavior. OBHDP, 50, 179-211.

Ajzen, I. (2006a). Construction of a standard questionnaire for the theory of planned behavior. Accessed November 30, 2006, from http://www.unix.oit.umass.edu/ aizen.

Ajzen, I. (2006b). The Theory of Planned Behavior. TPB Diagram. Accessed November 30, 2006, from http://www-unix.oit.umass.edu/ aizen/tpb.diag.html\#null-link.

Ajzen, I. \& Fishbein, M. (1977). Attitude-behavior relations: A theoretical analysis and review of empirical research. Psychol Bull., 84, 888-918.

Ajzen, I. \& Fishbein, M. (1980). Understanding attitudes and predicting human behavior. Englewood Cliffs, New Jersey: Prentice Hall.

Ajzen, I. \& Madden, T. (1986). Prediction of goal-directed behavior: attitudes, behavior and perceived behavioral control. J Exp Soc Psychol., 22, 453-474.

Akinbami, L. J. \& Schoendorf, K. C. (2002). Trends in childhood asthma: prevalence, health care utilization, and mortality. Pediatrics, 110, 315-322.

Andersen, R. E., Crespo, C. J., Bartlett, S. J., Cheskin, L. J., \& Pratt, M. (1998). Relationship of physical activity and television watching with body weight and level of fatness among 
children: results from the Third National Health and Nutrition Examination Survey. JAMA, 279, 938-942.

Armitage, C. J., \& Connor, M. (1999). The theory of planned behavior: Assessment of predictive validity and "perceived control." Br J Soc Psychol., 38, 35-54.

Armitage, C. J. \& Connor, M. (2001). Efficacy of the Theory of Planned Behaviour: a metaanalytic review. Br J Soc Psychol., 40, 471-499.

Bagozzi, R. P. \& Kimmel, S. K. (1995). A comparison of leading theories for the prediction of goal-directed behaviours. Br J Soc Psychol., 34, 437-461.

Barlow, S. E. \& Dietz, W. H. (1998). Obesity evaluation and treatment: Expert Committee recommendations. The Maternal and Child Health Bureau, Health Resources and Services Administration and the Department of Health and Human Services. Pediatrics, 102, E29.

Barlow, S. E., Dietz, W. H., Klish, W. J., \& Trowbridge, F. L. (2002). Medical evaluation of overweight children and adolescents: reports from pediatricians, pediatric nurse practitioners, and registered dietitians. Pediatrics, 110, 222-228.

Baskin, M. L., Ard, J., Franklin, F., \& Allison, D. B. (2005). Prevalence of obesity in the United States. Obes Rev., 6, 5-7.

Beatty, P. C. \& Beatty, S. F. (2004). Anaesthetists' intentions to violate safety guidelines. Anaesthesia, 59, 528-540.

Beeman G, Levy M, Hare M, \& Stender S. (2004). Appearance of Body Morphology: Poor Screening Tool for Recognizing Risk of Overweight African American Children in an Urban Pediatric Clinic. Presented to 2004 Pediatric Academic Societies’Meeting, San Francisco, CA.

Belamarich, P. F., Luder, E., Kattan, M., Mitchell, H., Islam, S., Lynn, H. et al. (2000). Do obese inner-city children with asthma have more symptoms than nonobese children with asthma? Pediatrics, 106, 1436-1441. 
Berkey, C. S., Rockett, H. R., Field, A. E., Gillman, M. W., Frazier, A. L., Camargo, C. A., Jr. et al. (2000). Activity, dietary intake, and weight changes in a longitudinal study of preadolescent and adolescent boys and girls. Pediatrics, 105, E56.

Berkey, C. S., Rockett, H. R., Gillman, M. W., \& Colditz, G. A. (2003). One-year changes in activity and in inactivity among 10- to 15 -year-old boys and girls: relationship to change in body mass index. Pediatrics, $111,836-843$.

Binkley, J. K., Eales, J., \& Jekanowski, M. (2000). The relation between dietary change and rising US obesity. Int J Obes Rela Metab Disord., 24, 1032-1039.

Bonetti, D., Eccles, M., Johnston, M., Steen, N., Grimshaw, J., Baker, R. et al. (2005). Guiding the design and selection of interventions to influence the implementation of evidencebased practice: an experimental simulation of a complex intervention trial. Soc Sci Med.., $60,2135-2147$.

Boon, C. S. \& Clydesdale, F. M. (2005). A review of childhood and adolescent obesity interventions. Crit Rev Food Sci Nutr., 45, 511-525.

Borjeson, M. (1976). The aetiology of obesity in children. A study of 101 twin pairs. Acta Paediatr Scand.., 65, 279-287.

Boutin, P. \& Froguel, P. (2001). Genetics of human obesity. Best Pract Res Clin Endocrinol Metab, 15, 391-404.

Braet, C., Mervielde, I., \& Vandereycken, W. (1997). Psychological aspects of childhood obesity: a controlled study in a clinical and nonclinical sample. J Pediatr Psychol., 22, $59-71$.

Bray, G. A. (2004). Obesity is a chronic, relapsing neurochemical disease. Int J Obes Relat Metab Disord., 28, 34-38.

Burniat W, Cole TJ, Lissau I, Poskitt E (2002). Child and adolescent obesity. 1st ed. Cambridge, United Kingdom: Cambridge University Press. 
Caprio, S., Bronson, M., Sherwin, R. S., Rife, F., \& Tamborlane, W. V. (1996). Co-existence of severe insulin resistance and hyperinsulinaemia in pre-adolescent obese children. Diabetologia, 39, 1489-1497.

Castro-Rodriguez, J. A., Holberg, C. J., Morgan, W. J., Wright, A. L., \& Martinez, F. D. (2001). Increased incidence of asthmalike symptoms in girls who become overweight or obese during the school years. Am J Respir Crit Care Med., 163, 1344-1349.

Cavadini, C., Siega-Riz, A. M., \& Popkin, B. M. (2000). US adolescent food intake trends from 1965 to 1996. West J Med., 173, 378-383.

Chan, J. M., Rimm, E. B., Colditz, G. A., Stampfer, M. J., \& Willett, W. C. (1994). Obesity, fat distribution, and weight gain as risk factors for clinical diabetes in men. Diabetes Care, 17, 961-969.

Cohen, J. (1977). Statistical power analysis for the behavioral sciences. New York: Academic Press.

Colditz, G. A., Willett, W. C., Rotnitzky, A., \& Manson, J. E. (1995). Weight gain as a risk factor for clinical diabetes mellitus in women. Ann Intern Med., 122, 481-486.

Cole, T. J. (1979). A method for assessing age-standardized weight-for-height in children seen cross-sectionally. Ann Hum Biol., 6, 249-268.

Comuzzie, A. G. \& Allison, D. B. (1998). The search for human obesity genes. Science, 280, 1374-1377.

Conner, M., \& Armitage, C. J. (1998). Extending the theory of planned behavior: A review and avenues for future research. J Appl Soc Psychol., 28, 1429-1464.

Coon, K. A., Goldberg, J., Rogers, B. L., \& Tucker, K. L. (2001). Relationships between use of television during meals and children's food consumption patterns. Pediatrics, 107, E7.

Coon, K. A. \& Tucker, K. L. (2002). Television and children's consumption patterns. A review of the literature. Minerva Pediatr., 54, 423-436. 
Connor, M., \& Sparks, P. (1996). The theory of planned behavior and health behaviors. In M. Connor, \& P. Norman's (Eds.), Predicting health behavior (pp. 121-162). Buckingham: Open University Press.

Cooper, D. M. (1994). Evidence for and mechanisms of exercise modulation of growth--an overview. Med Sci Sports Exerc., 26, 733-740.

Crespo, C. J., Smit, E., Troiano, R. P., Bartlett, S. J., Macera, C. A., \& Andersen, R. E. (2001). Television watching, energy intake, and obesity in US children: results from the third National Health and Nutrition Examination Survey, 1988-1994. Arch Pediatr Adolesc Med., 155, 360-365.

Daniels, S. R. (2006). The consequences of childhood overweight and obesity. Future Child, 16, 47-67.

Dencker, M., Thorsson, O., Linden, C., Wollmer, P., Andersen, L. B., \& Karlsson, M. K. (2007). BMI and objectively measured body fat and body fat distribution in prepubertal children. Clin Physiol Funct Imaging, 27, 12-16.

Dietz, W. H. \& Robinson, T. N. (1998). Use of the body mass index (BMI) as a measure of overweight in children and adolescents. J Pediatr., 132, 191-193.

Dietz, W. H. \& Bellizzi, M. C. (1999). Introduction: the use of body mass index to assess obesity in children. Am J Clin Nutr., 70, 123S-125S.

Dorsey, K. B., Wells, C., Krumholz, H. M., \& Concato, J. C. (2005). Diagnosis, evaluation, and treatment of childhood obesity in pediatric practice. Arch Pediatr Adolesc Med., 159, 632-638.

Duncan, C., Stein, M. J., \& Cummings, S. R. (1991). Staff involvement and special follow-up time increase physicians' counseling about smoking cessation: a controlled trial. Am J Public Health, 81, 899-901.

Eaton, D. K., Kann, L., Kinchen, S., Ross, J., Hawkins, J., Harris, W. A. et al. (2006). Youth risk behavior surveillance--United States, 2005. MMWR Surveill Summ., 55, 1-108. 
Eisenmann, J. C., Bartee, R. T., \& Wang, M. Q. (2002). Physical activity, TV viewing, and weight in U.S. youth: 1999 Youth Risk Behavior Survey. Obes Res., 10, 379-385.

Ellis, K. J., Abrams, S. A., \& Wong, W. W. (1999). Monitoring childhood obesity: assessment of the weight/height index. Am.J Epidemiol., 150, 939-946.

Epstein, L. H., Wing, R. R., \& Valoski, A. (1985). Childhood obesity. Pediatr Clin North Am., 32, 363-379.

Epstein, L. H., Paluch, R. A., Consalvi, A., Riordan, K., \& Scholl, T. (2002). Effects of manipulating sedentary behavior on physical activity and food intake. $J$ Pediatr., 140 , $334-339$.

Erdfelder, E., Faul, F. \& Buchner, A. (1996). GPOWER: A general power analysis program. Behavior Research Methods, Instruments, \& Computers, 28, 1-11.

Erermis, S., Cetin, N., Tamar, M., Bukusoglu, N., Akdeniz, F., \& Goksen, D. (2004). Is obesity a risk factor for psychopathology among adolescents? Pediatr Int., 46, 296-301.

Erickson, M. J., Hill, T. D., \& Siegel, R. M. (2001). Barriers to domestic violence screening in the pediatric setting. Pediatrics, 108, 98-102.

Faulkner, G. \& Biddle, S. (2001). Predicting physical activity promotion in health care settings. Am J Health Promot., 16, 98-106.

Figueroa-Colon, R., Franklin, F. A., Lee, J. Y., Aldridge, R., \& Alexander, L. (1997). Prevalence of obesity with increased blood pressure in elementary school-aged children. South Med J., 90, 806-813.

Fiorotto, M. L., Cochran, W. J., Funk, R. C., Sheng, H. P., \& Klish, W. J. (1987). Total body electrical conductivity measurements: effects of body composition and geometry. Am J Physiol., 252, R794-R800.

Fishbein, M. (1967). Attitude and the prediction of behavior. In M. Fishbein (Ed.), Readings in attitude theory and measurement (pp. 477-492). New York: Wiley. 
Fishbein, M. (1993). Introduction. In D. J. Terry, C. Gallois, \& M. McCamish (Eds.), The theory of reasoned action: Its application to AIDS-preventative behavior (pp. xv-xxv). Oxford, UK: Pergamon.

Fishbein, M. \& Ajzen, I. (1975). Belief, attitude, intention, and behavior: An introduction to theory and research, Reading, MA: Addison-Wesley.

Flegal, K. M., Wei, R., \& Ogden, C. (2002). Weight-for-stature compared with body mass indexfor-age growth charts for the United States from the Centers for Disease Control and Prevention. Am J Clin Nutr., 75, 761-766.

Flower, K. B., Perrin, E. M., Viadro, C. I., \& Ammerman, A. S. (2007). Using body mass index to identify overweight children: barriers and facilitators in primary care. Ambul Pediatr., 7, 38-44.

Fomon, S. J., Haschke, F., Ziegler, E. E., \& Nelson, S. E. (1982). Body composition of reference children from birth to age 10 years. Am J Clin Nutr., 35, 1169-1175.

Francis, J., Johnston, M., Eccles, M., Grimshaw, J., Kaner, E. (2004a). Measurement Issues in the theory of planned behavior. Accessed January 10, 2007 from http://www.rebeqi.org/ViewFile.aspx?itemID=219

Francis, J., Eccles, M., Johnston, M., Walker, A., Grimshaw, J., Foy, R., Kaner, E., Smith, L., \& Bonetti D. (2004b). Constructing questionnaires based on the theory of planned behavior: A manual for health services researchers. Accessed January 30, 2007 from http://www.rebeqi.org/?pageID $=34 \&$ ItemID $=72$

Freedman, D. S., Dietz, W. H., Srinivasan, S. R., \& Berenson, G. S. (1999). The relation of overweight to cardiovascular risk factors among children and adolescents: the Bogalusa Heart Study. Pediatrics, 103, 1175-1182.

Freedman, D. S., Khan, L. K., Dietz, W. H., Srinivasan, S. R., \& Berenson, G. S. (2001). Relationship of childhood obesity to coronary heart disease risk factors in adulthood: the Bogalusa Heart Study. Pediatrics, 108, 712-718. 
French, S. A., Story, M., Neumark-Sztainer, D., Fulkerson, J. A., \& Hannan, P. (2001). Fast food restaurant use among adolescents: associations with nutrient intake, food choices and behavioral and psychosocial variables. Int J Obes Relat Metab Disord., 25, 1823-1833.

Garn, S. M. \& Clark, D. C. (1976). Trends in fatness and the origins of obesity Ad Hoc Committee to Review the Ten-State Nutrition Survey. Pediatrics, 57, 443-456.

Garrow, J. S. \& Webster, J. (1985). Quetelet's index (W/H2) as a measure of fatness. Int J Obes., 9, $147-153$.

Gidding, S. S., Leibel, R. L., Daniels, S., Rosenbaum, M., Van, H. L., \& Marx, G. R. (1996). Understanding obesity in youth. A statement for healthcare professionals from the Committee on Atherosclerosis and Hypertension in the Young of the Council on Cardiovascular Disease in the Young and the Nutrition Committee, American Heart Association. Writing Group. Circulation, 94, 3383-3387.

Gilbert, M. J. \& Fleming, M. E. (2006). Pediatricians' approach to obesity prevention counseling with their patients. WMJ., $105,26-31$.

Godin, G. \& Kok, G. (1996). The theory of planned behavior: a review of its applications to health-related behaviors. Am J Health Promot., 11, 87-98.

Goodman, E. \& Whitaker, R. C. (2002). A prospective study of the role of depression in the development and persistence of adolescent obesity. Pediatrics, 110, 497-504.

Goran, M. I., Kaskoun, M. C., Carpenter, W. H., Poehlman, E. T., Ravussin, E., \& Fontvieille, A. M. (1993). Estimating body composition of young children by using bioelectrical resistance. J Appl Physiol., 75, 1776-1780.

Goran, M. I. \& Gower, B. A. (1998). Abdominal obesity and cardiovascular risk in children. Coron Artery Dis., 9, 483-487.

Goran, M. I., Toth, M. J., \& Poehlman, E. T. (1998). Assessment of research-based body composition techniques in healthy elderly men and women using the 4-compartment model as a criterion method. Int J Obes Relat Metab Disord., 22, 135-142. 
Gordon-Larsen, P., Adair, L. S., \& Popkin, B. M. (2002). Ethnic differences in physical activity and inactivity patterns and overweight status. Obes Res., 10, 141-149.

Guo, S. S., Chumlea, W. C., Roche, A. F., \& Siervogel, R. M. (1997). Age- and maturity-related changes in body composition during adolescence into adulthood: the Fels Longitudinal Study. Int J Obes Relat Metab Disord., 21, 1167-1175.

Gupta, N. K., Mueller, W. H., Chan, W., \& Meininger, J. C. (2002). Is obesity associated with poor sleep quality in adolescents? Am J Hum Biol., 14, 762-768.

Hair, J.F., Anderson, R.E., Tatham, R.L., \& Black, W.C. (1998). Multivariate data analysis (4th ed.). Upper Saddle River, NJ: Prentice Hall.

Hamm, P., Shekelle, R. B., \& Stamler, J. (1989). Large fluctuations in body weight during young adulthood and twenty-five-year risk of coronary death in men. Am J Epidemiol., 129, 312-318.

Haslam, D. W. \& James, W. P. (2005). Obesity. Lancet, 366, 1197-1209.

Hill, J. O. \& Trowbridge, F. L. (1998). Childhood obesity: future directions and research priorities. Pediatrics, 101, 570-574.

Himes, J. H. \& Dietz, W. H. (1994). Guidelines for overweight in adolescent preventive services: recommendations from an expert committee. The Expert Committee on Clinical Guidelines for Overweight in Adolescent Preventive Services. Am J Clin Nutr., 59, $307-$ 316.

Hubert, H. B., Feinleib, M., McNamara, P. M., \& Castelli, W. P. (1983). Obesity as an independent risk factor for cardiovascular disease: a 26-year follow-up of participants in the Framingham Heart Study. Circulation, 67, 968-977.

Hypponen, E., Virtanen, S. M., Kenward, M. G., Knip, M., \& Akerblom, H. K. (2000). Obesity, increased linear growth, and risk of type 1 diabetes in children. Diabetes Care, 23, 1755 1760. 
Janssen, I., Craig, W. M., Boyce, W. F., \& Pickett, W. (2004). Associations between overweight and obesity with bullying behaviors in school-aged children. Pediatrics, 113, 1187-1194.

Janssen, I., Katzmarzyk, P. T., Srinivasan, S. R., Chen, W., Malina, R. M., Bouchard, C. et al. (2005). Utility of childhood BMI in the prediction of adulthood disease: comparison of national and international references. Obes Res., 13, 1106-1115.

Jonides, L., Buschbacher, V., \& Barlow, S. E. (2002). Management of child and adolescent obesity: psychological, emotional, and behavioral assessment. Pediatrics, 110, 215-221.

Kalton, G. (1987). Introduction to survey sampling. Sage University Paper series on Quantitative Application in Social Sciences, Series/Number 07-035, Beverly Hills and London: Sage Pubns.

Kerner, M. S. \& Grossman, A. H. (2001). Scale construction for measuring attitude, beliefs, perception of control, and intention to exercise. J Sports Med Phys Fitness, 41, 124-131.

Keys, A., Fidanza, F., Karvonen, M. J., Kimura, N., \& Taylor, H. L. (1972). Indices of relative weight and obesity. J Chronic Dis., 25, 329-343.

Khosla, T. \& Lowe, C. R. (1967). Indices of obesity derived from body weight and height. $B r J$ Prev Soc Med., 21, 122-128.

Kirk, S., Zeller, M., Claytor, R., Santangelo, M., Khoury, P. R., \& Daniels, S. R. (2005). The relationship of health outcomes to improvement in BMI in children and adolescents. Obes Res., 13, 876-882.

Klesges, R. C., Klesges, L. M., Eck, L. H., \& Shelton, M. L. (1995). A longitudinal analysis of accelerated weight gain in preschool children. Pediatrics, 95, 126-130.

Kolagotla, L. \& Adams, W. (2004). Ambulatory management of childhood obesity. Obes Res., 12, 275-283.

Kraig, K. A. \& Keel, P. K. (2001). Weight-based stigmatization in children. Int J Obes Relat Metab Disord., 25, 1661-1666. 
Krebs, N. F. \& Jacobson, M. S. (2003). Prevention of pediatric overweight and obesity. Pediatrics, 112, 424-430.

Krude, H., Biebermann, H., Luck, W., Horn, R., Brabant, G., \& Gruters, A. (1998). Severe earlyonset obesity, adrenal insufficiency and red hair pigmentation caused by POMC mutations in humans. Nat Genet., 19, 155-157.

Kuczmarski, R. J., Ogden, C. L., Guo, S. S., Grummer-Strawn, L. M., Flegal, K. M., Mei, Z. et al. (2002). 2000 CDC Growth Charts for the United States: methods and development. Vital Health Stat., 11, 1-190.

Lambert, B. L., Salmon, J. W., Stubbings, J., Gilomen-Study, G., Valuck, R. J., \& Kezlarian, K. (1997). Factors associated with antibiotic prescribing in a managed care setting: an exploratory investigation. Soc Sci Med., 45, 1767-1779.

Latner, J. D. \& Stunkard, A. J. (2003). Getting worse: the stigmatization of obese children. Obes Res., 11, 452-456.

Lindsay, R. S., Hanson, R. L., Roumain, J., Ravussin, E., Knowler, W. C., \& Tataranni, P. A. (2001). Body mass index as a measure of adiposity in children and adolescents: relationship to adiposity by dual energy x-ray absorptiometry and to cardiovascular risk factors. J Clin Endocrinol Metab., 86, 4061-4067.

Lindsted, K., Tonstad, S., \& Kuzma, J. W. (1991). Body mass index and patterns of mortality among Seventh-day Adventist men. Int J Obes., 15, 397-406.

Liska, A.E. (1984). A Critical Examination of the Causal Structure of the Ajzen/Fishbein Attitude-Behavior Model. Soc Psychol Q., 47, 61-74.

Loos, R. J. \& Bouchard, C. (2003). Obesity--is it a genetic disorder? J Intern Med., 254, 401425.

Louthan, M. V., Lafferty-Oza, M. J., Smith, E. R., Hornung, C. A., Franco, S., \& Theriot, J. A. (2005). Diagnosis and treatment frequency for overweight children and adolescents at well child visits. Clin.Pediatr.(Phila), 44, 57-61. 
Luder, E., Melnik, T. A., \& DiMaio, M. (1998). Association of being overweight with greater asthma symptoms in inner city black and Hispanic children. J Pediatr., 132, 699-703.

Ludwig, D. S., Peterson, K. E., \& Gortmaker, S. L. (2001). Relation between consumption of sugar-sweetened drinks and childhood obesity: a prospective, observational analysis. Lancet, 357, 505-508.

Lurbe, E., Alvarez, V., Liao, Y., Tacons, J., Cooper, R., Cremades, B. et al. (1998). The impact of obesity and body fat distribution on ambulatory blood pressure in children and adolescents. Am J Hypertens., 11, 418-424.

Madden, T. J., Ellen, P. S., \& Ajzen, I. (1992). A comparison of the theory of planned behavior and the theory of reasoned action. Pers Soc Psychol Bull., 18, 3-9.

Magiakou, M.A., Mastorakos, G., Oldfield, E.H., Gomez, M.T., Doppman, J.L., Cutler, G.B. Jr, Nieman, L.K., Chrousos, G.P. (1994). Cushing's syndrome in children and adolescents. Presentation, diagnosis, and therapy. N Engl J Med., 331, 629-636.

Malina, R. M. \& Katzmarzyk, P. T. (1999). Validity of the body mass index as an indicator of the risk and presence of overweight in adolescents. Am J Clin Nutr., 70, 131S-136S.

Mamun, A. A., Lawlor, D. A., Alati, R., O'Callaghan, M. J., Williams, G. M., \& Najman, J. M. (2007). Increasing body mass index from age 5 to 14 years predicts asthma among adolescents: evidence from a birth cohort study. Int J Obes.(Lond), 31, 578-583.

Mannino, D. M., Mott, J., Ferdinands, J. M., Camargo, C. A., Friedman, M., Greves, H. M. et al. (2006). Boys with high body masses have an increased risk of developing asthma: findings from the National Longitudinal Survey of Youth (NLSY). Int J Obes.(Lond), 30, 6-13.

McGuire, M. T., Wing, R. R., Klem, M. L., Lang, W., \& Hill, J. O. (1999). What predicts weight regain in a group of successful weight losers? J Consult Clin Psychol., 67, 177-185.

Mei, Z., Grummer-Strawn, L. M., Pietrobelli, A., Goulding, A., Goran, M. I., \& Dietz, W. H. (2002). Validity of body mass index compared with other body-composition screening 
indexes for the assessment of body fatness in children and adolescents. Am J Clin Nutr., 75, 978-985.

Millstein, S. G. (1996). Utility of the theories of reasoned action and planned behavior for predicting physician behavior: a prospective analysis. Health Psychol., 15, 398-402.

Moyer, V. A., Klein, J. D., Ockene, J. K., Teutsch, S. M., Johnson, M. S., \& Allan, J. D. (2005). Screening for overweight in children and adolescents: where is the evidence? a commentary by the childhood obesity working group of the US Preventive Services Task Force. Pediatrics, 116, 235-238.

National Institutes of Health (1998). Clinical Guidelines on the Identification, Evaluation, and Treatment of Overweight and Obesity in Adults--The Evidence Report. Obes Res., 6 Suppl 2, 51S-209S.

Ornstein, R. M. \& Jacobson, M. S. (2006). Supersize teens: the metabolic syndrome. Adolesc Med Clin., 17, 565-587.

Ouellette, J.A., \& Wood, W. (1998). Habit and Intention in Everyday Life: The Multiple Processes by Which Past Behavior Predicts Future Behavior. Psychol Bull., 124, 54-74.

Pace CR. (1939). Factors influencing questionnaire returns from former university students. $J$ Applied Psych., 23, 388-397.

Patrick, K., Norman, G. J., Calfas, K. J., Sallis, J. F., Zabinski, M. F., Rupp, J. et al. (2004). Diet, physical activity, and sedentary behaviors as risk factors for overweight in adolescence. Arch Pediatr Adolesc Med., 158, 385-390.

Pearce, M. J., Boergers, J., \& Prinstein, M. J. (2002). Adolescent obesity, overt and relational peer victimization, and romantic relationships. Obes Res., 10, 386-393.

Perrin, E. M., Flower, K. B., \& Ammerman, A. S. (2004). Body mass index charts: useful yet underused. J Pediatr., 144, 455-460. 
Pietrobelli, A., Faith, M. S., Allison, D. B., Gallagher, D., Chiumello, G., \& Heymsfield, S. B. (1998). Body mass index as a measure of adiposity among children and adolescents: a validation study. J Pediatr., 132, 204-210.

Pine, D. S., Goldstein, R. B., Wolk, S., \& Weissman, M. M. (2001). The association between childhood depression and adulthood body mass index. Pediatrics, 107, 1049-1056.

Pinhas-Hamiel, O., Dolan, L. M., Daniels, S. R., Standiford, D., Khoury, P. R., \& Zeitler, P. (1996). Increased incidence of non-insulin-dependent diabetes mellitus among adolescents. J Pediatr., 128, 608-615.

Puffer, S. \& Rashidian, A. (2004). Practice nurses' intentions to use clinical guidelines. $J A d v$ Nurs., 47, 500-509.

Raats, M. M., Shepherd, R., \& Sparks, P. (1995). Including moral dimensions of choice within the structure of the theory of planned behavior. J Appl Soc Psychol., 25, 484-494.

Rabkin, S. W., Mathewson, F. A., \& Hsu, P. H. (1977). Relation of body weight to development of ischemic heart disease in a cohort of young North American men after a 26 year observation period: the Manitoba Study. Am J Cardiol., 39, 452-458.

Rallison, M.L., Dobyns, B.M., Keating, F.R., Rall, J.E., Tyler, F.H. (1975). Occurrence and natural history of chronic lymphocytic thyroiditis in childhood. J Pediatr. 86, 675-682.

Reed, G. R., Velicer, W. F., Prochaska, J. O., Rossi, J. S., \& Marcus, B. H. (1997). What makes a good staging algorithm: examples from regular exercise. Am J Health Promot., 12, $57-$ 66.

Redline, S., Tishler, P. V., Schluchter, M., Aylor, J., Clark, K., \& Graham, G. (1999). Risk factors for sleep-disordered breathing in children. Associations with obesity, race, and respiratory problems. Am J Respir Crit Care Med., 159, 1527-1532.

Reinehr, T., Kiess, W., Kapellen, T., \& Andler, W. (2004). Insulin sensitivity among obese children and adolescents, according to degree of weight loss. Pediatrics, 114, 1569-1573. 
Robinson, T. N. (1998). Does television cause childhood obesity? JAMA, 279, 959-960.

Robinson, J. P., Shaver, P. R., \& Wrightsman, L. S. (1991). Measures of personality and social psychological attitudes. San Diego: Academic Press.

Ronis, D. L., Yates, J. F., \& Kirscht, J. P. (1989). Attitudes, decisions, and habits as determinants of behavior. In A. R. Pratkanis, S. J. Breckler \& A. G. Greenwald (Eds), Attitude, structure, and function. Hillsdale, NJ: Erlbaum.

Rutter, D. (2000). Attendance and reattendance for breast cancer screening: a prospective 3-year test of the Theory of Planned Behavior. Br J Health Psychol., 5, 1-13.

Sable, M. R., Schwartz, L. R., Kelly, P. J., Lisbon, E., \& Hall, M. A. (2006). Using the theory of reasoned action to explain physician intention to prescribe emergency contraception. Perspect Sex Reprod Health, 38, 20-27.

Schaefer, F., Georgi, M., Zieger, A., \& Scharer, K. (1994). Usefulness of bioelectric impedance and skinfold measurements in predicting fat-free mass derived from total body potassium in children. Pediatr Res., 35, 617-624.

Schwimmer, J. B., Burwinkle, T. M., \& Varni, J. W. (2003). Health-related quality of life of severely obese children and adolescents. JAMA, 289, 1813-1819.

Serdula, M. K., Ivery, D., Coates, R. J., Freedman, D. S., Williamson, D. F., \& Byers, T. (1993). Do obese children become obese adults? A review of the literature. Prev Med., 22, 167177.

Sheeran, P., \& Taylor, S. (1999). Predicting intentions to use condoms: A meta-analysis and comparison of the Theories of Reasoned Action and Planned Behavior. J Appl Soc Psychol., 29, 1624-1675.

Shephard, R. J. (2004). Role of the physician in childhood obesity. Clin J Sport Med., 14, 161168. 
Sheppard, B.H., Hartwick, J., Warshaw, P. (1988). The Theory of Reasoned Action: A MetaAnalysis of Past Research with Recommendations for Modifications and Future Research. J Consum Res., 15, 325-343.

Shore, S. A. (2006). Obesity and asthma: cause for concern. Curr Opin Pharmacol., 6, 230-236.

Sinha, R., Fisch, G., Teague, B., Tamborlane, W. V., Banyas, B., Allen, K. et al. (2002). Prevalence of impaired glucose tolerance among children and adolescents with marked obesity. N Engl J Med., 346, 802-810.

Sjoberg, R. L., Nilsson, K. W., \& Leppert, J. (2005). Obesity, shame, and depression in schoolaged children: a population-based study. Pediatrics, 116, e389-e392.

Sparks, P., Guthrie, C., \& Shepherd, R. (1997). The dimensional structure of the perceived behavioral control construct. J Appl Soc Psychol., 27, 418-438.

Stice, E., Cameron, R. P., Killen, J. D., Hayward, C., \& Taylor, C. B. (1999). Naturalistic weight-reduction efforts prospectively predict growth in relative weight and onset of obesity among female adolescents. J Consult Clin Psychol., 67, 967-974.

Story, M. T., Neumark-Stzainer, D. R., Sherwood, N. E., Holt, K., Sofka, D., Trowbridge, F. L. et al. (2002). Management of child and adolescent obesity: attitudes, barriers, skills, and training needs among health care professionals. Pediatrics, 110, 210-214.

Strauss, R. S. (2000). Childhood obesity and self-esteem. Pediatrics, 105, e15.

Strobel, A., Issad, T., Camoin, L., Ozata, M., \& Strosberg, A. D. (1998). A leptin missense mutation associated with hypogonadism and morbid obesity. Nat Genet., 18, 213-215.

Sulit, L. G., Storfer-Isser, A., Rosen, C. L., Kirchner, H. L., \& Redline, S. (2005). Associations of obesity, sleep-disordered breathing, and wheezing in children. Am J Respir Crit Care Med., 171, 659-664.

Taheri, S. (2006). The link between short sleep duration and obesity: we should recommend more sleep to prevent obesity. Arch Dis Child, 91, 881-884. 
Terry, D. J., \& O'Leary, J. E. (1995). The theory of planned behaviour: The effects of perceived behavioural control and self-efficacy. Br J Soc Psychol., 34, 199-220.

Thompson, D. R., Obarzanek, E., Franko, D. L., Barton, B. A., Morrison, J., Biro, F. M. et al. (2007). Childhood overweight and cardiovascular disease risk factors: the National Heart, Lung, and Blood Institute Growth and Health Study. J Pediatr., 150, 18-25.

Toothaker L. (1993). Multiple comparison procedures. Sage University paper series on quantitative applications in the social sciences, 07-089. Newbury Park, CA: Sage.

Troiano, R. P., Briefel, R. R., Carroll, M. D., \& Bialostosky, K. (2000). Energy and fat intakes of children and adolescents in the united states: data from the national health and nutrition examination surveys. Am J Clin Nutr., 72, 1343S-1353S.

Troiano, R. P. (2002). Physical inactivity among young people. $N$ Engl J Med., 347, 706-707.

US Department of Health and Human Services. (1996). Physical Activity and Health: A Report of the Surgeon General. Atlanta, GA: US Dept of Health and Human Services, Centers for Disease Control and Prevention, National Center for Chronic Disease Prevention and Health Promotion.

US Department of Health and Human Services (US DHHS) (2000). With understanding and improving health and objectives for improving health. In: Healthy People 2010. Washington, DC: US Government Printing Office.

Walker, A. E., Grimshaw, J. M., \& Armstrong, E. M. (2001). Salient beliefs and intentions to prescribe antibiotics for patients with a sore throat. Br J Health Psychol., 6, 347-360.

Wang, G. \& Dietz, W. H. (2002). Economic burden of obesity in youths aged 6 to 17 years: 1979-1999. Pediatrics, 109, E81.

World Health Organization. (1995). Physical status: the use and interpretation of anthropometry. Report of a WHO Expert Committee. World Health Organ Tech Rep Ser., 854, 1-452. 
World Health Organization. (1998). Obesity: Preventing and Managing the Global Epidemic. Geneva, World Health Organization.

Weiss, R., Dziura, J., Burgert, T. S., Tamborlane, W. V., Taksali, S. E., Yeckel, C. W. et al. (2004). Obesity and the metabolic syndrome in children and adolescents. $N$ Engl J Med., $350,2362-2374$.

Wennberg, D. E. (1998). Variation in the delivery of health care: the stakes are high. Ann Intern Med., 128, 866-868.

Young, K. L. (2005). Treating overweight children and adolescents in the clinic. Clin Pediatr.(Phila), 44, 647-653.

Young, B., \& Hetherington, M. (1996). The literature on advertising and children's food choice. Nutr Food Sci., 99, 15-19

Zhang, Z. \& Lai, H. J. (2004). Comparison of the use of body mass index percentiles and percentage of ideal body weight to screen for malnutrition in children with cystic fibrosis. Am J Clin Nutr., 80, 982-991.

Zimmermann, M. B., Gubeli, C., Puntener, C., \& Molinari, L. (2004). Detection of overweight and obesity in a national sample of 6-12-y-old Swiss children: accuracy and validity of reference values for body mass index from the US Centers for Disease Control and Prevention and the International Obesity Task Force. Am J Clin Nutr., 79, 838-843. 


\section{APPENDICES}

Appendix A: Survey Instrument

Appendix B: First Mailing Cover Letter

Appendix C: Second Mailing Cover Letter 


\section{Appendix A: Survey Instrument}

\section{Body Mass Index Evaluation in Pediatric and Adolescents}

\section{SECTION I}

INSTRUCTIONS: Each statement in this section corresponds to MEASURING THE BODY MASS INDEX (BMI) of your pediatric and adolescent patients (age 2-18 years). Please circle the response that best describes your opinion. All responses will be kept confidential.

1. Please check $(\sqrt{ })$ which one of the following statements best describes your INTENTIONS or ACTIONS regarding measuring BMI in most $(>\mathbf{8 0} \%)$ of your pediatric and adolescent patients?

I have been measuring BMI in most of my patients for a long time (more than 6 months). I have been measuring BMI in most of my patients for a while (less than 6 months).

I have not been measuring BMI in most of my patients, but I intend to start doing so in the near future (sometime in the next month).

I have not been measuring BMI in most of my patients, but I intend to start doing so eventually (sometime in the next 6 months).

I have not been measuring BMI in most of my patients and I do not intend to start any time in the foreseeable future.

2. Please indicate the extent to which each of the following statements is LIKELY or UNLIKELY by circling the one number which best describes your opinion.

a. Measuring BMI will lengthen the consultation time.

\begin{tabular}{ccccccc}
$\begin{array}{c}\text { Extremely } \\
\text { Unlikely }\end{array}$ & & Neutral & \multicolumn{3}{c}{$\begin{array}{c}\text { Extremely } \\
\text { Likely }\end{array}$} \\
1 & 2 & 3 & 4 & 5 & 6 & 7 \\
1 & 2 & 3 & 4 & 5 & 6 & 7
\end{tabular}

b. BMI will help me identify those pediatric and adolescent patients who are underweight, overweight, or at risk of being overweight.

c. Using BMI for weight classification can lead to false labeling of muscular pediatric and adolescent patients as being overweight or at risk of being overweight.

d. BMI measurement will provide an adequate measure of body fat in pediatric and adolescent patients.

e. BMI can be used as an educational tool to motivate pediatric and adolescent patients to manage body weight.

f. I do not have adequate support staff (nurses, residents) to measure the height and weight of pediatric and adolescent patients.

$\begin{array}{ccccccc}1 & 2 & 3 & 4 & 5 & 6 & 7 \\ 1 & 2 & 3 & 4 & 5 & 6 & 7 \\ 1 & 2 & 3 & 4 & 5 & 6 & 7 \\ 1 & 2 & 3 & 4 & 5 & 6 & 7 \\ & & & & & & \\ 1 & 2 & 3 & 4 & 5 & 6 & 7\end{array}$

g. How likely are you to measure the BMI of your pediatric and adolescent patients if you do not have adequate support staff to take height and weight measurements? 
3. Please indicate the extent to which you AGREE or DISAGREE with each of the following statements by circling the one number which best describes your opinion.

$\begin{array}{lcc}\begin{array}{c}\text { Strongly } \\ \text { Disagree }\end{array} & \text { Neutral } & \begin{array}{c}\text { Strongly } \\ \text { Agree }\end{array}\end{array}$

a. Other practitioners measure the BMI of their pediatric and adolescent patients.

$\begin{array}{lllllll}1 & 2 & 3 & 4 & 5 & 6 & 7\end{array}$

b. The American Academy of Pediatrics and/or the American Academy of Family Physicians recommend that I should measure the BMI of my pediatric and adolescent patients.

$\begin{array}{lllllll}1 & 2 & 3 & 4 & 5 & 6 & 7\end{array}$

c. The Centers for Disease Control and Prevention (CDC) recommends that I should measure the BMI of my pediatric and adolescent patients. $\begin{array}{lllllllll}1 & 2 & 3 & 4 & 5 & 6 & 7\end{array}$

d. I feel confident that I can measure the BMI of my pediatric and adolescent patients if I wanted to.

$\begin{array}{lllllll}1 & 2 & 3 & 4 & 5 & 6 & 7\end{array}$

e. Whether or not I measure the BMI of my pediatric and adolescent patients is entirely within my control.

$\begin{array}{lllllll}1 & 2 & 3 & 4 & 5 & 6 & 7\end{array}$

f. People who are important to me recommend that I should measure the BMI of my pediatric and adolescent patients.

g. Doing what other practitioners do is important to me.

h. Doing what the American Academy of Pediatrics and/or the American Academy of Family Physicians recommend is important to me.

$\begin{array}{lllllll}1 & 2 & 3 & 4 & 5 & 6 & 7\end{array}$

i. Doing what the Centers for Disease Control and Prevention (CDC) recommends is important to me.

$\begin{array}{lllllll}1 & 2 & 3 & 4 & 5 & 6 & 7 \\ 1 & 2 & 3 & 4 & 5 & 6 & 7\end{array}$

j. Measuring the BMI of my pediatric and adolescent patients is difficult for me.

$\begin{array}{lllllll}1 & 2 & 3 & 4 & 5 & 6 & 7 \\ 1 & 2 & 3 & 4 & 5 & 6 & 7 \\ 1 & 2 & 3 & 4 & 5 & 6 & 7\end{array}$

k. Overall, I think that measuring the BMI of my pediatric and adolescent patients is beneficial.

$\begin{array}{lllllll}1 & 2 & 3 & 4 & 5 & 6 & 7\end{array}$

1. I intend to measure the BMI of my pediatric and adolescent patients. 
4. For each of the following outcomes of measuring the BMI in pediatric and adolescent patients, please indicate the extent of DESIRABILITY or UNDESIRABILITY of that outcome by circling the one number which best describes your opinion.

$\begin{array}{lll}\text { Extremely } & \text { Neutral } & \begin{array}{l}\text { Extremely } \\ \text { Desirable }\end{array} \\ \text { Undesirable } & & \end{array}$

a. Lengthening consultation time with pediatric and adolescent patients is:

$\begin{array}{lllllll}1 & 2 & 3 & 4 & 5 & 6 & 7\end{array}$

b. Identifying pediatric and adolescent patients who are underweight, overweight, or at risk of being overweight is:

$\begin{array}{lllllll}1 & 2 & 3 & 4 & 5 & 6 & 7\end{array}$

c. Falsely classifying muscular pediatric and adolescent patients as overweight or at risk of being overweight is:

d. Having an adequate measure of body fat in pediatric and adolescent patients is:

e. Having pediatric and adolescent patients who are motivated to manage their body weight is:

$\begin{array}{lllllll}1 & 2 & 3 & 4 & 5 & 6 & 7\end{array}$

\section{SECTION II}

INSTRUCTIONS: The following questions pertain to the ASSESSMENT of your overweight/obese pediatric and adolescent patients. For each item, please check-mark $(\sqrt{ })$ your frequency of assessment.

1. What methods do you routinely use to diagnose obesity in pediatric and adolescent patients?

$$
\text { Never Rarely Sometimes Often Always }
$$

a. Clinical Impression

b. Weight for height percentile

c. Weight for age percentile

d. Body mass index (BMI)

e. BMI percentile

f. Other (please specify)

2. What cutoff value do you use to diagnose obesity in pediatric and adolescent patients?

a. Weight for height percentile

$$
\geq 75^{\text {th }} \text { percentile } \geq 85^{\text {th }} \text { percentile } \geq 95^{\text {th }} \text { percentile } \geq 99^{\text {th }} \text { percentile }
$$

b. Weight for age percentile

c. BMI percentile 
3. In your evaluation of overweight/obese pediatric and adolescent patients, how often do you ask about FAMILY HISTORY for each of the following conditions?

$$
\text { Never Rarely Sometimes Often Always }
$$

a. Overweight

b. Diabetes mellitus

c. Gallbladder disease

d. Cardiovascular disease

e. Hypertension

f. Elevated cholesterol

g. Other (please specify)

4. How often do you request the following LABORATORY EVALUATIONS when caring for pediatric and adolescent patients who are overweight/obese?

$$
\text { Never Rarely Sometimes Often Always }
$$

a. Lipid profile

b. Insulin

c. Cortisol

d. Thyroid function tests

e. Other (please specify)

5. In your evaluation of overweight/obese pediatric and adolescent patients, how often in your HISTORY AND PHYSICAL EXAMINATION do you screen for the following conditions?

$$
\text { Never Rarely Sometimes Often Always }
$$

a. Diet history

b. Depression

c. Eating disorder

d. Tobacco use

e. Pseudtumour cerebri

f. Genetic disorders

g. Sleep disorder

h. Blood pressure

i. Television/screen time

j. Exercise 


\section{SECTION III}

INSTRUCTIONS: This section of the questionnaire gathers information about you and your practice. Please check-mark $(\sqrt{ })$ your response.

1. Please indicate the age group in which you belong:
a. $\_30$ years
c. $41-50$ years
e. __ $\geq 61$ years
b. $\quad 31-40$ years
d. $51-60$ years

2. Gender: __ Male _ Female

3. Number of years in current practice: Years

4. Your primary practice site is:
a. ___ Hospital based
c. ___ Group practice
b. __ Solo practice
d. ___ Other (please specify)

5. Average number of pediatric and adolescent patients do you see in a complete work week?

THANK YOU FOR YOUR TIME IN COMPLETING THIS QUESTIONNAIRE

Please return the completed questionnaire in the enclosed business reply envelope. 


\section{Appendix B: First Mailing Cover Letter}

August, 2006

Dear Doctor:

As a part of our research study we are conducting a survey of physicians' opinions regarding measurement of the body mass index (BMI) of pediatric and adolescent patients. We are also studying current physician practice patterns for identification and evaluation of obesity in pediatric and adolescent patients. Your name was randomly selected from a national list of physicians to receive the enclosed questionnaire. This research study is a part of a master's (M.S.) thesis project and is being funded by the West Virginia University School of Pharmacy. Your input as a physician is critical to understanding common practices and challenges regarding assessment and evaluation of obesity in pediatric and adolescent patients.

The questionnaire will take approximately 5-10 minutes to complete. The information you provide will be kept as confidential as legally possible. The questionnaire has an identification number for mailing purposes only. This code does not in any way connect your name to your answers; it only allows us to remove your name from the mailing list after you have returned the questionnaire so that you will not receive a second copy. Once we receive your questionnaire, your answers will be analyzed in combination with those of all other respondents. You do not have to answer every question and participation at any time while completing the questionnaire is voluntary; however, once we receive the questionnaire, your responses will become anonymous and you will be unable to withdraw your data since there will be no way to identify individual information.

Please return the completed survey in the enclosed postage-paid reply envelope. We thank you in advance for your time in providing this valuable information. If you have any questions or concerns, please do not hesitate to contact Rahul Khanna at (304) 293-6991 or Dr. Virginia (Ginger) Scott at (304) 293-1553.

Sincerely,

Rahul Khanna, B.S., MBA

Virginia (Ginger) Scott, Ph.D., R.Ph.

Master's Candidate

Professor 


\section{Appendix C: Second Mailing Cover Letter}

August 2006

Dear Doctor:

About two weeks ago, we sent you a survey asking you about your opinions regarding measurement of the body mass index (BMI) and the current practice patterns for identification and evaluation of obesity in pediatric and adolescent patients. If it was just mailed, we thank you and request that you disregard this letter. If you have not completed the survey, we request you to kindly do so.

This research study is a part of a master's (M.S.) thesis project and is being funded by the West Virginia University School of Pharmacy. The questionnaire will take approximately 5-10 minutes to complete. The information you provide will be kept as confidential as legally possible. Once we receive your questionnaire, your answers will be analyzed in combination with those of all other respondents. You do not have to answer every question and participation at any time while completing the questionnaire is voluntary; however, once we receive the questionnaire, your responses will become anonymous and you will be unable to withdraw your data since there will be no way to identify individual information.

Since the size of this study is limited, your input is very important to its success. We understand that your time is valuable, but once again ask if you could take a few minutes to complete the enclosed questionnaire. Please return the completed questionnaire in the enclosed postage-paid reply envelope by September 17, 2006.

If you have any questions regarding this study, please do not hesitate to contact Rahul Khanna at (304) 293-6991 or Dr. Virginia (Ginger) Scott at (304) 293-1553. Again, thank you for your assistance.

Sincerely,

Rahul Khanna, B.S., MBA

Master's Candidate
Virginia (Ginger) Scott, Ph.D., R.Ph.

Professor 


\section{CURRICULUM VITAE}

\section{Rahul Khanna}

112 Ellen Lane, Apt 5

Morgantown, WV 26505

(312) 2180890 (Cell Phone)

rkhanna@hsc.wvu.edu

\section{RESEARCH INTEREST}

Claims Database Analysis, Behavioral Sciences Research, Decision Analysis and Pharmacoeconomic Evaluations

\section{ACADEMIC CREDENTIALS}

April 2005

Master of Science, Department of Pharmaceutical Systems and Policy, School of Pharmacy, West Virginia University

Title of Thesis: Predicting Physicians' Intention to Measure BMI and Assessing their Identification and Evaluation Practices in Overweight Children and Adolescents

Aug 2004 - Current

Graduate Student, Department of Pharmaceutical Systems and Policy, School of Pharmacy, West Virginia University

July 2002 - April 2004

Master of Business Administration in International Business, Indian Institute of Foreign Trade, India

Sep 1997 - May 2001

Bachelor of Pharmacy, Delhi University, India

\section{PROFESSIONAL EXPERIENCE}

June 2006 - Current

Graduate Research Assistant, Building Research Infrastructure and Capacity (BRIC) funded by the Agency for Healthcare Research and Quality, School of Pharmacy, West Virginia University

Responsibilities include formatting of large claims datasets, managing a data repository, and performing data analysis 
Aug 2004 - May 2006

Graduate Teaching Assistant, School of Pharmacy, West Virginia University

Responsibilities included grading, managing course materials, and conducting class exercises

May 2003 - July 2003

Summer Intern, ITC International Business Division (ITC-IBD), India

Developed business plan for the company to enter organic product market and created a potential supplier base

Aug 2001 - Nov 2001

Medical Representative, Aventis Pharma Limited, India

Developed marketing strategies and delivered sales presentations

\section{PUBLICATIONS}

Khanna R, Smith MJ. Patterns of Medical Services and Prescription Medication Use for Rheumatoid Arthritis Among Recipients Covered by a State Medicaid Program. (Under Review)

Khanna R, Smith MJ, Kamal KM. Utilization and costs of drugs and office services among recipients of Medicaid with rheumatoid arthritis with versus without comorbid depression. (In Preparation)

\section{Recipient of 2006 Graduate Student Recognition Award from the Association of} Rheumatology Health Professionals

\section{PRESENTATIONS}

Khanna R, Smith MJ. Utilization patterns of drugs and medical services among recipients with rheumatoid arthritis in a Medicaid population. Accepted for poster presentation at the $134^{\text {th }}$ American Public Health Association (APHA) Annual Meeting and Exposition, November 4 - 8, 2006, Boston, MA

Khanna R, Smith MJ. Patterns of medical services and prescription medication use among recipients with rheumatoid arthritis covered by a state Medicaid program. Poster presentation at the $42^{\text {nd }}$ Annual Meeting of the Drug Information Association, June $18-22,2006$, Philadelphia, PA

Khanna R, Kavookjian J. A systematic review of physician knowledge and practice patterns related to colorectal cancer screening. Poster presentation at the $10^{\text {th }}$ Annual International Society for Pharmacoeconomics and Outcomes Research (ISPOR) Conference, May 15 - 18, 2005, Washington, DC 


\section{PROFESSIONAL AFFILIATIONS}

2006-2007 President (WVU ISPOR Student Chapter)

2006-2007 Member (ISPOR Meeting Planning Committee)

2006-2007 Member of Rho Chi Pharmaceutical Honor Society

2005-2006 Treasurer (WVU ISPOR Student Chapter)

2006-2007 Member of Association of Rheumatology Health Professionals

\section{COMPUTER PROFICIENCY}

Statistical packages: SPSS, SAS, AMOS

Database software: Microsoft FoxPro

Decision analysis software: DATA TreeAge

Bibliographic: Reference Manager

\section{RELEVANT COURSES}

Research Design and Data Analysis I and II, Pharmacoeconomics, Social and Behavioral Theory, Multivariate Analysis, Secondary Data Analysis, Decision Analysis in Healthcare, Pharmacoepidemiology, Survey Research Methods, Health Outcomes Research Method, Health Systems, Healthcare Finance, Statistical Analysis System, Applied Biostatistics, Healthcare Organization/Operation

\section{REFERENCES}

Available upon request 